\title{
Naturalistic Decision Making in Power Grid Operations: Implications for Dispatcher Training and Usability Testing
}

\section{FL Greitzer R Podmore}

November 2008 


\title{
DISCLAIMER
}

This report was prepared as an account of work sponsored by an agency of the United States Government. Neither the United States Government nor any agency thereof, nor Battelle Memorial Institute, nor any of their employees, makes any warranty, express or implied, or assumes any legal liability or responsibility for the accuracy, completeness, or usefulness of any information, apparatus, product, or process disclosed, or represents that its use would not infringe privately owned rights. Reference herein to any specific commercial product, process, or service by trade name, trademark, manufacturer, or otherwise does not necessarily constitute or imply its endorsement, recommendation, or favoring by the United States Government or any agency thereof, or Battelle Memorial Institute. The views and opinions of authors expressed herein do not necessarily state or reflect those of the United States Government or any agency thereof.

\author{
PACIFIC NORTHWEST NATIONAL LABORATORY \\ operated by \\ BATTELLE \\ for the \\ UNITED STATES DEPARTMENT OF ENERGY \\ under Contract DE-AC05-76RL01830
}

\author{
Printed in the United States of America \\ Available to DOE and DOE contractors from the \\ Office of Scientific and Technical Information, \\ P.O. Box 62, Oak Ridge, TN 37831-0062; \\ ph: (865) 576-8401 \\ fax: (865) 576-5728 \\ email: reports@adonis.osti.gov
}

\author{
Available to the public from the National Technical Information Service, \\ U.S. Department of Commerce, 5285 Port Royal Rd., Springfield, VA 22161 \\ ph: (800) 553-6847 \\ fax: (703) 605-6900 \\ email: orders@ntis.fedworld.gov \\ online ordering: http://www.ntis.gov/ordering.htm
}




\section{Executive Summary}

The Blackout of 2003 demonstrated that the North American interconnected electric system is vulnerable to cascading outages and widespread blackouts. Investigations of large-scale outages often attribute the causes to the three T's: Trees, Training, and Tools. The focus of the present study is on improved training approaches to accelerate learning and improved methods for analyzing effectiveness of tools within a high-fidelity power grid simulated environment. A theory-based model has been developed to document and understand the mental processes that an expert power system operator uses when making critical decisions. The theoretical foundation for the method is based on the concepts of situation awareness, the methods of cognitive task analysis, and the naturalistic decision making (NDM) approach of Recognition Primed Decision Making. The method has been systematically explored and refined as part of a capability demonstration of a highfidelity real-time power system simulator under normal and emergency conditions. To examine NDM processes, we analyzed transcripts of operator-to-operator conversations during the simulated scenario to reveal and assess NDM-based performance criteria. The results of the analysis indicate that the proposed framework can be used constructively to map or assess the Situation Awareness Level of the operators at each point in the scenario. We can also identify the mental models and mental simulations that the operators employ at different points in the scenario. This report documents the method, describes elements of the model, and provides appendices that document the simulation scenario and the associated mental models used by operators in the scenario.

The methodology described and advanced in this report can be used to identify improved training strategies to accelerate learning as well as to structure human factors testing of analytical and visualization tools for power system operators. It is concluded that the NDM approach provides an ideal framework for human factors evaluations of decision aids and for systematic training management of team-based training scenarios using highfidelity power grid simulators. As a result of this test case, we recommend the following research and applied thrusts to advance human factors theory and practice within the power industry:

1. Continue application of this HF framework and analysis approach to advance and demonstrate the value of the analyses, in conjunction with simulation capabilities of the EIOC, to further the DOE mission in improving and strengthening the electric power utility infrastructure.

2. Continue to advance the HF framework and methodology to provide direct benefits to stakeholders within the electric power grid community, specifically to accelerate training programs for new power system operators and to systematically evaluate the usability of next generation of tools for managing a Smart Grid.

3. Conduct evaluations and enhance the design of Wide Area visualization/decision support tools. 
4. Engage directly with utility operators to apply the methodology toward improving their operations, conducting demonstrations and evaluations of advanced training concepts, and providing a testbed and associated HF methods to assess the effectiveness of tools and procedures.

5. Pursue opportunities to exploit the PNNL EIOC for training workshops, based on the framework described in this report, and as a test bed for evaluating new procedures, decision aids, and visualization techniques.

In conclusion, this research demonstrates the capability to meet critical mission objectives of the DOE as well as strengthen the role of PNNL and the EIOC as a resource and test bed for power grid training and visualization analysis. 


\section{Acknowledgments}

The authors wish to thank Ross Guttromson at the Pacific Northwest National Laboratory (PNNL), who made it possible for this collaboration through an internally funded PNNL project, Human Factors for Situation Awareness in Power Grid Operations. We acknowledge Doug Harrington for encouraging us to apply the Recognition Primed Decision Model to power grid human factors and Chuck Johansen, Senior Trainer with SOS Intl, for motivating us to integrate concepts of the R/M Model. We also wish to thank our other respective colleagues at PNNL, Southwest Power Pool, Incremental Systems Corporation, PowerData Corporation, and SOS Intl for their support, ideas, and discussions. 


\section{Contents}

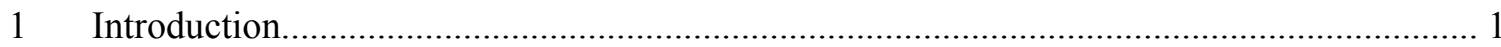

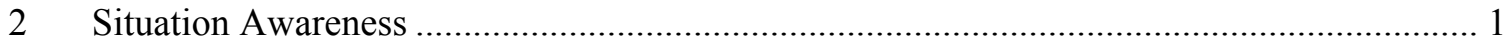

$3 \quad$ Naturalistic Decision Making Models ……………………………………………… 3

3.1 Recognition-Primed Decision Model...……………................................................. 3

3.2 Recognition/Metacognition (R/M) Model …………................................................ 4

3.3 An Integrated Model for Power Grid Operations ………………………………….. 4

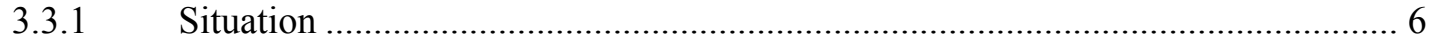

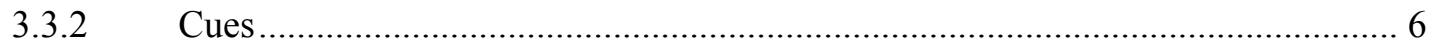

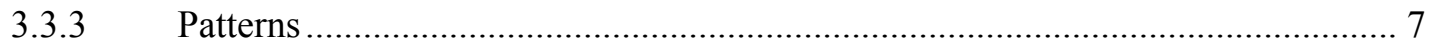

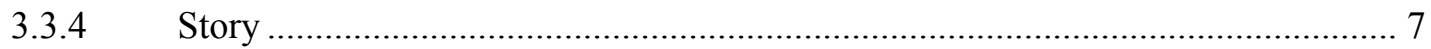

3.3.5 Action Scripts ....................................................................................

3.3.6 Mental Models.......................................................................................... 8

3.3.7 Mental Simulations ………………………………………………….... 8

4 Illustration and Application of the Model: A Power Grid Restoration Scenario.................... 9

$4.1 \quad$ Cognitive Task Analysis .................................................................................. 10

4.2 Object and Action / Object Analysis.................................................................... 11

4.3 State and Situation Awareness Level Analysis.......................................................... 15

4.4 Mental Model and Story Analysis .................................................................... 15

4.5 Summary of the Cognitive Task Analysis ……………………………………...... 16

4.6 Benefits of the Model and Analysis..................................................................... 17

5 Application to Training on Power Grid Critical Decision Making......................................... 17

5.1 Measuring Performance of Experts versus Rookies ................................................... 19

5.2 Identifying Gaps in Knowledge ....................................................................... 19

5.3 Developing More Advanced Scenarios................................................................. 19

6 Application to Usability Testing of Power Grid Analytical and Visualization Tools .......... 20

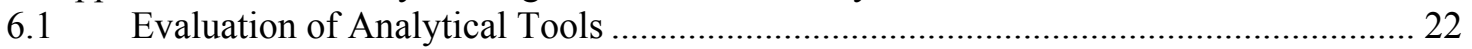

6.2 Evaluation of Visualization Tools........................................................................ 23

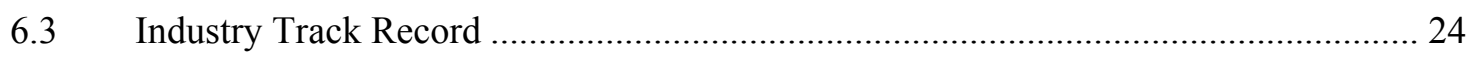

6.4 Benefits of a Human Factors Framework ………................................................... 25

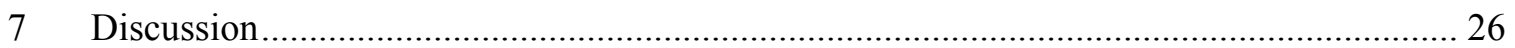

8 Conclusions and Recommendations ...........................................................................2 26

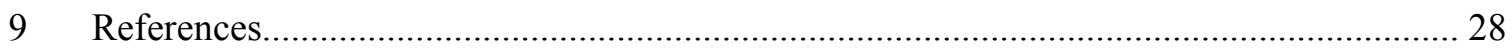

Appendix 1: Analysis of the Restoration Scenario ............................................................. 1-1

Summary of the Main Story .......................................................................................... 1-1

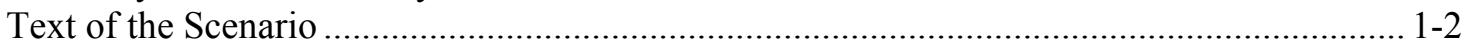

RPD Analysis of the Scenario Script …………………………………………………... 1-6

Illustration of Operator Performance Assessment Based on Scenario Script ......................... 1-24

SA Level 1: Perceiving critical cues........................................................................... 1-24

SA Level 2: Understanding what the critical cues mean .................................................. 1-24

SA Level 3: Understanding what will happen in the near future...................................... 1-24

Shared understanding ........................................................................................ 1-24

Finding the right mental model.............................................................................. 1-24

Finding the correct action …………………………………………………….... 1-24

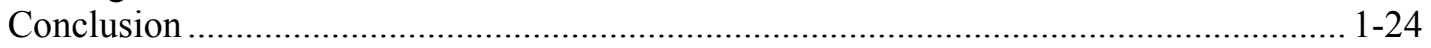

More detailed monitoring of cues................................................................................. 1-24

Short-Term Working Memory versus Long-Term Memory …………………………….... 1-25

Underlying Premise of RPDM ................................................................................... 1-25 


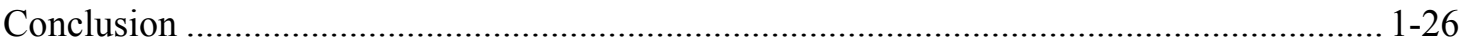

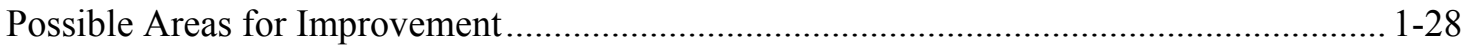

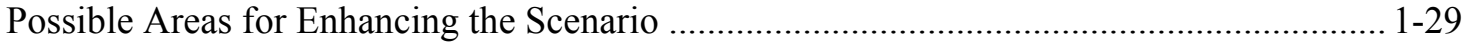

Lessons Learned for Voltage Control Under System Restoration ...................................... 1-29

Appendix 2: Relevant Mental Models................................................................................. 2-1

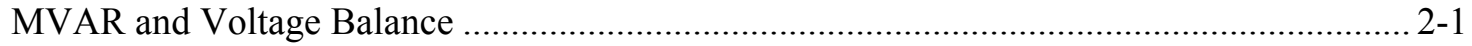

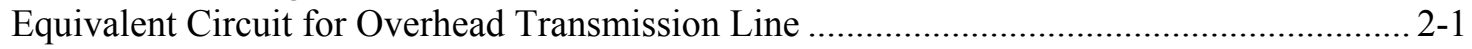

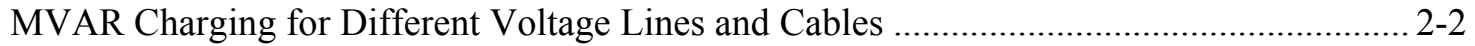

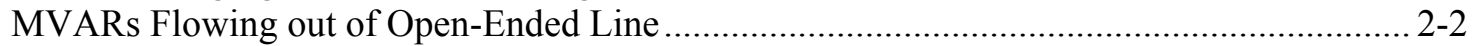

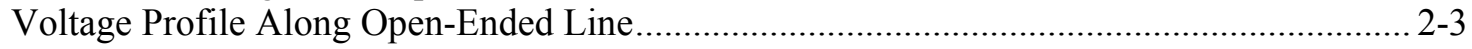

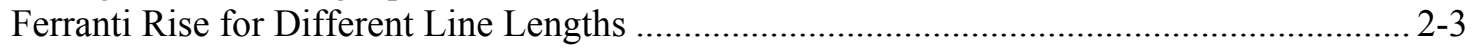

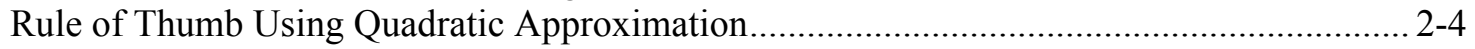

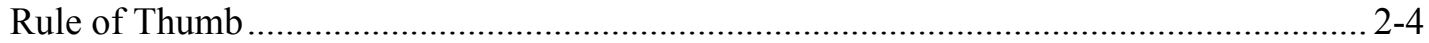

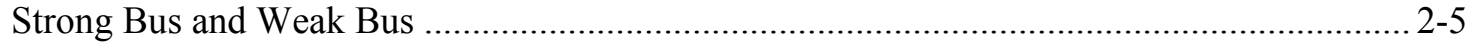

Effect of Ferranti Rise with Weak and Strong Source Bus ................................................. 2-5

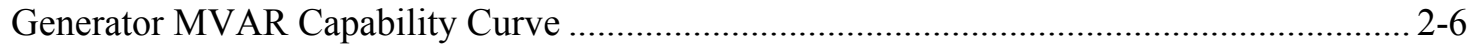

MVARs Flow Down Hill on Voltage Magnitude Difference ............................................... 2-7

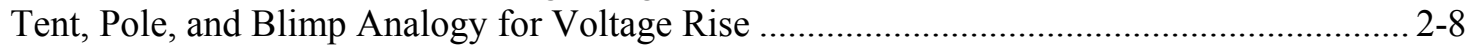

Tent, Pole, and Weight Analogy for Voltage Sag............................................................. 2-9

Diagram of Physical Arrangement of Transformer Core, Windings, and Taps.................... 2-10

Transformer Damage with Exposure to High Voltages ......................................................... 2-11

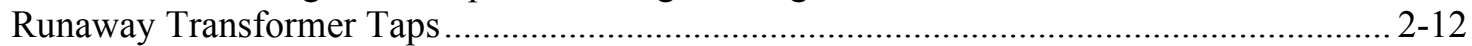

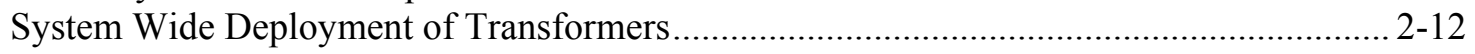




\section{Figures}

Figure 1. Klein's Recognition-Primed Decision Model 3

Figure 2. Proposed Integrated Naturalistic Decision Making Model 5

Figure 3. A Real-World Problem 10

Figure 4. NDM Framework 11

Figure 5: General Training Development/Management Process 18

\section{Tables}

Table 1. Object Analysis Results ............................................................................ 112

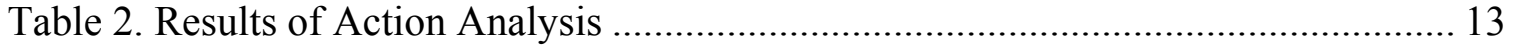

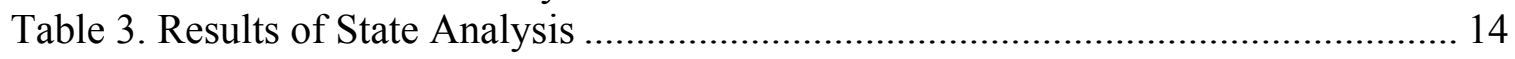




\section{Naturalistic Decision Making in Power Grid Operations: Implications for Dispatcher Training and Usability Testing}

\section{Introduction}

Despite advances in technology, power system operators must assimilate overwhelming amounts of data to keep the grid operating. Analyses of recent blackouts have clearly demonstrated the need to enhance the operator's ability to understand the state of the system and anticipate possible problems. Engineers, computer scientists, and human factors (HF) experts have borrowed from other experiences to discover or apply new tools and techniques to transform data into information and facilitate the decision making process of operations personnel. With increasing complexity and interconnectivity of the grid, the scope and complexity of power grid operations continues to grow. To address this escalation of complexity, new paradigms are needed to guide research, tool development, and training to enhance and improve operations. This report applies current models and theories of decision making and situation awareness (SA) from a power grid perspective and offers a more detailed framework, based on this theoretical perspective, to guide development of tools and training approaches to increase grid operator SA and enhance operational performance.

\section{Situation Awareness}

In a widely accepted definition, situation awareness (SA) is described as the perception of the elements in the environment within a volume of time and space, the comprehension of their meaning, and the projection of their status in the near future (Endsley, 1988; 1995). In this empiricist view of SA, stimuli (information elements) are processed to yield meaning, and a common solution to human information processing limitations is to design methods to facilitate processing of more information through limited processing channels. Naturalistic Decision Making (NDM) is a research domain that takes a slightly different approach to the SA problem, adopting an ecological view where awareness is an intrinsic feature of the functional relationship between the environment and the person (Dekker et al, 2004). While the NDM perspective acknowledges the existence of "elements," its focus is on the role the elements play in constructing a plausible "story" of what is going on, not for building an accurate mental model of an external world. In this sense, the NDM perspective on SA is consistent with current ideas about sensemaking as an active strategy for dealing with a complex world (Weick, 1995), (Klein et al, 2006). Thus, in studying SA, in addition to examining the lack of correspondence between actual and experienced worlds, one should examine the decision makers" "unfolding experience of the situation in which they found themselves."

The NDM/sensemaking perspective on SA is distinct from the traditional branch of HF research, which focuses more on ergonomics and the transactional relationship between the human operator and the systems. This transactional relationship is a prime source of complexity in 
system design that focuses on the form and literal content of isolated transactions (e.g., friendly input/output formats) rather than their function in the larger system (Greitzer et al., 1985). Interaction in this transactional approach is at best only locally optimal and the user is left somehow to configure a host of local transactions to meet the broader system goals.

The conventional SA and NDM/sensemaking perspectives tend to lead us to ask different questions. The traditional information processing/empiricist view of SA compels the investigator to identify what the decision makers failed to notice, what they did not know, or what they should or should not have done (which is in some ways a retrospective analysis). In contrast, the $\mathrm{NDM} /$ sensemaking perspective suggests that it is not about providing more information (more data, more elements), but rather about clarifying priorities to help the decision maker understand what matters. Thus, from the point of view of the decision maker in the situation, deficiencies such as failures to notice an element in the environment or perform a critical action may not even exist - they may be artifacts of retrospective hindsight.

Another way of thinking about the differences between the more empirical/information processing and the more ecological NDM/sensemaking perspectives on SA is to consider the way we approach the design of information analysis and decision support systems. In focusing on the information processing issues, we tend to think about design enhancements for humansystem "transactions" embodied in features of displays and visualizations that seek to overcome human information processing limitations (attention, perception, memory limits) at the expense of considering deeper (e.g., goal-directed) cognitive processes engaged in sensemaking and critical decision making - transactions between goals, observations, and actions - that might also be implicated in the loss of SA. Consider, for example, the frequently cited human limitation described as Miller's (1956) magical number seven, plus or minus two: Miller's insightful observation that humans have a limited capacity in the number of items or "chunks" of information they can maintain in working memory tends to be interpreted as a hard limitation (information processing bottleneck). This factor is situation-dependent; research has shown that experts have the ability to reduce complex stimuli into coherent chunks so that the $7+2$ constraint is rarely a limit on expert performance in natural environments.

Relating to the cognitive and sensemaking underpinnings of SA, it has been suggested that poor SA reflects the lack of a basis for decomposing complex data or information into coherent chunks (Klein, 1993). Thus, we should ask our models of SA to (a) explain how skilled decision makers chunk information so they can navigate smoothly through the problem space; (b) to point out where experts might make poor judgments and interpretations; and (c) to describe how a novice's understanding of a situation would differ from that of an expert. A major feature of a leading NDM model of decision making, Klein's (1993) Recognition-Primed Decision Model (RPDM), specifically calls out some important differences between the expert and non-expert in decision making tasks; namely, that experts tend to "see" solutions early-i.e., they do not engage in formal analyses of alternative options or hypotheses but instead identify a plausible solution and proceed to examine and execute it, while looking for potential inconsistencies that would lead them to reject the solution and find another. 
The RPDM has great potential for guiding research in decision making that follows this ecological perspective; still, additional detail and specification of a more normative implementation of the model is needed to support the development of specific/prescriptive techniques to enhance training effectiveness or assess new decision support systems. In the case of user interface design approaches to SA, one goal of a more prescriptive model is to define more explicit connections across levels of abstraction to improve awareness of patterns and relationships (Flach et al., 2004). Such specification of connections among patterns and relationships would also improve the precision of training mitigation options. The main objective of the present research was to develop the additional depth of detail within a NDM/sensemaking approach, embodied within the RPDM framework, to achieve a more systematic and rigorous training management methodology to apply in power grid operations training.

\section{$3 \quad$ Naturalistic Decision Making Models}

\subsection{Recognition-Primed Decision Model}

The RPDM has been successfully applied to training mission critical teams in a number of industries including crews of airline pilots and teams of nuclear plant operators. Following the August 14, 2003 blackout, the RPDM was introduced to the power industry and was successfully applied to the planning, development, and implementation of grid operator training systems such as the Virtual Instructor and PowerSimulator (Podmore et al., 2008). A descriptive diagram of the RPDM is shown in Figure 1 (after Hunter et al., 2000).

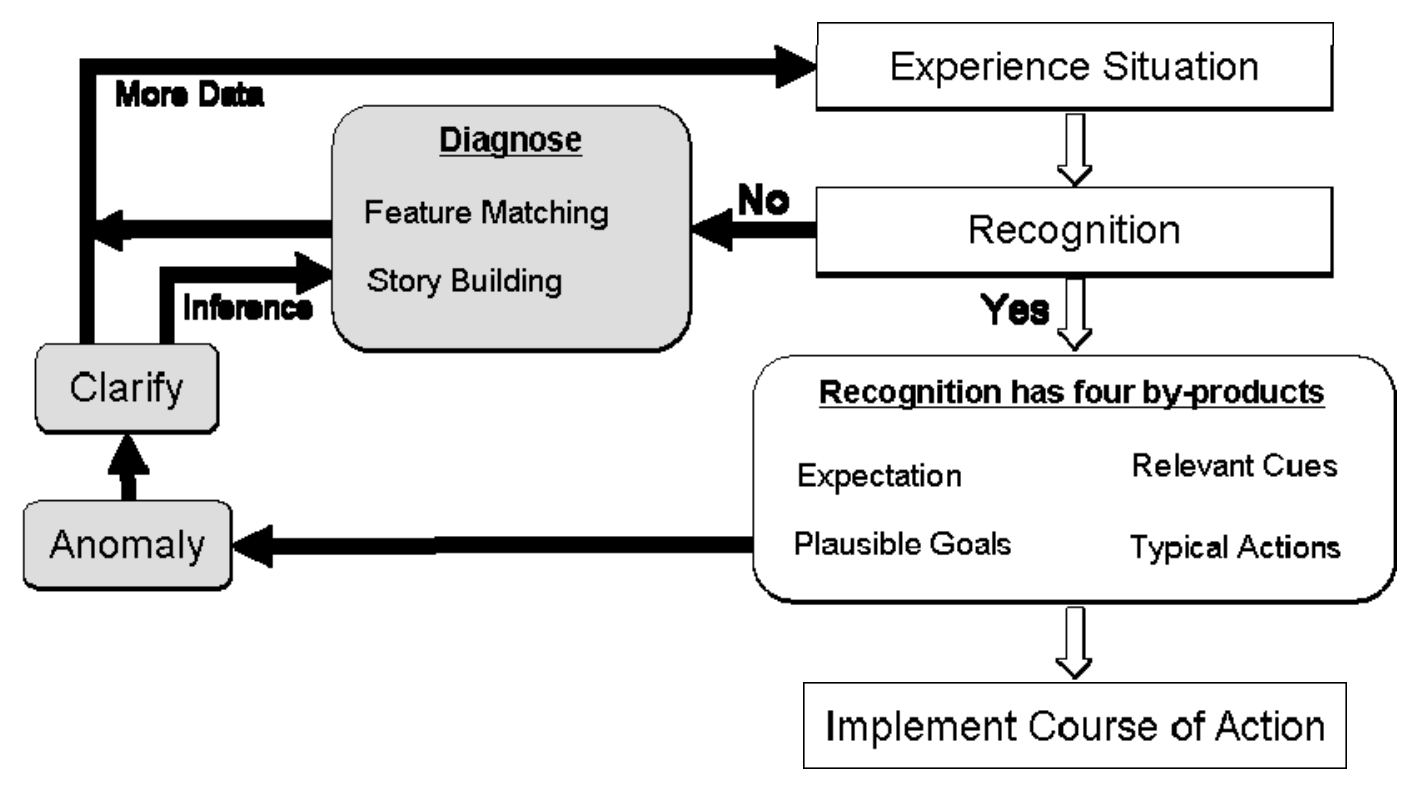

Figure 1. Klein's Recognition-Primed Decision Model

This figure shows that while experts may typically immediately recognize the situation and see the applicability of associated actions (following the path of the unshaded process in Figure 1), in some cases - such as novel/unfamiliar situations - the cues in the environment do not immediately match known or expected patterns and problems. In this case, a diagnostic process 
must intervene to assess the situation (this is depicted in the shaded portions of the figure). This requires more mental resources and utilization of knowledge stored in the decision maker's longterm memory, and the assessment would be limited or hampered if there were severe time constraints.

\subsection{Recognition/Metacognition (R/M) Model}

In addressing the diagnostic process used to reconcile conflicting or missing data, Cohen and colleagues (Cohen et al., 1997) point out that NDM approaches to decision making, which emphasize recognition processes, may be inadequate when no familiar pattern of cues fits the current situation. They argue that processes that improve SA in novel situations are metarecognitional in function. Their NDM approach therefore highlights metarecognitional skills. This follows the line of thinking that metacognition involves splitting cognitive processes into three levels. The object level comprises recognitional processes that activate schemas in response to internal and external cues. The metalevel monitors the object level and maintains a model or description of the object level. This level includes processes that identify problems with the recognition schemas and processes that correct or modify the situation model and plan. A higher-level process, called the quick test, controls both the object level and metalevel processes by taking into account the time available, costs of an error, degree of uncertainty, and novelty. When stakes are high and time is available, the quick test process is used to critique the situation in order to find incomplete, unreliable, or conflicting information. Skills used in the critiquing process include identifying key assessments and the recognition support for them, checking stories and plans based on those assessments for completeness; noticing conflicts among the recognition meanings of cues; elaborating stories to explain a conflicting cue (rather than discarding it); etc. The process also regulates the use of these skills based on available time, stakes, and novelty of the situation.

The R/M framework builds upon the NDM foundation provided by the RPDM model and offers a mechanism to account for how experienced decision makers test and improve the results of initial recognition-primed decisions. The $\mathrm{R} / \mathrm{M}$ framework focuses on critical thinking processes within situation assessment that direct the decision maker to look for gaps and conflicts in the "story" so that when unexpected or conflicting events occur, the mental model and/or action script can be adjusted.

\subsection{An Integrated Model for Power Grid Operations}

An integrated model of NDM integrates concepts of SA (Endsley, 1997), recognition-primed decision making (RPD) (Klein, 1993), metacognition (Cohen et al., 1997), and considerations about levels of expertise. Levels of expertise refer to distinctions between skill-based, rule-based, and knowledge-based behavior - reflecting the fact that decision makers perform at different levels of expertise (Hammond et al., 1987; Rasmussen, 1993). People who are highly experienced with a task tend to process information at the skill-based level, reacting to the raw perceptual elements at an automatic, subconscious level; they do not need to interpret and integrate cues or consider possible alternate actions but instead respond to cues and patterns that are already associated with actions. If the decision maker is familiar with the task but lacks extensive experience, he or she must process input and perform at the rule-based level. Rules are 
if-then "recipes" for action that are associated with cues and patterns (or they may be available as written procedures that a less experienced decision maker can follow at the rule-based level of processing). In novel situations where there are no stored rules based on previous experience, even expert decision makers operate at the knowledge-based level that comprises analytical processing. Effective decision making uses all three levels of processing. The goal of training for critical decision making is to provide the learner with experiences and instruction on cues, patterns, mental models, and actions that effectively establish a repertoire of well-learned concepts that enable the operator to perform predominantly at the skill-based level of processing, while providing a sufficient knowledge-based foundation to perform well in novel situations.

Figure 2 depicts an integrated NDM model that we find useful in training of power grid operational decision making. It is strongly influenced by insights of Weick (1995) on sensemaking concepts that have been applied to power grid operations (Greitzer et al., 2008), and largely based on the RPD model; it incorporates the metacognitive/critique portion of the $\mathrm{R} / \mathrm{M}$ model by invoking additional mental models and mental simulations in the pattern recognition process. Here the initial processing of cues and patterns may be modulated by a critiquing process (using mental models and simulations) that occurs early in the recognitionprimed process of situation assessment. Additional mental simulation processes occur following selection of a course of action (action script), as the decision maker examines or tests whether the proposed response action works as anticipated. The main advantage of this characterization is that it acknowledges the role of mental models in the SA component of decision making as well as in response selection.

The shape-coding in Figure 2 is meant to suggest the primary locus and role of each of the processes in the human information processing system. The ellipses represent the external realworld environment. The cues are part of the real world. They are also the boundary between the real world and the system operator. The cues are monitored by the system operator's five senses,

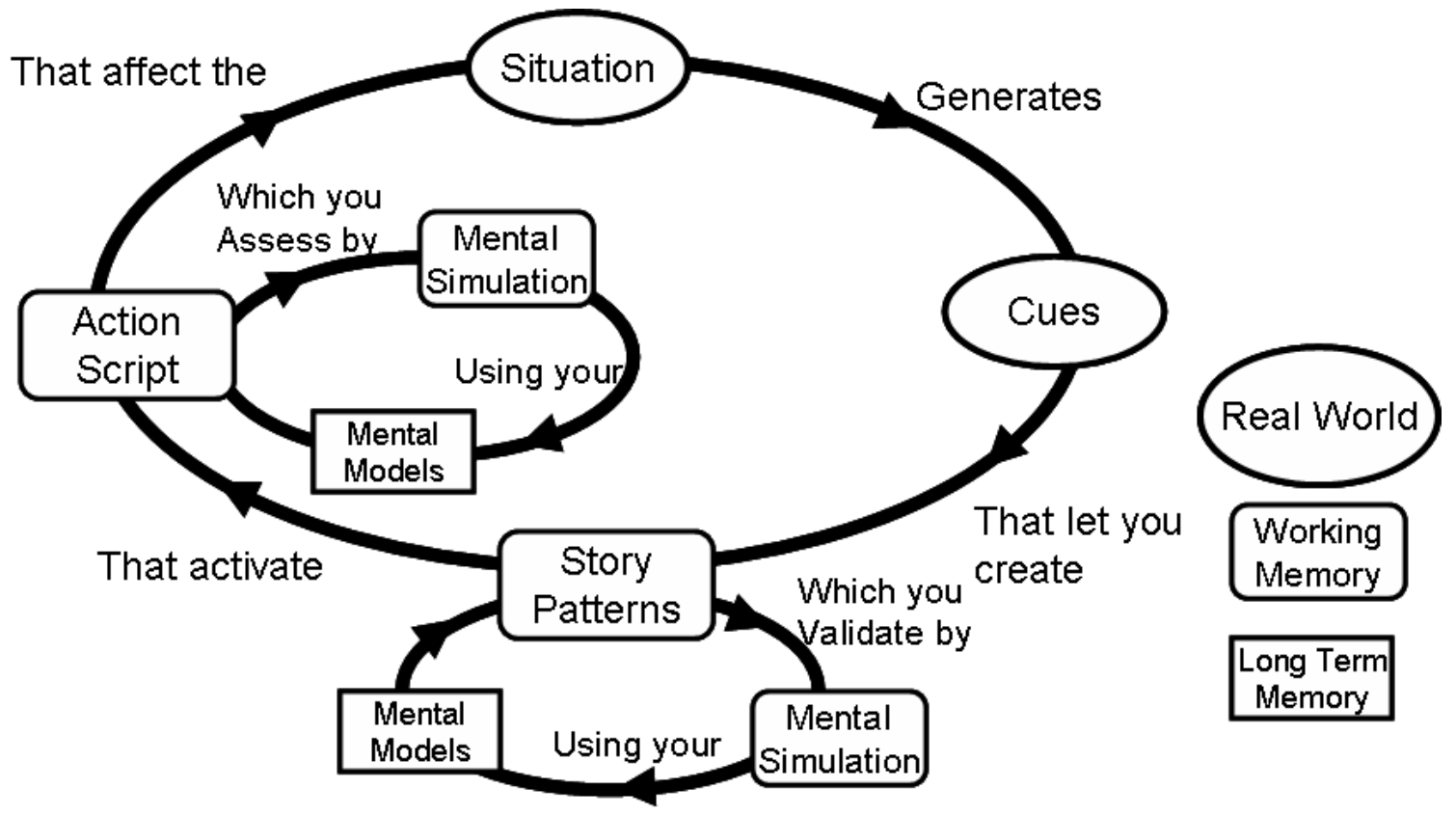

Figure 2. Proposed Integrated Naturalistic Decision Making Model. 
primarily sight and hearing. The rectangles with rounded corners represents deliberate controlled processes carried out in working memory (WM) - these may reflect rule-based activity or analytical/knowledge-based activity depending on the decision maker's experience with the situation. The pure rectangles depict mental models that are retrieved from long-term memory (LTM). The metacognitive R/M quick test is accommodated in the initial mental simulation loop. The second mental simulation loop reflects the need for the system operator to assess and anticipate the impacts of their control actions. The following sub-sections describe the main concepts and components of the model from a power grid operations perspective.

\subsubsection{Situation}

The situation or state of the system will vary based upon a number of factors, including:

- time of day

- current and forecasted system load and weather conditions for local and interconnected areas

- current and forecasted generation and transmission maintenance outages for local and interconnected areas

- current and forecasted interchange levels and flow patterns.

The situation or state of the system is presented to the system operator from a variety of sources, including:

- measurements from the SCADA system and data links

- communications with plant operators, substation operators, line crews, distribution operators, and neighboring control area operators

- reports on results of on-line analysis programs, results from operation planning studies, and operation planning engineers.

\subsubsection{Cues}

The Cues describe the operator's level of awareness regarding the current situation. The Cues are analogous to a sphere of understanding. A more experienced operator will have a larger sphere of understanding. He or she will be more sensitive to and will have a greater appreciation for various explicit and sometimes subtle inputs. Cues for the system operator are generated from system summary displays, alarm logs, abnormal summaries, charts, map boards, system overview displays. There are potentially thousands of variables for a Transmission Operator to look at. The saying "Too much data and not enough information" is often used to describe this situation. The more experienced operators can extract and focus on the key variables to summarize the overall situation. Examples include:

- MVAR reserves in an area

- voltage stability P-V margin

- sustained ramping capacity

- spinning reserves

- Area Control Error (ACE). 


\subsubsection{Patterns}

Using the cues to recognize key patterns is a critical step in the decision making process. Only by recognizing the correct patterns can the operator determine the appropriate actions. Some examples of the patterns that can be recognized from the various cues include:

- The system is vulnerable to a single line contingency; branch overloads are about to cause cascading thermal outages.

- The voltages in an area are very weak.

- A neighboring system is experiencing voltage problems and is drawing excessive MVARs from our system.

- The system is on the verge of voltage collapse.

- The system has large standing phase angles.

- A unit in our own control area has tripped and the generation reserves are insufficient to comply with the NERC CPS2 criteria.

The more experienced operators will be able to recognize a wider range of patterns and will more quickly detect when a new pattern has emerged.

\subsubsection{Story}

Using the cues to build a Story is a critical step in the decision making process. By using the mental models and the mental simulations to build a complete and consistent story the operators increase their SA.

The building of the Story corresponds to increasing the operator's level of SA from Level 1 through Level 3: (Endsley, 1997)

- Level 1: perceiving critical factors in the environment

- Level 2: understanding what those factors mean, particularly when integrated together in relation to the person's goals

- Level 3: understanding what will happen in the near future.

The more experienced operators are able to monitor a wider range of cues and are able to build a more complete and consistent Story compared to less experienced operators. Experienced decision makers work with evolving situation models or stories. They assimilate new cues with these models as a reference, while at the same time looking for gaps and conflicts while being prepared for surprises. When an unexpected or conflicting event occurs, they elaborate the story to take it into account. They maintain an awareness of their elaborative efforts and stay alert to the danger of going too far (Cohen et al., 1997).

\subsubsection{Action Scripts}

Action scripts are stored in our memory based upon past experience. The more experienced operators will have a wider range of action scripts. Based upon the different patterns that we recognize, our mind selects one or more action scripts for us to execute. Examples of action scripts include corrective actions such as:

- generator rescheduling

- adjusting control area interchanges

- adjusting phase shifters 
- line switching

- changing transformer taps

- $\quad$ switching shunt capacitors or reactors.

The NERC (2004) policy states that these corrective actions should be implemented as quickly as possible without regard to the economic cost. If there are lines or transformers that are exceeding their Short Term Emergency Ratings or buses that are exceeding their voltage limits, the System Operator has the authority and responsibility to implement the necessary remedial actions, including shedding load, to alleviate these overloads and violations.

\subsubsection{Mental Models}

As operators decide which corrective actions to implement, they test the prospective actions using various mental models to anticipate their impacts on the system. The experienced operator can usually estimate the directional trends that will occur for various control actions. Examples of mental models are ${ }^{1}$ :

- adding capacitance will increase local bus voltages

- a line will be unloaded by decreasing generation at the sending end and increasing generation at the receiving end.

Estimating the quantitative effects of control actions when the system is an unusual operating condition can be very difficult. A simulation or contingency analysis tool may be able supplement the operator's mental models. But in many cases, even if simulation or contingency analysis tools are available, the operator may not have sufficient time to use them. Experienced operators possess mental models and scripts that reflect the art of how to control the system a little at a time, monitor the changes, and then decide on a more definitive action. But unusual situations and abnormal events are problematic because required intuitive knowledge and scripts may not be readily available. Such conditions trigger a slightly different set of tactical, analytic thought processes and techniques - mental simulations represent this more controlled, analytic, and deliberative level of decision making.

\subsubsection{Mental Simulations}

The experienced system operator performs a mental simulation by first retrieving certain relevant mental models from long-term memory. The operator then runs a mental simulation using these mental models and checks to see if there is consistency with the cues that are being observed. Sometimes these mental models need to be triggered to be activated and retrieved from longterm memory. There is sometimes difficulty in connecting or associating mental models to see what in retrospect was an obvious consequence. An operator's understanding of the mental model is reflected in the depth and nature of the mental simulation.

As the operator processes the cues, he or she runs consistency checks such as:

"Are the MVARs flowing downhill on voltage?"

"Is the total MW into the bus equal to the total MW out of the bus?"

"Is the line loaded above or below the surge impedance loading level?"

"Are the MVARs for the open-ended line flowing into the bus?"

\footnotetext{
${ }^{1}$ Many more examples of mental models relevant to power grid operations are described in Appendix 2 of this report.
} 
Once the operator decides which corrective actions to implement, he or she tests the actions using mental models to anticipate their impact on the system. The experienced operator can usually estimate the directional trends that will occur for various control actions. For example:

- Adding capacitance will increase local bus voltages.

- A line will be unloaded by decreasing generation at the sending end and increasing generation at the receiving end.

However, when the system is in an unfamiliar/unusual operating state, estimating the quantitative effects of control actions can be very difficult. A simulation or contingency analysis tool may be able supplement the mental models of the operators. However, in many cases, even if they are available, there may not be sufficient time to use these tools. Experienced operators know the art of how to control the system a little at a time, monitor the changes, and then decide on a more definitive action. When faced with such unfamiliar or complex situations in which time does not allow contingency analysis or relevant analyses or simulations are not available, operators will turn to each other to discuss and get other perspectives. Developing and maintaining this shared SA is another critical factor in successful performance.

\section{$4 \quad$ Illustration and Application of the Model: A Power Grid Restoration Scenario}

The abstract concepts of NDM are best described, as well as tested and extended, when applied to real-world problems. To illustrate the analysis, we have developed an illustrative scenario.

The scenario involves a system restoration. Put simply, system restoration involves in part connecting islands to the entire system. At this point, operators are several days into the scenario and they need to connect the West system, operating as a separate electrical island to the Central system. The voltages at the Homer station are high and the voltages at the Moses station are low. The voltages have to be matched more closely before the Breakers 8 and 9 at Moses can be closed to tie the West and the Central system together, thus connecting the island to the system. In summary, the real-world problem is that data must be assimilated, voltages matched, and then the island can be connected to restore the system. A complete script of the scenario is provided in Appendix 1.

The problem is shown in Figure 3: Three power system operators are responsible for different sections of the power system:

- The West operator monitors and controls the west system, which includes the Homer Substation.

- The East operator monitors and controls the East System, which includes the Locher generating substation.

- The Central operator monitors and controls the Central system, which includes the Moses substation.

- The Reliability Coordinator (RC) oversees the West, East, and Central Systems. 


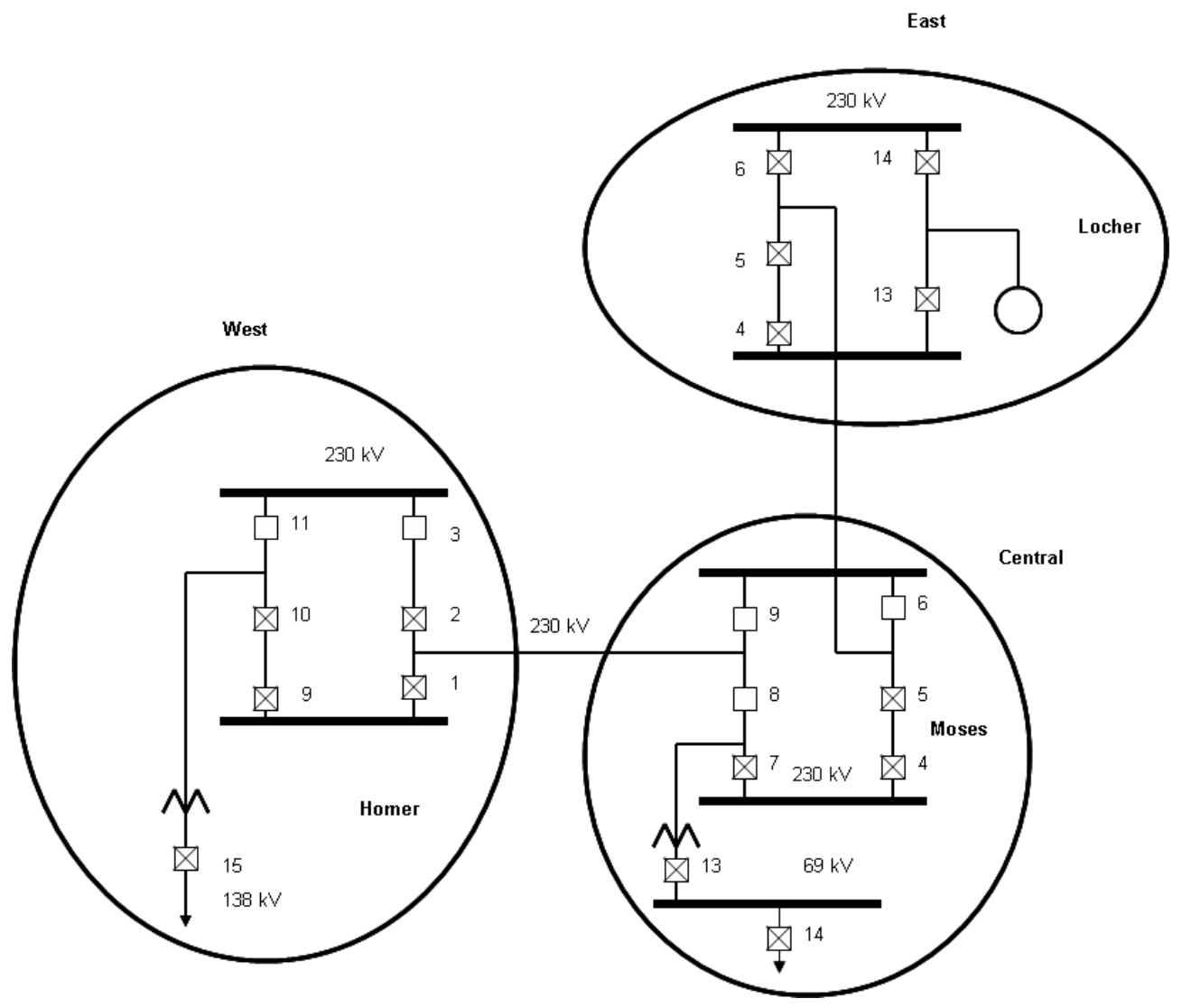

Figure 3. A Real-World Problem

\subsection{Cognitive Task Analysis}

We use cognitive task analysis (CTA) to capture and describe operator knowledge that relates to a real-world decision making task. CTA includes a number of methods to describe cognitive processes underlying performance as well as patterns of reasoning, problem solving, decision making, and collaborating and domain expertise and skill (Hoffman \& Militello, 2008, p. 5). CTA is challenging because experts have accumulated large bodies of knowledge through experience, and their perceptual and cognitive skills are hard to verbalize, especially when described by experts who are not performing the task in a realistic environment (Gordon \& Gill, 1997).

The use of a high-fidelity Electric Utility Grid Simulator effectively overcomes the major challenges of CTA for the following reasons:

- A very realistic environment can be created using simulation. The thoughts and reactions of operators under these conditions are therefore also very realistic.

- By having multiple role players and scenarios that force interaction between the roles, operators are required to explain thought processes to each other. The process that Klein (1993) calls Knowledge Elicitation or extracting information through observations, about cognitive events, structures, or models is therefore maximized. 
The manner in which the NDM processes have been integrated and applied to perform the CTA is shown in Figure 4. In this NDM Framework:

- Experts can perform a wide variety of normal, emergency, and system restoration tasks under simulated conditions.

- Tasks are performed under very realistic conditions. To truly capture expertise, the framework will cover near misses and difficult, tough, or unusual cases.

- Audio recording of conversations between operators will document the thought processes of each operator.

- Historical data recording and playback system will allow state of system to be rewound and reviewed.

- System operator vital signs including body temperature, pulse rate, respiration rate, blood pressure, perspiration, and brain activity can be optionally measured and recorded.

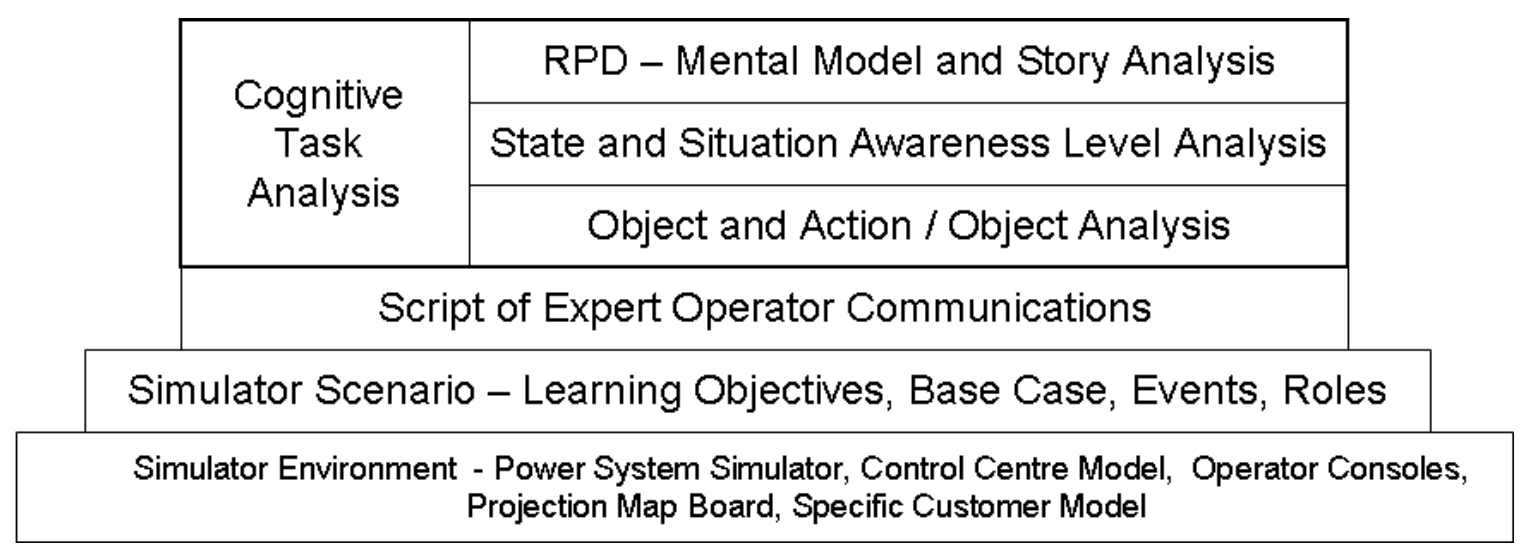

Figure 4. NDM Framework

\subsection{Object and Action / Object Analysis}

To support observation and analysis, we have applied object-oriented modeling methods to analyze the script of operator conversations. Object-oriented models are useful to understand problems, communicate with application experts and model enterprises (Rumbaugh, 1991). A script developed by subject matter experts (SMEs) in the electric utility industry was used. At the most basic level, the following analyses have been developed:

- Object Analysis - derived by listing all the nouns in the conversations

- Action Analysis - derived by listing all the verb and noun combinations referenced in the conversations.

- State Analysis - derived by listing all the observations or questions about the past, current, and projected future system state. 
These analyses can all be performed rather mechanically by processing the script of operator communications when this is available. They can also be performed without a written script. One can listen to the operator communications and note the new objects, the new action / object combinations as the scenario evolves. Tables 1, 2 and 3 show the results of the Object Analysis, Action Analysis, and State Analysis (respectively).

Table 1. Object Analysis Results

\begin{tabular}{|c|c|c|}
\hline Object & Object & Object \\
\hline $1 \mathrm{kV}$ limit & indications of line flows & request \\
\hline $138 \mathrm{kV}$ load centers & indications on breakers & required level \\
\hline 50 MVAR increment in output & island & $\begin{array}{l}\text { requirements of interconnection } \\
\text { check list }\end{array}$ \\
\hline adjacent substations & level & resources to raise voltage \\
\hline angle specification & level to allow closing & restoration check list \\
\hline another six hours & line breaker & restoration plan \\
\hline breaker & line capacitance & SCADA \\
\hline breakers on both sides of line & line crews & SCADA indications \\
\hline bus breaker & line ends & status boards \\
\hline cap banks & megawatt flow & substation \\
\hline central area & megavar flow & substation voltage \\
\hline concurrence from RC & megavar injections & system voltage \\
\hline current island & megavar transfers & the $230 \mathrm{kV}$ \\
\hline distribution load centers & megavars at no load & visual inspection \\
\hline end of line & megawatt transfers & voltage \\
\hline fault indication & method to raise voltage & voltage control devices \\
\hline faulted micro switch & megavar constraints & voltage differential \\
\hline faulty breaker position indicator & mvar reserves remaining & voltage differential across breaker \\
\hline frequency specification & note in system & line flows \\
\hline generator & open position & line status \\
\hline generator MVAR output & other restoration efforts & local voltage increase \\
\hline generator nominal levels & outside substation & voltage mismatch \\
\hline independent islands & personnel & voltage specification \\
\hline indications & position of breaker & west area \\
\hline
\end{tabular}


Table 2. Results of Action Analysis

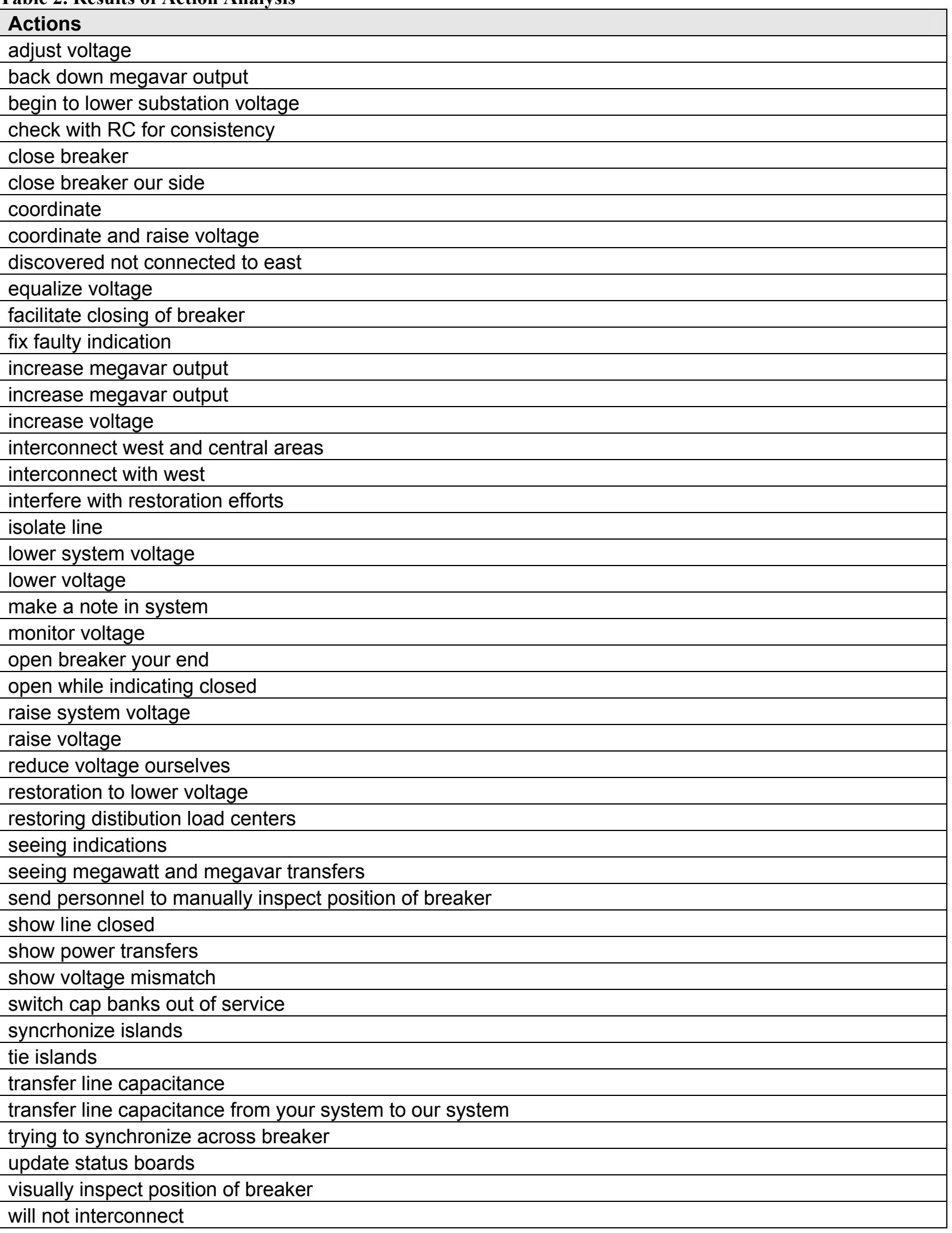


Table 3. Results of State Analysis

\begin{tabular}{|c|c|c|c|}
\hline Order & Step & State & Phase \\
\hline 1 & 21 & no way to raise voltage & current \\
\hline 2 & 25 & locher generator connected & current \\
\hline 3 & 25 & locher generator operating at nominal levels & current \\
\hline 4 & 25 & can increase megavar output to raise voltage & future \\
\hline 5 & 25 & make sure changing voltage will not interfere with other restoration efforts & future \\
\hline 6 & 26 & $230 \mathrm{kV}$ line is lightly loaded & current \\
\hline 7 & 26 & $230 \mathrm{kV}$ is able to handle additional megavar flow & current \\
\hline 8 & 30 & will there be sufficient reserves remaining & future \\
\hline 9 & 47 & voltage is unchanged & current \\
\hline 10 & 47 & line flows are not changed & current \\
\hline 11 & 47 & indications that breakers are closed & current \\
\hline 12 & 51 & seeing local voltage increase & current \\
\hline 13 & 51 & not seeing indications of increased line flows & current \\
\hline 14 & 51 & breakers both sides indicate closed & current \\
\hline 15 & 53 & breakers are closed & current \\
\hline 16 & 53 & voltage is not changing & current \\
\hline 17 & 61 & megavar output has been reduced & current \\
\hline 18 & 65 & have visually inspected breaker & current \\
\hline 19 & 65 & have found breaker open & current \\
\hline 20 & 65 & SCADA is indicating breaker is closed & current \\
\hline 21 & 66 & operating as independent islands & current \\
\hline 22 & 67 & areas are not connected & current \\
\hline 23 & 71 & line is out of service & current \\
\hline 24 & 71 & in process of repairing faulty micro-switch & current \\
\hline 25 & 71 & have micro-switch replaced by end of day & future \\
\hline 26 & 76 & there was a faulty breaker position indicator & current \\
\hline 27 & 76 & we will have to reduce voltage difference ourselves & future \\
\hline 28 & 77 & restoration for distribution load centers is taking longer & past \\
\hline 29 & 77 & line crews are stretched thin & current \\
\hline 30 & 77 & central to take 6 hours to restore $138 \mathrm{kV}$ load centers & future \\
\hline 31 & 79 & only megavar injections at Homer are from Homer-Moses line at our end & current \\
\hline 32 & 79 & Homer-Moses line is connected at our end but open at your end & current \\
\hline 33 & 81 & $\begin{array}{l}\text { Opening the Homer breaker to isolate the Homer - Moses line would lower the } \\
\text { voltage at Homer }\end{array}$ & future \\
\hline 34 & 82 & $\begin{array}{l}\text { Open the breaker your end, isolate the line, close the break our side. Transfer } \\
\text { line capacitance from your system to our system. Lower voltage at Homer, raise } \\
\text { voltage at Moses }\end{array}$ & future \\
\hline 35 & 87 & We can interconnect on the $230 \mathrm{kV}$ system using Homer breaker 1 & future \\
\hline 36 & 100 & Homer breaker 1 indicates open & current \\
\hline 37 & 102 & Moses breaker 8 indicates closed & current \\
\hline 38 & 106 & All requirements of Interconnection Checklist have been met & current \\
\hline 39 & 107 & The interconnection checklist is complete & current \\
\hline 40 & 113 & Voltage, frequency, phase are within spec & current \\
\hline 41 & 113 & We are seeing megawatt and megavar transfers across the line & current \\
\hline 42 & 118 & west and central are now interconnected & current \\
\hline
\end{tabular}




\subsection{State and Situation Awareness Level Analysis}

The SA Level Analysis is performed by listing in a separate column all the observations or questions about the past, current, and projected future system state. No elaboration is required. This is simply a matter of extracting relevant portions of the conversation.

The entries for the SA Level Analysis are color coded to indicate the SA Level (Endsley 1997) for the operator that is speaking.

- Orange: Level 1: perceiving critical factors in the environment

- Blue: Level 2: understanding what those factors mean, particularly when integrated together in relation to the person's goals

- Green: Level 3: understanding what will happen in the near future

- Red: identifies a point when there is an opportunity for the operator to exhibit or develop Level $2 \mathrm{SA}$, but this is not occurring.

As the scenario unfolds, the color codes progress from Orange to Blue to Green as we would expect. The color codes clearly show the quality of communication and shared SA among the operators. In the first scenario that we analyzed with four operators, the communications were clear, met the criteria to be considered excellent, and the colors all tended to be consistent at different points in the scenario. The SA Levels should be analyzed by someone familiar with the technique, but an expert power system operator is not necessary for analysis. Refer to Appendix 1 for the complete analysis table for the illustrative scenario.

\subsection{Mental Model and Story Analysis}

The theoretical proposition put forth in this report is that a competent system operator should have a basic mental model of all the objects and action / object combinations that are used in the expert operator conversations.

In the illustrative scenario, 72 objects and 55 action / object combinations were identified. Examples of objects were faulty breaker position indicator, frequency specification, generator, generator MVAR output, independent islands, indications of line flows, line breaker, line capacitance, and line crews. Examples of action / object combinations included interconnect west and central areas, interfere with restoration efforts, isolate line, lower system voltage, make a note in system, synchronize islands, transfer line capacitance from your system to our system, try to synchronize across breaker, and update status boards. For the illustrative scenario that we analyzed, the mental model of transmission line acting as a capacitor was not mentioned by the participants until Step 82 in the scenario. After this mental model was mentioned, it was quickly accepted and used by the all the operators. An effective solution was then quickly developed and agreed upon, specifically:

- Step 86: Central Operator to RC Operator: "We have a plan that should reduce the voltage mismatch across the $230 \mathrm{kV}$ Moses to Homer line and allow us to interconnect 
West and Central service areas. We propose to transfer the line capacitance of the $230 \mathrm{kV}$ Homer - Moses line from West to Central."

- Step 87: Central Operator to RC Operator: "West will open the $230 \mathrm{kV}$ Homer breakers 1 and 2. Central will close the $230 \mathrm{kV}$ Moses breaker 8 . This should lower the voltage at Homer and raise the voltage at Moses. If all goes according to plan, we can then interconnect on the $230 \mathrm{kV}$ system, using the Homer breaker 1."

The most essential element of this scenario can be found in the Action / Object combination: "transfer the line capacitance of the $230 \mathrm{kV}$ Homer - Moses line from West to Central." This key mental model did not seem to be in working memory of any operators until well into the scenario.

Another result of the analysis is to identify tacit knowledge of operators. The illustrative scenario was designed for experienced system operators who, by definition, possess a wealth of tacit knowledge, including how to recognize cues, a vast array of mental models, an ability to conduct a variety of mental simulations to predict what will happen on their system, and an ability to make intuitive decisions for reasons that are not at all obvious to the novice. Thus, the analysis helps to distinguish between expert and non-expert performance, which informs the instructional process.

\subsection{Summary of the Cognitive Task Analysis}

The Cognitive Task Analysis is a useful tool for explaining the thought processes of the system operators at all the steps in the scenario. The results from the scenario analysis can be summarized as follows:

- When expert power systems operators participate in a team-based simulator scenario that requires them to coordinate operations, their thought processes are naturally captured in their conversations.

- The script of operator conversations can be analyzed with an Object and Action / Object Analysis to determine the mental models used by the operators.

- The script of operator conversations can be analyzed to extract comments on the system state. These comments can be used to rank the SA Levels of each participant at each step of the scenario using the three levels defined by Endsley (1997).

- The analysis of the SA Levels seems to demonstrate the effectiveness of the operator communications.

- The mental models that are crucial to solving the particular operating problem are very clearly identified along with the time when the operators retrieve this model from longterm memory.

- The mental simulations and mental models used by the operators can be identified.

- The action scripts that are considered and selected are clearly identified. 
The results of this cognitive task analysis test case have significant implications for training, as will be discussed in Section 5.

\subsection{Benefits of the Model and Analysis}

The potential benefits of the RPD analysis can be summarized as follows:

- The RPD analysis provides a systematic approach for conducting a session debrief.

- The RPD provides a framework for the expert and novice operator to answer the question "What were you thinking at the time you made such and such a decision."

- The RPD analysis converts all the tacit assumptions and knowledge of the expert operator into an explicit, clearly documented description.

It is well known that with "Monday morning quarterbacking" we can always gain more insight compared to when the players are in the middle of the game. The framework and associated analysis method that we have established provides a systematic means of identifying such insight and behaviors requiring training intervention or mitigation during or immediately following execution of the scenario.

\section{$5 \quad$ Application to Training on Power Grid Critical Decision Making}

The training development/training management process is depicted in Figure 5. The process is continually and dynamically updated but may begin with selection of a problem domain from a list of operational issues and training requirements that must be addressed over an operator's career. Typically, learning objectives are specified only at a general level, such as "the operator will demonstrate skills in interpersonal communication protocols in multi-balancing authority coordinated operations." Based on the selected problem area and learning objectives, a training scenario is developed that includes problems that exercise the desired skills. When informed by the more specific and rigorous concepts and performance criteria available in cognitive task analysis and naturalistic decision making approaches, the instructional design team is able to prepare a detailed training management and mitigation plan that is based on the operator's demonstration of understanding (or lack of understanding) of requisite cues, patterns, mental models, action scripts, etc. that are involved in critical decision making solutions to the scenario. That is, instead of reacting to relatively gross behavior or outcomes, the training manager/instructor is armed with specific guidelines or behavioral/performance "targets" (indicators) that identify possible deficiencies. With this detailed information, the trainer may choose to interrupt the exercise immediately to discuss problems, or he/she may note the discrepancies between actual and optimal performance and review the incorrect or missing concepts in an after-action debriefing. In this way, we believe that training will progress more efficiently, and with an enhanced ability to identify deficiencies and instill greater understanding in trainees that may be taken away and applied in the field. 


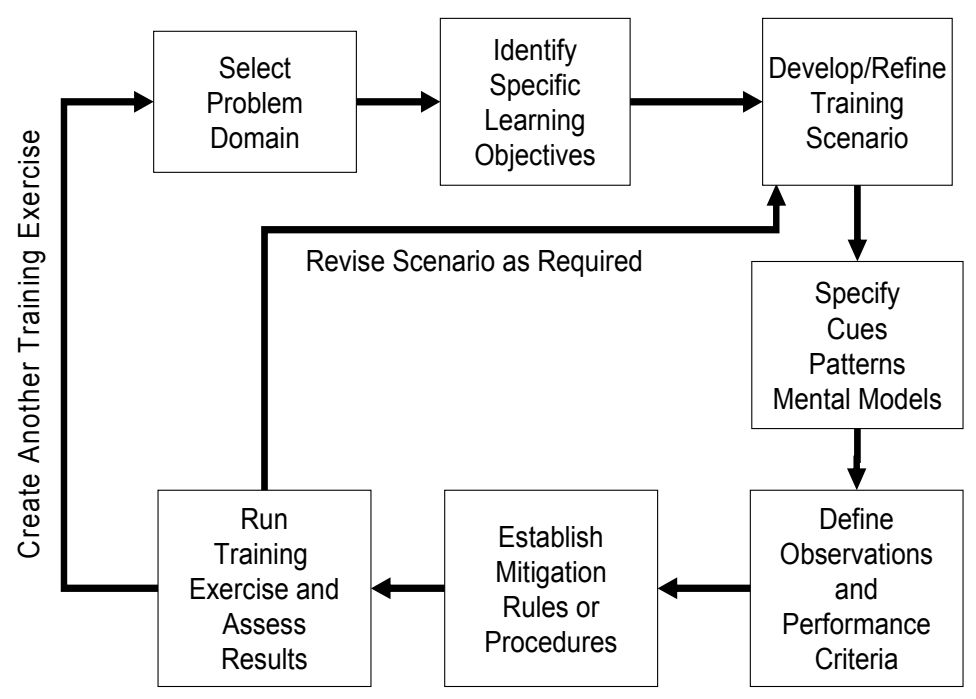

Figure 5: General Training Development/Management Process

Since the RPD model was introduced to the power industry following the blackout of 2003, training has been structured so that there is a much stronger linkage between the classroom content and the simulator-based exercises. This includes explicit training about cues, patterns, and mental models that are critical to perform various operating tasks. Currently, over 2000 system operators are trained each year using the PowerSimulator (Podmore et al., 2008).

Cognitive debriefing resulting from simulation training is critical to capturing the knowledge and expertise of the expert participants. In the simulation environment, very little explicit knowledge is captured (Nonaka, 1987). In the medical field, which also heavily uses simulation training, the literature points to Cognitive dispositions to respond (CDR) as patterns of thought that may lead to suboptimal decisions. These patterns have three components: heuristics, affective, and emotional (Bond et al., 2006). A debrief to identify these patterns as well as styles of thinking such as "thinking in silos," a vertical line failure, are essential in reducing decision errors.

The NDM analysis of recorded and transcribed conversations will allow the instructor to conduct a detailed analysis of the training sessions. From this analysis, additional scenarios and training curricula can be developed with increasingly more precision with the goal of minimizing cognitive errors, or the root biases and failed heuristics underlying them. Thus, the methodology described here significantly strengthens and informs the feedback loop in Figure 5.

If we can really measure the operator thought processes in terms of Cues Monitored, Levels of Situational Awareness, Mental Models retrieved, Mental Simulations being run, and Stories being built as accurately and as simply as this example suggests, then this could have some fairly profound impacts on how we develop training curricula and programs.

Of course, more scenarios need to be analyzed to see if this one is typical or atypical. 


\subsection{Measuring Performance of Experts versus Rookies}

It has been noted in general that experts spend more time and care in observing and orienting themselves to their environment and situation before making a decision and taking an action (Endsley, 1997). The authors have also personally noted that expert power system operators like to spend more time thinking through the plan and developing a complete and consistent story compared to rookie operators. The addition of the loop to "Validate the Story with a Mental Simulation Using Your Mental Models" was added at the insistence of Mr. Chuck Johansson to stress the importance of this step. Time and again in simulator scenarios we see the rookie attitude of "let's close it in a see what happens" (no doubt encouraged by their time with video games) balanced by the more experienced operator's cautions of "no let's look a little further and be sure we can anticipate what will happen." As we perform more experiments with groups of Rookie and Expert operators, we will be able to use the Human Factors Analysis to clearly document their level of SA at each step of the scenario.

\subsection{Identifying Gaps in Knowledge}

The draft NERC PER 005 Personnel Standard requires that Reliability Coordinators, Transmission Operators, and Balancing Authority Operators measure the competency gap for their individual system operators. The Object and Action Analysis provides a list of basic concepts for both rookie and expert operators to review and make sure that they have mental models for all of the objects and actions. The Object and Action Analysis implements and accelerates an informal approach that is sometimes used in on the job training. System operators sometimes teach themselves by noting every term that is unfamiliar and then asking their mentor to explain this when they have the time. The Object and Action Analysis can be performed simply without requiring a complete transcript of the conversations. During the scenario, the instructor can designate that one of the team members should take note of all the new objects and action / object combinations are they occur in the conversations. This assignment is a good one for the most junior member in the class.

\subsection{Developing More Advanced Scenarios}

There is an art to being a simulator instructor that can adapt on the fly and introduce the right amount of complexity into a scenario as it evolves. This art and intuition are needed to answer questions such as:

- How well are the students keeping up with the current scenario?

- If I add this event, how do I expect the system and the students respond?

- What concepts can I add in addition to the ones currently being covered?

The Object and Action Analysis can be a useful tool for identifying and communicating how complexity can be added to scenarios. The analysis identifies the Objects and Actions that were used and communicated in the particular scenario, but there may be other important Objects and Actions that were not used and/or not relevant to this scenario. 
A review of the scenario object and action list can trigger an instructor to identify areas where the scenario may be taken to another level. For example, in the illustrative island synchronization scenario, there was no mention of the terms weak bus, runaway transformer taps or the tap changers. A more detailed review of the scenario might raise the following questions:

- What if the Moses bus is very weak compared to the Homer bus? Could transferring the line capacitance from Homer to Moses create an over-voltage on the Moses bus?

- What if there is no synchronizing breaker at Moses and we are forced to synchronize at Homer? Can the voltage at Moses be lowered by adjusting tap settings at Homer?

- What about runaway transformer taps? Leave the tap changers in auto mode. Make sure the system operators put them in manual mode; otherwise, tap will run away and create extreme high side voltages.

- What if the Moses island has limited megavar reserves? It may not be able absorb the charging megavars from the Homer - Moses line and could cause over-excitation and generator damage.

In summary, the object, action, and state analysis gives the instructor a low-cost tool to review what the students were thinking during the scenario. It provides a vehicle to close what is otherwise an open loop for the instructor.

\section{$6 \quad$ Application to Usability Testing of Power Grid Analytical and Visualization Tools}

There is a trend in the industry where vendors are supplying data display subsystems that can be retrofitted onto existing SCADA and Energy Management Systems. Each of these systems can potentially present usability challenges when integrated into operational environments. The framework and methodology described in this report may be used to systematically evaluate the usability of these tools and visualizations. Examples of commercial products in this general category of enhanced displays and subsystems include:

- PI Historian from OSIsoft. The PI system brings all operational data into a single system that can deliver it to users at all levels of the company-from the plant floor to the enterprise level.

- PowerWorld Retriever from PowerWorld. PowerWorld Retriever gives operators a realtime or historic view of the power system and its various parameters quickly, accurately, and in a format that increases situational awareness.

- eterravision from Areva. eterravision helps operators anticipate and prevent potential problems by enabling them to fully visualize their networks in real time.

- PowerVisuals from Incremental Systems and PowerData is a family of Net-enabled graphical user interface products that can be used for monitoring and controlling real- 
time event-driven processes as well as maintaining and accessing their underlying databases. PowerVisuals supports user-defined display types that are typically found in modern Energy Management, SCADA, and process control systems including:

- system overview schematic diagrams

- substation one-line diagrams

- Repeat tabular (spreadsheet) displays.

In addition, there are several products being developed as part of U.S. government research that present similar challenges for usability testing. The U.S. government is investing significant resources into research and development of advanced methods for Grid Visualization:

- Visual Analytics Centers. In 2004, the U.S. Department of Homeland Security (DHS) chartered the National Visualization and Analytics Center ${ }^{\mathrm{TM}}$ (NVAC ${ }^{\mathrm{TM}}$ ) at the Pacific Northwest National Laboratory to define a long-term research and development agenda for visual analytics. NVAC established the family of Visualization and Analytics Centers (VACs) through academic, government, and industrial partnerships. ${ }^{2}$ The U.S. government faces critical challenges in identifying and preventing attacks on U.S. soil. At the same time, businesses have a driving need to understand rapidly changing markets to remain financially healthy. Disaster management requires rapid assessment of complex and dynamic situations to save lives and property. The VACs are a national and international resource, fulfilling a fundamental need to provide advanced analytical tools to make progress in understanding and addressing these challenges. VACs will provide high throughput visual analytics that are accessible to all, enabling anticipation and prediction of, preparedness for, and response to man-made and natural disasters and terrorist incidents for resilient national freedoms and security. VACs' primary task is supporting DHS's mission by giving analysts and emergency responders technology and capabilities to detect, prevent, and reduce the threat of terrorist attacks; identify and assess threats and vulnerabilities to the United States; and recover and minimize damage from terrorist attacks, should they occur.

- VERDE. Visualizing Energy Resources Dynamically on Earth (VERDE) is a U.S. Department of Energy (DOE) Office of Electricity Delivery and Energy Reliability sponsored effort. ${ }^{3}$ The VERDE project was initiated by DOE in response to the devastating hurricanes in 2005. The goal of VERDE is to coordinate federal response to natural disasters or major events. The project is being performed by Oak Ridge National Laboratory (ORNL), in partnership with the Tennessee Valley Authority (TVA). VERDE is a real-time grid visualization tool that will initially assess status of transmission lines in the Southeast. VERDE provides real-time status of transmission lines, real-time weather overlays, predictive impact models and animated replay data analysis, and energy infrastructure interdependencies (such as coal delivery and rail lines, refinery and oil wells, natural gas pipelines, transportation and evacuation routes, and population impacts). VERDE is connected via an ICCP data link to NERCnet, which provides real-time data every minute. TVA extracts data and translates line status - in or out of service. ORNL provides an electric dynamic grid analysis that overlays weather,

${ }^{2}$ http://nvac.pnl.gov/docs/VisualizingAnalytics.pdf

${ }^{3}$ http://phasors.pnl.gov/Meetings/2007_may/presentations/verde brief.pdf 
population, transportation, and electrical network data; visual displays are sent to DOE every minute.

Another trend is specialized vendors supplying add-on analytical tools with their own closely coupled user interfaces. Examples of such analytical tool systems include:

- The DSATools from PowerTech, Vancouver, Canada. DSATools provides the complete assessment of system security including all forms of stability. The key components in the suite, VSAT, TSAT, and SSAT, have also been designed to be used for on-line dynamic security assessment (DSA). In this mode, the software is connected directly to a power system's energy management system (EMS) and computes system security in a continuous cycle. The software provides system operators with important information about system security limits, critical contingencies, and remedial actions needed to prevent system failures.

- Secure Suite from Bigwood Systems. Secure Suite includes: Transient Stability Analysis and Enhancement (TEPCO-BCU), Voltage Stability Analysis and Enhancement (VSA\&E), Small-Signal Stability Analysis and Enhancement (ECLIPS), Static Security Assessment and Corrective Control (SSA\&C), and Security-Constrained Available Transfer Capability Analysis (SC-ATC).

- Physical and Operational Margins (POM) from V and R Systems. POM-RT is a powerful voltage stability and contingency analysis tool that provides real-time solutions for the operations environment. POM-TS is an add-on module integrated into POM. It is a fast and comprehensive dynamic simulation program that offers the capability to simulate balanced and unbalanced faults and determine transient stability limits after any disturbance is applied to a power system network.

The Human Factors framework that has been outlined in the previous sections can be used for the systematic evaluation of usability for existing and new analytical and visualization toolsthose described above as well as other displays, analysis, and visualization tools that are in development at the Pacific Northwest National Laboratory. The evaluation methodology, based on the framework presented in this report, is described in the following subsections.

\subsection{Evaluation of Analytical Tools}

The RPDM has been successful and widely adopted because it really does describe how an expert human makes a decision for many fields. A big problem for Power System Analytical Tools is that they often do not include the operator in the decision making loop and they provide recommendations that are counter-intuitive. This can be a problem even when the counterintuitive recommendations are correct. There is a spiral of trust that must be built between the system operator and the analytical tool.

This is the case with PowerSimulator. There may be cases where the system will black out due to an action by the power system operator. If the cause of the blackout is not obvious, there is a tendency to blame the program. The robustness of the program has now developed to the point where, in almost all cases, we can point to operating error as the cause. This has greatly increased the trust that operators have in the program compared to the early days when islands 
would black out due to various non-physical reasons. The problem is aggravated for the Power System Analytical Tool Developer when we tell him or her that the program does not work like an expert operator, but we can not give any specifics on how an expert operator makes a decision. With the Human Factors Framework, we can record and analyze the performance of an expert team of operators with and without the Analytical Tool. We can also record and analyze the performance of a rookie team of operators with and without the Analytical Tool. A good Analytical Tool should make a measurable improvement in the performance of the expert operators and an even more significant improvement in the performance of the rookie operators.

The Human Factors Framework will allow analysts to provide much more specific feedback on how Power System Analytical Tools should be enhanced for usability, robustness, and performance.

\subsection{Evaluation of Visualization Tools}

Visualization Tools have been developed almost universally from the viewpoint of presenting a complex system state to the power system operator. This in itself is a complex problem. An operator essentially has to be able to visualize the system in three dimensions.

- Spatial - what is the pattern of voltages and flows across the current system state?

- Temporal - how will the system change over the course of a shift as the load picks up or drops off and transactions come and go? What will the pattern of voltages and flows across the system look like in the future?

- Contingency - how will the system respond to the most severe single contingency and certain multiple contingencies? What will the pattern of voltages and flows across the system look like if these events occur right now? What will the pattern of voltages and flows across the system look like if these events occur in the future?

The true effectiveness of the advanced display techniques can only be really tested when the system moves into an emergency or restorative state. Under these conditions, when large volumes of data are rapidly changing on a wide-area basis, it is critical that the system remain responsive. Ideally, the system should allow the operator to understand the root-cause events that created the current situation and help him/her quickly evaluate options for restoring the system to a normal state.

The Human Factors framework developed in the present study can provide an excellent test bed for evaluating a range of visualization tools:

- The Areva System can naturally be used to test the Areva eterravision system on customers that have an Areva DTS operational.

- Some Areva customers, e.g.. ISO New England and Southwest Power Pool, have integrated PowerWorld Retriever with the Areva Energy Management System. 
- PowerSimulator can be used to demonstrate the effectiveness of the PowerVisuals System Map and Station displays for a wide range of models under normal, emergency, and restoration conditions.

PowerSimulator has been designed in such a way that it can be linked to third-party Visualization Tools and third party Analytical Tools with relative ease. PowerSimulator includes an openly published real-time Application Program Interface (API) so the third-party display systems and third-party applications can retrieve the following data from the simulator:

- breaker oriented model of the power system

- bus branch oriented model of the power system

- real-time simulation of the SCADA data.

The third-party Visualization Tools and Analytical Applications are not meant to replace the basic user interface that is being supplied by existing EMS vendors for SCADA operations. They are focused on providing a view of the big picture. PowerSimulator includes the basic SCADA and AGC functions so that system operators can implement the necessary control actions in a real-time closed loop fashion after they have developed the required level of situational awareness with the third party Visualization and Analytical Tools.

\subsection{Industry Track Record}

The Energy Management industry has a spotty track record in prototyping, developing, and implementing widespread deployment of advanced analytical tools and visualization methods. Even steady state network applications such as state estimator and contingency analysis are notoriously difficult to commission and then maintain. Customers often use the phrases:

- "Designed by engineers for engineers."

- “An engineer's dream and operator's nightmare."

- "Too many tabular displays."

The Eastern U.S. blackout of 2003 is an indication of the complexity these programs. The MISO state estimator was turned off by the application engineer, but the MISO system operator was not aware of this.

These problems are not unique to the power business. They occur in many industries. Operators shape tools based on their interests, constraints, and task demands. They stick with stereotypical routines to avoid getting lost in large and complex menu structures and complex sets of alternative methods (Miller and Woods, 1997). 


\subsection{Benefits of a Human Factors Framework}

A systematic Human Factors based analysis of the analytical tools and visualization methods for mission critical real-time environments has been a major focus of research conducted at the Pacific Northwest National Laboratory (PNNL) in support of power grid operations (Greitzer et al., 2008; Guttromson et al., 2007) as well as in the broader naturalistic decision making community.

As stated earlier, Visualization Tools have been developed almost universally from the viewpoint of presenting a complex system state to the power system operator. While this is a very important part of the problem, it is only a partial solution. The other, equally important, part of the problem is how to stimulate the operator to recall the correct mental models that are required to solve the problem. This is certainly a challenge and goal for training, but it also may be considered a possible contribution of operator aids and decision support systems. A possible operator aid would be a collection of mental models that would be indexed to certain types of problems, so they would be readily available for reference during off-normal operations. This might increase the likelihood that the decision aids would be applied appropriately. Appendix 2 is an initial step toward documenting mental models - a more interactive implementation could conceivably serve as a decision aid or cueing function to prompt and enable decision makers to consider appropriate mental models earlier. ${ }^{4}$

Some of the benefits of using the Human Factors Framework to perform usability testing are:

- Ensure that the interface design is compatible with an expert operator's mental model of the system. These mental models will be precisely identified.

- Ensure ease of navigation through menus by both novice and experienced users.

- Usability testing can be done on the back end of the development cycle for existing systems.

- Usability testing can be done one the front end of the development cycle for new applications, especially ones that use Phasor Measurement Units (PMUs).

- It decreases the time to market success and increases the acceptance rate of these applications.

- It is transition oriented - providing better displays about events, targets, and transitions.

- It is future oriented-while existing systems focus on capturing current configuration, this approach supports methods and mind-sets for projecting the state of the system into the future.

\footnotetext{
${ }^{4}$ Imagine, for example, if we were to show the operator a picture of a transmission line mental model (example 2 or 4 in Appendix 2 ) as a prompt early in the restoration scenario illustrated in this report. This would likely have led to the consideration of the most important mental model earlier in the process.
} 
- It is pattern based-system operators can scan at a glance and pick up possible unexpected or abnormal system conditions about the transmission grid rather than having to read and integrate each individual piece of data to make an overall assessment.

\section{Discussion}

In this report, the processes and principles of Recognition Primed Decision Making, Recognition/Meta-Recognition, and SA have been combined into an integrated decision making model. This integrated model has been applied along with a Cognitive Task Analysis to develop a more detailed approach to electric power system operator training for emergency scenarios within a grid simulation environment. The theory and approach described how conversations that occur when expert power systems operators participate in a team-based scenario may be used to inform the analysis and specify critical learning criteria that are tied to a model-based framework for naturalistic decision making. Results are promising and are being applied to the development of new training scenarios as well as to establish a more rigorous environment for testing and evaluating new operator decision aids or displays. The key findings are that the framework described in this research can explain the thought processes of the system operators at all the steps in an operational scenario; it supports the identification of key mental models that are critical to solving power grid operations problems; and it provides a basis from which to inform and enhance training programs for power grid operations and accelerate learning of key learning objectives.

Among the most significant findings are:

- The enhanced RPD model is able capture the thought processes of the system operators at all steps in the scenario.

- The situational awareness of the system operators can be measured using Endsley's three Levels of SA at each step of the scenario.

- The mental models crucial to solving the particular operating problem may be clearly identified along with the time when the operators either retrieve or fail to retrieve the model from long-term memory.

- The mental simulations that the operators deploy using this mental model are clearly identified.

\section{Conclusions and Recommendations}

Some of the benefits of using the Human Factors Framework to inform design, perform usability testing, and improve training for power grid operations are:

- ensures that the interface designs will be compatible with an expert operators mental model of the system. These mental models will be precisely identified 
- ensures ease of navigation through menus by both novice and experienced users.

- can be done on the back end of the development cycle for existing systems

- can be done at the front end of the development cycle for new applications

- can decrease the time to market success and increase the acceptance rate of these applications

- transition oriented — better displays about events, targets, and transitions

- future oriented-existing systems focus on capturing current configuration and how to project state of system into the future

- pattern based - system operators can scan at a glance and pick up possible unexpected or abnormal system conditions about the transmission grid rather than having to read and integrate each individual piece of data to make an overall assessment

- more effective training scenarios, keyed to specific learning objectives and naturalistic decision making components (mental models, etc.)

- more effective performance measures and criteria for training management and accelerated learning for power grid critical decision making.

Our theoretical proposition regarding the application of RPDM to power grid operational training and decision making, and to assessment of the usability and effectiveness of new tools and visualizations, has produced interesting and promising findings. We have shown how to develop strong linkages among simulated learning opportunities, integrated feedback, and debriefings that are informed by the theoretical framework outlined here. Analysis of usability and effectiveness appears to be enhanced and informed by the application of the RPDM framework.

As a result of this test case, we recommend the following research and applied thrusts to advance human factors theory and practice within the power industry:

1. Continue application of this HF framework and analysis approach to advance and demonstrate the value of the analyses, in conjunction with simulation capabilities of the EIOC, to further the DOE mission in improving and strengthening the electric power utility infrastructure. Specifically, this objective may be accomplished by identifying strategies for improving training and providing HF analyses to guide the development of next-generation Wide Area Display technologies.

2. Continue to advance the HF framework and methodology to provide direct benefits to stakeholders within the electric power grid community. Specific aims are to more precisely measure the cognitive gaps in novice and expert power system operators; apply the results of this analysis to accelerate the training programs for new power system operators; and systematically evaluate the usability of the next generation of tools for managing a Smart Grid. 
3. Conduct evaluations and enhance the design of Wide Area visualization/decision support tools. Bring together the HF analysis methods with the capabilities of the EIOC to provide a unique platform for researching, developing, and deploying technologies to better manage and control the grid. Ongoing PNNL research focuses on developing real-time tools and supporting their integration into operating systems. New tools can provide a better view of the power grid, as well as faster and more accurate predictions of what might be happening so operators can quickly respond. We can use our human factors methods and advanced evaluation framework to examine the potential effectiveness of such tools. Examples are the Modal Analysis of Grid Operations (MANGO) tool that allows grid operators to "see" in real-time, the oscillations on the grid such as those that led to the 1996 West Coast and 2003 East Coast blackouts; the newly conceived Transient Analysis of Grid Operations (TANGO) tool that will allow grid operators to anticipate in real time the transient stability margins; and other new computational and visualization techniques.

4. Engage directly with utility operators. We have identified several commercial utilities whose models we can get running quickly in the EIOC. We can offer an attractive package for improving their operations, conducting demonstrations and evaluations of advanced training concepts, and providing a testbed and associated HF methods to assess the effectiveness of tools and procedures that will address both technical and human-factor issues such as those experienced during the August 2003 Blackout event and its restoration process.

5. Pursue opportunities to exploit the PNNL EIOC for training workshops, based on the framework described in this report, and as a test bed for evaluating new procedures, decision aids, and visualization techniques. Implementing a comprehensive HF Framework within the EIOC will provide a systematic foundation for validating and verifying that system operators will perform their jobs better with the proposed new tools and training. Because the EIOC is a safe setting, researchers can work through the iterative process of developing and refining technology more quickly.

In conclusion, this research demonstrates the capability to meet critical mission objectives of the DOE as well as strengthen the role of PNNL and the EIOC as a resource and test bed for power grid training and visualization analysis.

\section{$9 \quad$ References}

Bond, W., Deitrick, L., Eberhardt, M., Barr, G., Kane, B., Worrilow, C., Arnold, D., \& Croskerry, P. (2006). Cognitive versus technical debriefing after simulation training. Academic Emergency Medicine, 13, (3), p. 276-283.

Cohen, M. S., Freeman, J. T. \& Thompson, B. B. (1997). Training the Naturalistic Decision Maker (Chapter 25), in C.E. Zsambok \& G. Klein (eds.), Naturalistic Decision Making. Mahwah, NJ: Lawrence Erlbaum Associates.

Dekker, S. and M. Lutzhoft. (2004), "Correspondence, cognition and sensemaking: A radical empiricist view of situation awareness," In S. Banbury and S. Tremblay (Eds.), A cognitive approach to situation awareness: Theory and application. Burlington, VT: Ashgate Publishing Company. Pp. 22-41. 
Endsley, M. R. (1988). "Design and evaluation for situation awareness enhancement," In Proc. Human Factors Society 32nd Annual Meeting, Santa Monica, CA, 1988.

Endsley, M. R. (1995), "Toward a theory of situation awareness in dynamic systems," Human Factors, vol. 37(1), pp.32-64.

Endsley, M. R. (1997). The role of situation awareness in naturalistic decision making (Chapter 26), in C.E. Zsambok \& G. Klein (eds.), Naturalistic Decision Making. Mahwah, NJ: Lawrence Erlbaum Associates.

Flach, J., M. Mulder, and M. M. van Paasen (2004). The concept of the situation in psychology," In S. Banbury and S. Tremblay (Eds.), A cognitive approach to situation awareness: Theory and application. Burlington, VT: Ashgate Publishing Company. Pp. 42-60.

Gordon, S. E. \& Gill, R. T. (1997). Cognitive Task Analysis (Chapter 13), in C.E. Zsambok \& G. Klein (eds.), Naturalistic Decision Making. Mahwah, NJ: Lawrence Erlbaum Associates.

Greitzer, F. L., R. L. Hershman, and J. Kaiwi (1985), "Intelligent interfaces for C ${ }^{2}$ operability", in Proceedings of the IEEE International Conference on Systems, Man, and Cybernetics. November 1985.

Greitzer, F. L., Schur, A., Paget, M., \& Guttromson, R. T. (2008). A sensemaking perspective on situation awareness in power grid operations. Proceedings, IEEE Power \& Energy Society Annual Meeting, 20-24 July 2008, Pittsburgh, PA. PNNL-SA-58145

Guttromson, R.T., A Schur, FL Greitzer, \& M Paget (2007). Human factors for situation awareness in power grid operations. Pacific Northwest National Laboratory: Report PNNL-167803. August, 2007.

Hammond, K. R., Hamm, R. M., Grassia, J., \& Pearson, T. (1987). Direct comparison of the efficacy of intuitive and analytical cognition in expert judgment. IEEE Transactions on Systems, Man, and Cybernetics, SMC-17(5), 753-770.

Hoffman, R., \& Militello, L. (2008). Perspectives on cognitive task analysis: Historical origins and modern communities of practice. New York: Psychology Press.

Hunter, K.O., W.E. Hart, \& C. Forsythe. (2000). A naturalistic decision making model for simulated human combatants. Technical Report SAND2000-0974. Albuquerque, NM: Sandia National Laboratories. Retrieved from: http://www.osti.gov/bridge/product.biblio.jsp?osti_id=756444 and http://209.85.173.104/search?q=cache:F3V0I9191d0J:nsdl.org/resource/2200/20061005024437856T+Hunter+Hart+Forsythe+Simulat $\underline{\text { ed }+ \text { Human }+ \text { Combatants } \& h l=\text { en } \& \mathrm{ct}=\text { clnk\&cd }=2 \& \mathrm{gl}=\mathrm{us}}$ and http:/www.sisostds.org/index.php?tg=fileman\&idx=get\&id=2\&gr=Y\&path=CGF-BRIMS\%2F9th+CGFBR\%2F9TH+Abstracts $\% 2 \mathrm{C}+$ Papers + and + Presentations \&file $=$ RPDfinal.rtf

Klein, G. A. (1993). A recognition-primed decision (RPD) model of rapid decision making. In G. A. Klein, J. Orasanu, R. Calderwood, \& C.E. Zsambok (Eds.), Decision making in action: Models and methods (pp. 138-147). Norwood, NJ: Ablex.

Klein, G., B. Moon, and R. F. Hoffman (2006), "Making sense of sensemaking I: Alternative perspectives," IEEE Intelligent Systems, 21(4), 70-73.

Miller, G. A. (1956). "The magical number seven, plus or minus two: Some limits on our capacity to process information," Psychological Review, 63, 81-96.

Miller, T. E. \& Woods, D. D., (1997). Key Issues for Naturalistic Decision Making Researchers in System Design, (Chapter 14), in C.E. Zsambok \& G. Klein (eds.), Naturalistic Decision Making. Mahwah, NJ: Lawrence Erlbaum Associates.

NERC (2004). A Review of System Operations Leading up to the Blackout of August 14, 2003. North American Electric Reliability Corporation (NERC), Princeton, New Jersey. 
Nonaka, I. (1987). "The Knowledge Creating Company, Harvard Business Review on Knowledge Management”, Harvard Business School Press.

Podmore, R., Robinson, M., Sadinsky, M. \& Sease, R. (2008). A virtual instructor for simulator training, Proceedings, IEEE Power \& Energy Society Annual Meeting, 20-24 July 2008, Pittsburgh, PA.

Rasmussen, J. (1993). Skill, rules, and knowledge: Signals, signs and symbols, and other distinctions in human performance models. IEEE Transactions on Systems, Man, and Cybernetics, SMC-13(3), 257-267.

Rumbaugh, J. (1991). Object Oriented Modeling and Design, Prentice Hall, 1991.

Weick, K. E. (1995), Sensemaking in organizations. Thousand Oaks, CA: Sage Publications.

U.S.-Canada Power System Outage Task Force, 2004, "Final Report on the August 14, 2003 Blackout in the United States and Canada: Causes and Recommendations."

U.S. House of Representatives Full Committee on Energy and Commerce, Hon. John D. Dingell, Chairman. (2003). Transcripts of the August 14, 2003 Midwest ISO Control Center. Available from: http://energycommerce.house.gov/reparchives/108/Hearings/09032003hearing1061/heari ng.htm 


\section{Appendix 1: Analysis of the Restoration Scenario}

Note: Typically, performance assessment would be done based on actual operator behaviors that are observed during the simulated scenario. For illustrative purposes, here we examine the hypothetical script that we constructed for this scenario.

\section{Summary of the Main Story}

The scenario involves a system restoration. Put simply, system restoration involves in part connecting islands to the entire system. At this point, operators are several days into the scenario and they need to connect the West system, operating as a separate electrical island to the Central system. The voltages at the Homer station are high and the voltages at the Moses station are low. The voltages have to be matched more closely before the Breakers 8 and 9 at Moses can be closed to tie the West and the Central system together, thus connecting the island to the system. In summary, the real-world problem is that data must be assimilated, voltages matched, and then the island can be connected to restore the system. A complete script of the scenario is provided in the "Text of Scenario" section below.

The problem is shown in Figure 1-1: Three power system operators are responsible for different sections of the power system:

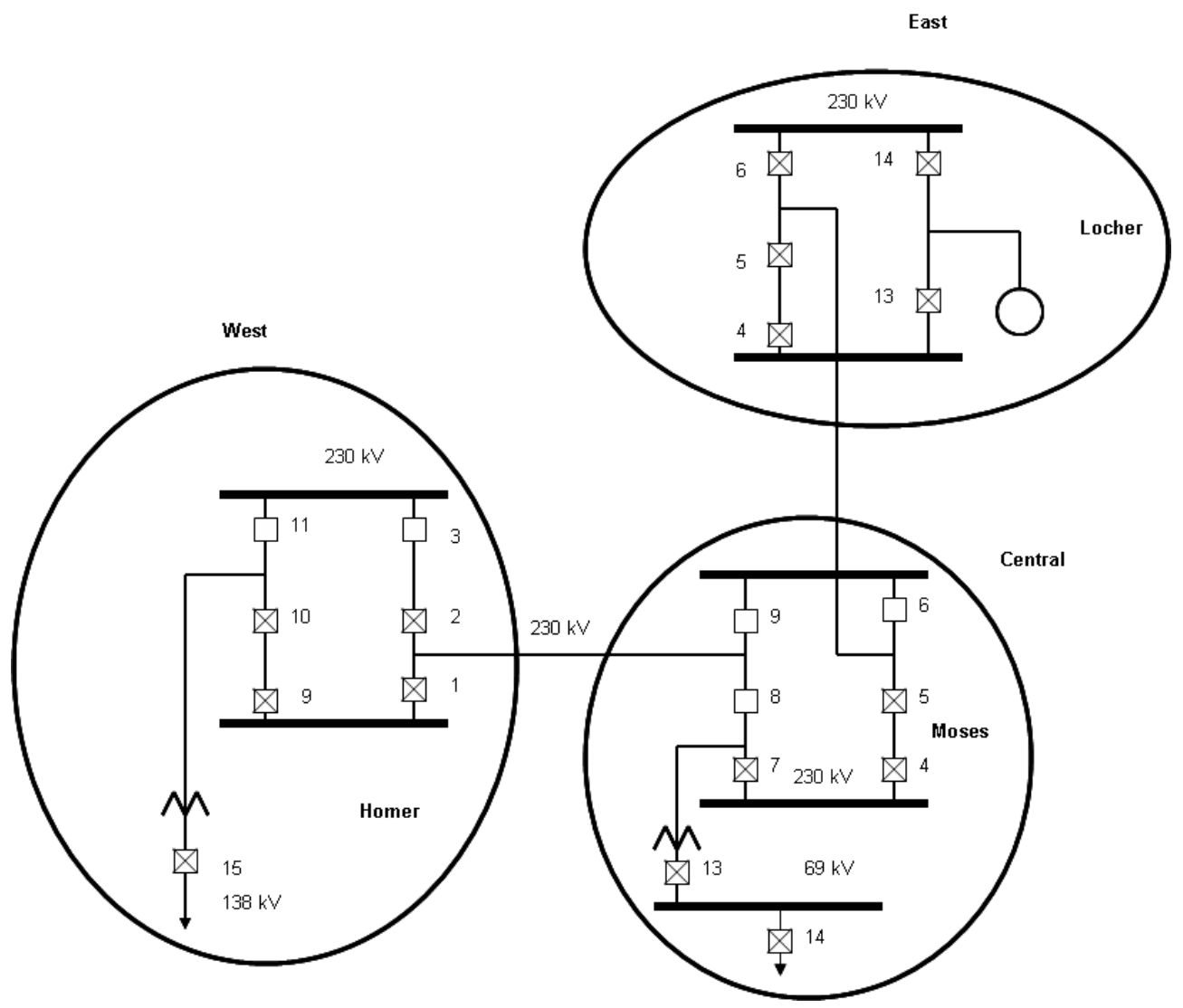

Figure 1-1. A Real-World Problem 
- The West operator monitors and controls the West system, which includes the Homer Substation.

- The East operator monitors and controls the East system, which includes the Locher generating substation.

- The Central operator monitors and controls the Central system, which includes the Moses substation.

- The Reliability Coordinator (RC) oversees the West, East, and Central Systems.

Overview: The operators are able to synchronize the islands. They communicate clearly; RC provides overall direction of goals. Central, West and East work as a team to meet the goals. The $\mathrm{RC}$ is informed before Central, West, or East takes any actions. After missing a critical mental model that the unloaded Homer-Moses line acts as a capacitor (Steps 11-37), the operators work through their process until they recognize that the cues do not match their initial mental model (Steps 38-42). The Central Operator (Steps 47-66 and 79) successfully applies the mental model of MVAR flow and bus voltages to detect that the Homer-Moses line must be open, in spite of the breaker indications showing that it is in service; and the solution for the interconnection then becomes apparent (Steps 106-120).

West's Homer station is operating as a separate island from the Central Moses station. The Homer-Moses line is acting as shunt capacitor. It is about 75 miles long. Each mile of $230 \mathrm{kV}$ generates about 0.3 MVAR of charging.

The Homer $230 \mathrm{kV}$ bus is a weak bus. It is energized from the $115 \mathrm{kV}$ side of the Homer $230 / 115 \mathrm{kV}$ transformer.

The situation at Homer is unusual. The $230 \mathrm{kV}$ bus will normally be stronger than the $115 \mathrm{kV}$ bus. Bus strength can be measured by the sum of the reactances in series to the closest generator. The charging from the Homer-Moses line is going through a number of reactances in series before it can be absorbed by a generator somewhere. MVARs have to flow downhill on voltage. So the Homer $230 \mathrm{kV}$ voltage has to be raised to support the downhill flow.

\section{Text of the Scenario}

\begin{tabular}{|c|c|c|}
\hline Step & Speaker & Conversation \\
\hline 1 & RC: & RC to West. RC to Central: \\
\hline 2 & & $<$ West Acknowledge $><$ Central Acknowledge $>$ \\
\hline 3 & & $\begin{array}{l}\text { Per the restoration plan the next step is to tie the West Island and the Central Island } \\
\text { together. To do this it will be necessary to close the } 230 \mathrm{kV} \text { Moses to Homer breaker, } \\
\text { breaker } 8 . .\end{array}$ \\
\hline 4 & Central: & 10-4. This is Central. We acknowledge \\
\hline 5 & & $\begin{array}{l}\text { My indications show voltage mismatch across the } 230 \mathrm{kV} \text { Moses to Homer breaker } 8 \text {. The } \\
\text { value exceeds the } 1 \mathrm{kV} \text { limit indicated in the restoration checklist. I cannot close the } \\
\text { breaker. }\end{array}$ \\
\hline 6 & West: & West to RC \\
\hline 7 & & $<R C$ Acknowledge $>$ \\
\hline 8 & & I am seeing the same indications \\
\hline
\end{tabular}




\begin{tabular}{|c|c|c|}
\hline Step & Speaker & Conversation \\
\hline 9 & RC: & 10-4 West. RC to West and Central: \\
\hline 10 & & $<$ West Acknowledge $><$ Central Acknowledge $>$ \\
\hline 11 & & $\begin{array}{l}\text { Coordinate to equalize voltage across the } 230 \mathrm{kV} \text { Moses to Homer breaker } 8 \text {. Once you've } \\
\text { agreed on a plan, contact me prior to synchronizing the two islands. }\end{array}$ \\
\hline 12 & West: & This is West: $10-4$ \\
\hline 13 & Central: & This is Central: $10-4$ \\
\hline 14 & West: & West to Central: \\
\hline 15 & & <Central acknowledge> \\
\hline 16 & & Is there anything you can do at the Moses substation to raise the voltage? \\
\hline 17 & Central: & No, is there anything you can do to lower the voltage at Homer? \\
\hline 18 & West: & We don't have any voltage control devices at Homer, or any adjacent substation. \\
\hline 19 & Central: & $\begin{array}{l}\text { West, do you have an estimate on how long it will take for the restoration to lower voltage } \\
\text { by that level? }\end{array}$ \\
\hline 20 & West: & $\begin{array}{l}\text { I would estimate at Central another six hours before we can begin to lower the Homer } \\
\text { sub-station voltage to a level that would allow closing the } 230 \mathrm{kV} \text { Moses breaker } 8 \text {. Are } \\
\text { there any actions that you can take outside of the Moses substation to raise the voltage? }\end{array}$ \\
\hline 21 & Central: & $\begin{array}{l}\text { Within our current island we have no way to raise the voltage. We are connected to East. I } \\
\text { can check with them and see if they can help raise the voltage on our side. }\end{array}$ \\
\hline 22 & Central: & East this is Central \\
\hline 23 & & <East Acknowledges> \\
\hline 24 & & $\begin{array}{l}\text { We are trying to synchronize our island with West but the voltage differential is too high to } \\
\text { synchronize across the breaker. West is not able to lower their system voltage due to } \\
\text { Megavar constraints and we do not have any method to raise voltage. Do you have any } \\
\text { resources to raise the voltage in our system? }\end{array}$ \\
\hline 25 & East & $\begin{array}{l}\text { Central, at present we have Locher generator connected and operating at nominal levels. } \\
\text { We could increase its Megavar output to raise voltage. We will need to check with the RC } \\
\text { to make sure that changing the voltage by this level will not interfere with other restoration } \\
\text { efforts. }\end{array}$ \\
\hline 26 & Central: & $\begin{array}{l}\text { Sounds good. Let's proceed. The } 230 \mathrm{kV} \text { is lightly loaded, it should be able to handle } \\
\text { additional Megavar flow. }\end{array}$ \\
\hline 27 & East: & $\mathrm{RC}$ this is East \\
\hline 28 & & <RC Acknowledges> \\
\hline 29 & & $\begin{array}{l}\text { I have a request from Central to increase the Megavar output of Locher in order to raise } \\
\text { their system voltage so they can connect to West. I am checking to make sure that raising } \\
\text { the voltage in our island will not negatively impact other restoration efforts. }\end{array}$ \\
\hline 30 & RC: & $\begin{array}{l}\text { East, this is RC. After the Locher unit has increased the voltage at Central's Moses } \\
\text { substation, will there be sufficient Megavar reserves remaining? }\end{array}$ \\
\hline 31 & East: & $\begin{array}{l}\mathrm{RC} \text { this is East. Locher has the Megavars reserves to sufficiently raise the voltage at } \\
\text { Moses. }\end{array}$ \\
\hline 32 & RC: & East and Central, this is RC. \\
\hline 33 & & $<$ East Acknowledge $><$ Central Acknowledge $>$ \\
\hline 34 & & Coordinate and raise voltage at Central's Moses substation. \\
\hline 35 & East: & RC this is East: $10-4$. \\
\hline 36 & Central: & RC this is Central: $10-4$ \\
\hline 37 & East: & $\begin{array}{l}\text { Central this is East. Since we have concurrence from the RC I suggest we increase the } \\
\text { output Locher in } 50 \text { MVAR increments until your voltage differential is reduced to the } \\
\text { required level. }\end{array}$ \\
\hline 38 & Central: & East this is Central: $10-4$, we'll monitor voltage while you change the output at Locher. \\
\hline 39 & East: & $\begin{array}{l}\text { Central, the output at Locher has been increased by 50MVAR; by how much did that } \\
\text { affect the voltage at Moses? }\end{array}$ \\
\hline 40 & Central: & $\begin{array}{l}\text { East this is Central. We are still seeing the same voltage level at Moses, there is no } \\
\text { apparent change. Could you try raising the output by another 50MVAR? }\end{array}$ \\
\hline 41 & East: & 10-4 Central. Raising increasing Locher reactive output an additional 50MVAR \\
\hline 42 & & $\begin{array}{l}\text { Central this is East. We are seeing an increase on the output of Locher and increased } \\
\text { voltage at Moses. }\end{array}$ \\
\hline 43 & Central: & East, could you try raising the output by another 50MVAR \\
\hline 44 & East: & 10-4. Give me a minute. \\
\hline 45 & Central: & 10-4. Appreciate it. \\
\hline 46 & East: & Central, Locher output has been increased another 50 MVAR and the voltage at Locher \\
\hline
\end{tabular}




\begin{tabular}{|c|c|c|}
\hline Step & Speaker & Conversation \\
\hline & & has increased further. Are you seeing any increase in voltage at Moses? \\
\hline 47 & Central: & $\begin{array}{l}\text { East this is Central. The voltage is still unchanged at Moses. I also noticed that the line } \\
\text { flows on the } 230 \mathrm{kV} \text { Moses to Locher line has not changed, even though I have indications } \\
\text { that the breakers at both ends are closed. I will check with the RC to see if their } \\
\text { indications are consistent with what we are seeing. }\end{array}$ \\
\hline 48 & East: & Central, I agree. \\
\hline 49 & Central: & Central to RC. \\
\hline 50 & & $<$ RC Acknowledges $>$ \\
\hline 51 & & $\begin{array}{l}\text { East has increased the Megavar output on the Locher unit and is seeing local voltage } \\
\text { increase. The voltage on the Moses, however, has not changed. Additionally, we are not } \\
\text { seeing indications of increased line flows on the Moses to Locher line, but the breakers on } \\
\text { both sides indicate that they are closed. Can you confirm what you are seeing? }\end{array}$ \\
\hline 52 & RC: & Central this is RC... wait one. \\
\hline 53 & & $\begin{array}{l}\text { My system is indicating that the bus and line breakers at the Locher end of the Moses to } \\
\text { Locher line are closed and the bus breaker at the Moses end of the Moses to Locher line } \\
\text { are closed. But there is no Megawatt flow and only a small amount of Megavar flow. This } \\
\text { seems to indicate that breakers t Moses amight be open. The fact that the voltage at } \\
\text { Moses is not changing seems to confirm this. }\end{array}$ \\
\hline 54 & Central: & $\begin{array}{l}\text { RC this is Central. Since we are all seeing the same indications I suggest that we send } \\
\text { personnel to manually inspect the position of Moses breaker } 5 . .\end{array}$ \\
\hline 55 & RC: & $\begin{array}{l}\text { Central this is RC. That's a good idea. I think we should visually inspect the position of } \\
\text { breaker } 5 \text { at Moses }\end{array}$ \\
\hline 56 & Central: & $\begin{array}{l}\text { Central to RC. Agreed. We will visually inspect the breaker at Locher and Moses and } \\
\text { report back. }\end{array}$ \\
\hline 57 & RC: & East this is RC. \\
\hline 58 & & <East Acknowledges> \\
\hline 59 & & $\begin{array}{l}\text { East, we suggest you back down the Megavar output of Locher in order to facilitate the } \\
\text { closing of any breaker that is found to be open while indicating closed. }\end{array}$ \\
\hline 60 & East: & $\mathrm{RC}$ this is East. $10-4$ \\
\hline 61 & & RC this is East. Locher 1 MVAR output has been reduced 150MVAR. \\
\hline 62 & & $<$ RC Acknowledges $>$ \\
\hline 63 & Central: & RC this is Central. \\
\hline 64 & & $<$ RC Acknowledges $>$ \\
\hline 65 & & $\begin{array}{l}\text { We have visually inspected the Moses to Locher breaker } 5 \text { and found that it is actually } \\
\text { open even though our SCADA is indicating that it's closed. So Central and East are } \\
\text { currently not connected. }\end{array}$ \\
\hline 66 & RC: & $\begin{array}{l}\text { Central this is RC. Confirming, visual inspection has shown the } 230 \mathrm{kV} \text { Moses to Locher } \\
\text { breaker } 5 \text { in the open position contrary to SCADA indications. East and Central are } \\
\text { operating as independent islands. }\end{array}$ \\
\hline 67 & East: & RC this is East. East concurs. We are not connected to Central. \\
\hline 68 & RC: & Central this is RC. \\
\hline 69 & & $<$ Central Acknowledges $>$ \\
\hline 70 & & $\begin{array}{l}\text { We will update our status boards and make a note in our system that the present line } \\
\text { status was incorrect. Central, what are your plans to fix this fault indication? }\end{array}$ \\
\hline 71 & Central: & $\begin{array}{l}\text { RC this is Central. Since this line is already out of service we are in the processes of } \\
\text { having the faulty micro-switch repaired. We hope to have the faulty micro-switch replaced } \\
\text { by the end of the day. }\end{array}$ \\
\hline 72 & RC: & $\begin{array}{l}\text { 10-4 Central. Since the line will be out of service for repairs to the breaker we will not } \\
\text { interconnect Central and East at this time. Central, you will need to find a way to adjust } \\
\text { voltage to interconnect with West without the aid of East. }\end{array}$ \\
\hline 73 & & $<$ East Acknowledge $><$ Central Acknowledge $>$ \\
\hline 74 & Central: & West this is Central. \\
\hline 75 & & $<$ West Acknowledges $>$ \\
\hline 76 & & $\begin{array}{l}\text { We attempted to coordinate with East to raise the voltage in our island but it was } \\
\text { discovered that we are not currently connected to East. We thought that we were but there } \\
\text { was a faulty breaker position indicator at Moses. We will have to determine how to reduce } \\
\text { the voltage difference ourselves. }\end{array}$ \\
\hline 77 & West: & $\begin{array}{l}\text { Central this is West. The restoration of the distribution load centers is taking longer than } \\
\text { expected, the line crews are stretched pretty thin; it will still be at Central } 6 \text { hours to }\end{array}$ \\
\hline
\end{tabular}




\begin{tabular}{|c|c|c|}
\hline Step & Speaker & Conversation \\
\hline & & restore $138 \mathrm{kV}$ load centers. \\
\hline 78 & Central: & $\begin{array}{l}\text { 10-4. The voltage difference is still too high and we can't wait for restoration of the } 138 \mathrm{kV} \\
\text { load centers. Do you have any cap banks at Homer that can be switched out of service? }\end{array}$ \\
\hline 79 & West: & $\begin{array}{l}\text { No, the only Megavar injections at Homer are from the } 230 \mathrm{kV} \text { Homer-Moses line which is } \\
\text { connected at our end but open on your end.. The Homer - Moses } 230 \mathrm{kV} \text { line produces } \\
\text { about } 15 \mathrm{MVAR} \text { at no load. }\end{array}$ \\
\hline 80 & Central: & $\begin{array}{l}\text { If you opened the } 230 \mathrm{kV} \text { Homer breaker and isolated the } 230 \mathrm{kV} \text { Homer-Moses line, would } \\
\text { that significantly impact the voltage level at any of the other substations in your island? }\end{array}$ \\
\hline 81 & West & $\begin{array}{l}\text { It would lower the voltage at Homer but the voltage level at the other sub-stations } \\
\text { shouldn't cause any problems. }\end{array}$ \\
\hline 82 & Central: & $\begin{array}{l}\text { Ok West. I suggest that you open the } 230 \mathrm{kV} \text { Homer breaker } 1 \text {, isolate the } 230 \mathrm{kV} \text { line and } \\
\text { we close the } 230 \mathrm{kv} \text { breaker on our side. This will transfer the line capacitance from your } \\
\text { system to ours and should lower the voltage at Homer and raise the voltage at Moses. }\end{array}$ \\
\hline 83 & West: & West-(to Central): I agree. Let's confirm with the RC before we proceed. \\
\hline 84 & Central: & Central to RC. \\
\hline 85 & & $<$ RC Acknowledges $>$ \\
\hline 86 & & $\begin{array}{l}\text { We have a plan that should reduce the voltage mismatch across the } 230 \mathrm{kV} \text { Moses to } \\
\text { Homer line and allow us to interconnect West and Central service areas. We propose to } \\
\text { transfer the line capacitance of the } 230 \mathrm{kV} \text { Homer - Moses line from West to Central. }\end{array}$ \\
\hline 87 & & $\begin{array}{l}\text { West will open the } 230 \mathrm{kV} \text { Homer breaker } 1 \text {. Central will close the } 230 \mathrm{kV} \text { Moses breaker } \\
8 \text {. This should lower the voltage at Homer and raise the voltage at Moses. If all goes } \\
\text { according to plan, we can then interconnect on the } 230 \mathrm{kV} \text { system, using the Homer } \\
\text { breaker } 1 .\end{array}$ \\
\hline 88 & RC: & Central 10-4. West are you listening in? \\
\hline 89 & & $<$ West Acknowledges $>$ \\
\hline 90 & & $\begin{array}{l}\text { This seems like a valid plan. Let me confirm: West will open breaker } 1 \text { at Homer. Central } \\
\text { will then close the breaker } 8 \text { at Moses. This will switch the proposed tie point to the Homer } \\
\text { end of the } 230 \mathrm{kV} \text { Moses to Homer line. The capacitance of the } 230 \mathrm{kV} \text { line will be used to } \\
\text { enhance the voltage on the Central side while lowering the voltage on the West side. Is } \\
\text { that correct, Central? }\end{array}$ \\
\hline 91 & Central: & RC, Central. That is correct. \\
\hline 92 & RC: & RC to West, do you concur with this plan? \\
\hline 93 & West: & RC this is West. We concur. \\
\hline 94 & RC: & Central and West, this is RC. Proceed with that plan. Please keep me informed. \\
\hline 95 & & $<$ Acknowledge West $><$ Acknowledge Central $>$ \\
\hline 96 & West: & West to Central. \\
\hline 97 & & <Central Acknowledges $>$ \\
\hline 98 & & Central, we will now open the Homer breaker 1. Standby \\
\hline 99 & & The Homer breaker, 1 , indicates open. \\
\hline 100 & & $\begin{array}{l}\text { The Homer breaker } 1 \text { now indicates open on our system. The voltage at Homer is } \\
\text { kV. }\end{array}$ \\
\hline 101 & Central: & $\begin{array}{l}1-4, \text { West. Breaker } 1 \text { at Homer now indicate open. We are now closing the } 230 \mathrm{kV} \text { Moses } \\
\text { breaker } 8 \text {. Standby. }\end{array}$ \\
\hline 102 & & The 230kV Moses breaker 8, indicates closed. The voltage at Moses is reading $\ldots \mathrm{kV}$. \\
\hline 103 & West: & $\begin{array}{l}\text { Roger that, Central. Our EMS confirms breaker } 8 \text { at Moses closed with a voltage of } \\
\mathrm{kV} \text {. }\end{array}$ \\
\hline 104 & RC: & 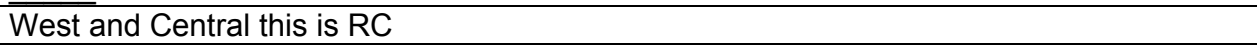 \\
\hline 105 & & <Central Acknowledges > <West Acknowledges $>$ \\
\hline 106 & & $\begin{array}{l}\text { Since all requirements of the Interconnection Checklist have been met, West and Central, } \\
\text { you are clear to interconnect your islands. Inform me when it is complete so we can } \\
\text { continue with the restoration plan. }\end{array}$ \\
\hline 107 & Central: & $\begin{array}{l}\mathrm{RC} \text { this is Central: } 10-4 \text {. The Interconnection Checklist is complete and Central and West } \\
\text { will attempt to connect our two islands. }\end{array}$ \\
\hline 108 & & Central to West. \\
\hline 109 & & <West Acknowledges $>$ \\
\hline 110 & & $\begin{array}{l}\mathrm{RC} \text { has given approval to connect our two islands. The last step is for you to close the } 230 \\
\mathrm{~V} \text { Homer breaker, breaker } 1 \text {. Do you agree? }\end{array}$ \\
\hline 111 & West: & $\begin{array}{l}\text { Central this is West. West agrees that the voltage, frequency and phase are within spec } \\
\text { according to the Interconnection Checklist for closing the } 230 \mathrm{kV} \text { breaker, } 1 .\end{array}$ \\
\hline
\end{tabular}




\begin{tabular}{|r|l|l|}
\hline Step & Speaker & Conversation \\
\hline 112 & & Closing. Homer 1. Standby \\
\hline 113 & & $\begin{array}{l}\text { The 230 kV Homer breaker, 1, is now indicating closed on our end and we are seeing } \\
\text { Megawatts and Megavar transfers across the line. }\end{array}$ \\
\hline 114 & & <Central Acknowledge $>$ \\
\hline 115 & Central: & $\begin{array}{l}\text { 10-4, West. Our SCADA is also indicating breaker 1 is closed and that there are Megawatt } \\
\text { and Megavar flows on the line. }\end{array}$ \\
\hline 116 & West: & West to RC: \\
\hline 117 & & <RC Acknowledges $>$ \\
\hline 118 & & $\begin{array}{l}\text { We have closed the 230 kV Homer breaker 1 and the 230kV Homer-Moses line is now in } \\
\text { service. West and Central are now interconnected. }\end{array}$ \\
\hline 119 & RC: & $\begin{array}{l}\text { RC-(to West): 10-4 West and Central. We also show the 230 kV Homer to Moses line } \\
\text { closed and power transfers on that line. The West and Central areas are connected. }\end{array}$ \\
\hline
\end{tabular}

\section{RPD Analysis of the Scenario Script}

The RPD analysis is performed by examining the Script, step by step, and adding "analysis" columns that point out critical observations that reflect correct, incorrect, or missing cues, mental models, and actions:

- The cues that are actually monitored in comparison to the cues that should be monitored.

- The mental models that are actually applied in comparison to the mental models that should be applied.

- The actions that are actually considered in comparison to the actions that should be considered.

- The actions that are actually applied in comparison to the actions that should be applied.

- The story that is actually developed in comparison to the story that should be developed.

The full analysis is summarized in Table 1-1. 
Table 1-1. Analysis Summary

\begin{tabular}{|c|c|c|c|c|c|c|c|c|c|c|c|}
\hline Step & Speaker & Conversation & Objects & Action & $\begin{array}{l}\text { State - current, past, } \\
\text { projection }\end{array}$ & Objectives & Cues & $\begin{array}{l}\text { Mental Models/ } \\
\text { Simulations }\end{array}$ & \begin{tabular}{|l} 
Level of \\
Situation \\
Awareness \\
\end{tabular} & Actions & Narration \\
\hline 1 & RC: & $\mathrm{RC}$ to West. RC to Central: & & & & & & & & & \\
\hline 2 & & $\begin{array}{l}<\text { West Acknowledge }><\text { Central } \\
\text { Acknowledge }>\end{array}$ & & & & & & & & & \\
\hline 4 & Central: & 10-4. This is Central. We acknowledge & & & & $\begin{array}{l}\text { Tie two } \\
\text { islands } \\
\text { together }\end{array}$ & & \begin{tabular}{|l|} 
Two electrical \\
islands rotating \\
asynchronously \\
\end{tabular} & & & \\
\hline 5 & & $\begin{array}{l}\text { My indications show voltage mismatch } \\
\text { across the } 230 \mathrm{kV} \text { Moses to Homer breaker } \\
8 \text {. The value exceeds the } 1 \mathrm{kV} \text { limit } \\
\text { indicated in the restoration checklist. I } \\
\text { cannot close the breaker. }\end{array}$ & $\begin{array}{l}\text { voltage } \\
\text { mismatch, } 1 \\
\text { kV limit, } \\
\text { restoration } \\
\text { checklist } \\
\end{array}$ & $\begin{array}{l}\text { show voltage } \\
\text { mismatch }\end{array}$ & & & $\begin{array}{l}\text { Voltage } \\
\text { differenc } \\
\text { e across } \\
\text { open } \\
\text { breaker } \\
\end{array}$ & $\begin{array}{l}\text { Line charging } \\
\text { into weak bus } \\
\text { causes voltage } \\
\text { rise }\end{array}$ & $\begin{array}{l}\text { Monitoring bus } \\
\text { voltages }\end{array}$ & & $\begin{array}{l}\text { For this scenario it is } \\
\text { assumed that the voltage } \\
\text { differential must be less than } \\
1 \mathrm{kV} \text { in order to safely } \\
\text { synchronize and close a } \\
\text { breaker. }\end{array}$ \\
\hline 6 & West: & West to RC & & & & & & & & & \\
\hline 7 & & $<$ RC Acknowledge $>$ & & & & & & & & & \\
\hline 8 & & I am seeing the same indications & indications & $\begin{array}{l}\text { seeing } \\
\text { indications } \\
\end{array}$ & & & & & & & \\
\hline 9 & RC: & 10-4 West. RC to West and Central: & & & & & & & & & \\
\hline 10 & & $\begin{array}{l}<\text { West Acknowledge }><\text { Central } \\
\text { Acknowledge }>\end{array}$ & & & & & & & & & \\
\hline 11 & & $\begin{array}{l}\text { Coordinate to equalize voltage across the } \\
230 \mathrm{kV} \text { Moses to Homer breaker } 8 . . \text { Once } \\
\text { you've agreed on a plan, contact me prior } \\
\text { to synchronizing the two islands. }\end{array}$ & voltage & $\begin{array}{l}\text { equalize } \\
\text { voltage, } \\
\text { coordinate, } \\
\text { synchronize } \\
\text { islands } \\
\end{array}$ & & $\begin{array}{l}\text { Coordinate } \\
\text { and equalize } \\
\text { voltage }\end{array}$ & & $\begin{array}{l}\text { Misses mental } \\
\text { model that the } \\
\text { unloaded Homer } \\
\text { - Moses line is a } \\
\text { capacitor }\end{array}$ & $\begin{array}{l}\text { Misses mental } \\
\text { model that the } \\
\text { unloaded } \\
\text { Homer - Moses } \\
\text { line is a } \\
\text { capacitor }\end{array}$ & & \\
\hline 12 & West: & This is West: $10-4$ & & & & & & & & & \\
\hline
\end{tabular}




\begin{tabular}{|c|c|c|c|c|c|c|c|c|c|c|c|}
\hline Step & Speaker & Conversation & Objects & Action & $\begin{array}{l}\text { State - current, past, } \\
\text { projection }\end{array}$ & Objectives & Cues & $\begin{array}{l}\text { Mental Models/ } \\
\text { Simulations }\end{array}$ & \begin{tabular}{|l|} 
Level of \\
Situation \\
Awareness \\
\end{tabular} & Actions & Narration \\
\hline 13 & Central: & This is Central: $10-4$ & & & & & & & & & \\
\hline 14 & West: & West to Central: & & & & & & & & & \\
\hline 15 & & $<$ Central acknowledge $>$ & & & & & & & & & \\
\hline 16 & & $\begin{array}{l}\text { Is there anything you can do at the Moses } \\
\text { substation to raise the voltage? }\end{array}$ & voltage & raise voltage & & & & & & & \\
\hline 17 & Central: & $\begin{array}{l}\text { No, is there anything you can do to lower } \\
\text { the voltage at Homer? }\end{array}$ & & $\begin{array}{l}\text { lower } \\
\text { voltage }\end{array}$ & & & & $\begin{array}{l}\text { Misses mental } \\
\text { model that the } \\
\text { unloaded Homer } \\
\text { - Moses line is a } \\
\text { capacitor } \\
\end{array}$ & $\begin{array}{l}\text { Misses mental } \\
\text { model that the } \\
\text { unloaded } \\
\text { Homer - Moses } \\
\text { line is a } \\
\text { capacitor }\end{array}$ & & \\
\hline 18 & West: & (1) & 西 & & & & & $\begin{array}{l}\text { Homer } 230 \mathrm{kV} \text { is } \\
\text { a weak bus, } \\
\text { because it is } \\
\text { being fed from } \\
\text { the } 69 \mathrm{kV} \\
\text { system. } \\
\text { Misses mental } \\
\text { model that the } \\
\text { unloaded Homer } \\
\text { - Moses line is a } \\
\text { capacitor. Misses } \\
\text { the standard } \\
\text { operating } \\
\text { procedure on } \\
\text { Open Weak end } \\
\text { First or Close the } \\
\text { Strong End First. }\end{array}$ & $\begin{array}{l}\text { Homer } 230 \mathrm{kV} \\
\text { is a weak bus, } \\
\text { because it is } \\
\text { being fed from } \\
\text { the } 69 \mathrm{kV} \\
\text { system. } \\
\text { Misses mental } \\
\text { model that the } \\
\text { unloaded } \\
\text { Homer - Moses } \\
\text { line is a } \\
\text { capacitor. } \\
\text { Misses the } \\
\text { standard } \\
\text { operating } \\
\text { procedure on } \\
\text { Open Weak end } \\
\text { First or Close } \\
\text { the Strong End } \\
\text { First. } \\
\end{array}$ & & \\
\hline 19 & Central: & $\begin{array}{l}\text { West, do you have an estimate on how } \\
\text { long it will take for the restoration to lower } \\
\text { voltage by that level? }\end{array}$ & level & $\begin{array}{l}\text { restoration to } \\
\text { lower } \\
\text { voltage }\end{array}$ & & & & & & & \\
\hline
\end{tabular}




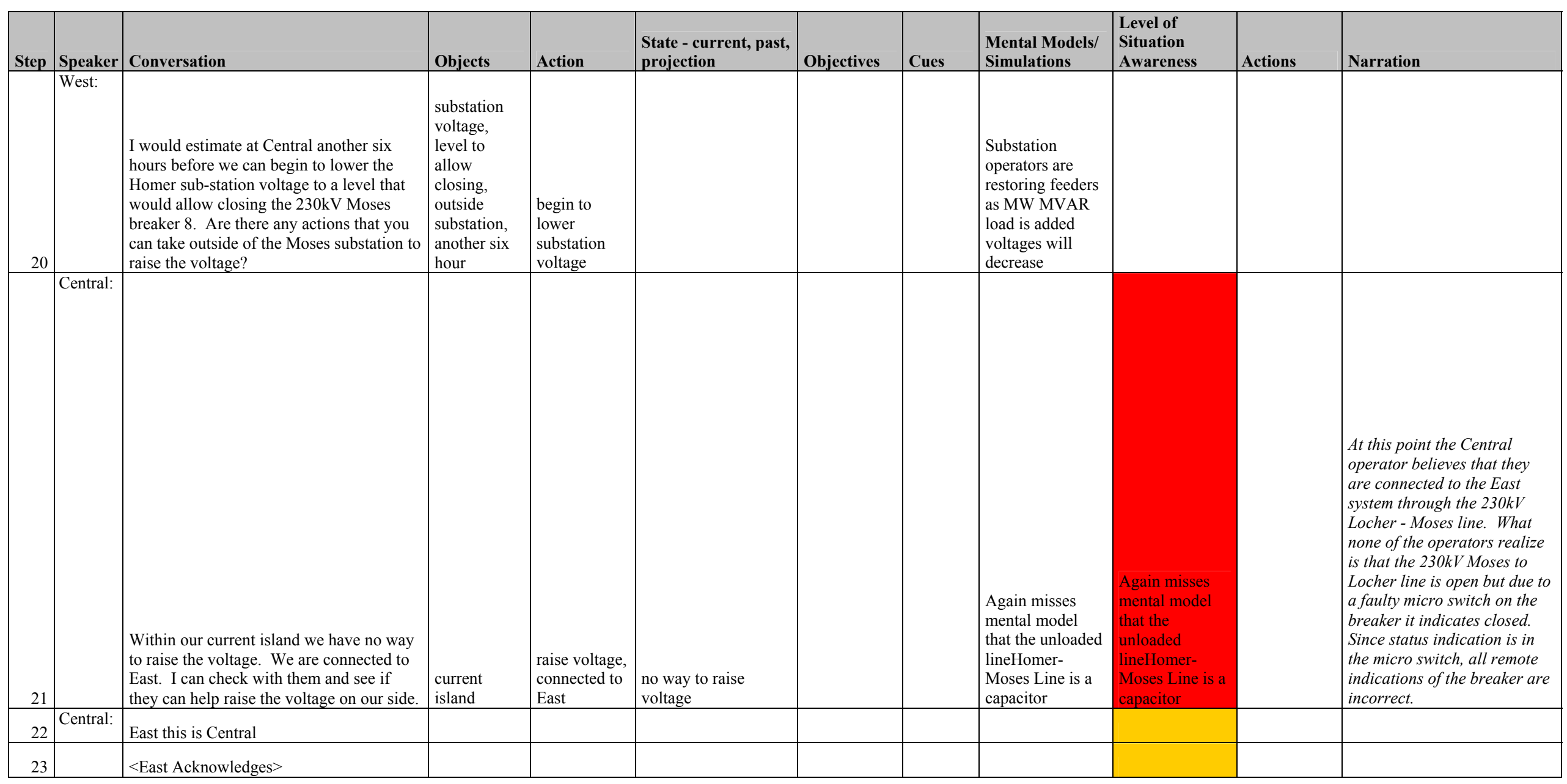




\begin{tabular}{|c|c|c|c|c|c|c|c|c|c|c|c|}
\hline Step & Speaker & Conversation & Objects & Action & $\begin{array}{l}\text { State - current, past, } \\
\text { projection }\end{array}$ & Objectives & Cues & $\begin{array}{l}\text { Mental Models/ } \\
\text { Simulations }\end{array}$ & $\begin{array}{l}\text { Level of } \\
\text { Situation } \\
\text { Awareness }\end{array}$ & Actions & Narration \\
\hline 24 & & $\begin{array}{l}\text { We are trying to synchronize our island } \\
\text { with West but the voltage differential is } \\
\text { too high to synchronize across the breaker. } \\
\text { West is not able to lower their system } \\
\text { voltage due to Megavar constraints and we } \\
\text { do not have any method to raise voltage. } \\
\text { Do you have any resources to raise the } \\
\text { voltage in our system? }\end{array}$ & \begin{tabular}{|l} 
voltage \\
differetial \\
across \\
breaker, \\
MVAr \\
constraints, \\
method to \\
raise \\
voltage, \\
resources to \\
raise voltage \\
\end{tabular} & \begin{tabular}{|l} 
trying to \\
synchonize, \\
synchronize \\
across \\
breaker, \\
lower system \\
voltage, raise \\
system \\
voltage \\
\end{tabular} & & & & & $\begin{array}{l}\text { Know voltage } \\
\text { difference } \\
\text { across breaker } \\
\text { is too high to } \\
\text { synchronize }\end{array}$ & & \\
\hline 25 & East & $\begin{array}{l}\text { Central, at present we have Locher } \\
\text { generator connected and operating at } \\
\text { nominal levels. We could increase its } \\
\text { Megavar output to raise voltage. We will } \\
\text { need to check with the RC to make sure } \\
\text { that changing the voltage by this level will } \\
\text { not interfere with other restoration efforts. }\end{array}$ & $\begin{array}{l}\text { generator, } \\
\text { nominal } \\
\text { levels, } \\
\text { generator } \\
\text { MVAR } \\
\text { output, other } \\
\text { restoration } \\
\text { efforts }\end{array}$ & \begin{tabular}{|l|} 
Increase \\
Megavar \\
output, raise \\
voltage, \\
changing the \\
voltage, \\
interfere with \\
restoration \\
efforts
\end{tabular} & $\begin{array}{l}\text { Locher generator } \\
\text { connected and } \\
\text { operating at nominal } \\
\text { levels. We could } \\
\text { increase its Megavar } \\
\text { output to raise } \\
\text { voltage. We will } \\
\text { need to check with } \\
\text { the RC to make sure } \\
\text { that changing the } \\
\text { voltage by this level } \\
\text { will not interfere with } \\
\text { other restoration } \\
\text { efforts. } \\
\end{array}$ & & & $\begin{array}{l}\text { Locher } \\
\text { generators can } \\
\text { raise voltage and } \\
\text { increase MVAR } \\
\text { output }\end{array}$ & $\begin{array}{l}\text { Understand how } \\
\text { Locher } \\
\text { generators can } \\
\text { raise voltage } \\
\text { and increase } \\
\text { MVAR output } \\
\text { but this will not } \\
\text { be applicable } \\
\end{array}$ & & \begin{tabular}{|l} 
\\
\\
\\
Locher Power Station \\
contains 11200 MW unit. \\
Sincethe units is already \\
running, they are able to \\
change reactive power output \\
in a short period of time.
\end{tabular} \\
\hline 26 & Central: & $\begin{array}{l}\text { Sounds good. Let's proceed. The } 230 \mathrm{kV} \\
\text { is lightly loaded, it should be able to } \\
\text { handle additional Megavar flow. }\end{array}$ & $\begin{array}{l}\text { The } 230 \mathrm{Kv} \text {, } \\
\text { megavar } \\
\text { flow }\end{array}$ & & $\begin{array}{l}230 \mathrm{kV} \text { line is lightly } \\
\text { loaded, Able to } \\
\text { handle additional } \\
\text { Megavar flow } \\
\end{array}$ & & & $\begin{array}{l}230 \mathrm{KV} \text { line is } \\
\text { closed at both } \\
\text { ends and is } \\
\text { serving some } \\
\text { small load }\end{array}$ & $\begin{array}{l}\text { Assme } 230 \mathrm{KV} \\
\text { line is closed at } \\
\text { both ends and is } \\
\text { serving some } \\
\text { small load but it } \\
\text { is really open. } \\
\end{array}$ & & $\begin{array}{l} \\
\text { At this point the operators are } \\
\text { seeing that the line appears in } \\
\text { service, and are } \\
\text { misinterpreting reactive line } \\
\text { charging as a light load. The } \\
\text { light reactive loading is due } \\
\text { to the transmission line } \\
\text { characteristics. }\end{array}$ \\
\hline 28 & & $<$ RC Acknowledges $>$ & & & & & & & & & \\
\hline
\end{tabular}




\begin{tabular}{|c|c|c|c|c|c|c|c|c|c|c|c|}
\hline Step & Speaker & Conversation & Objects & Action & $\begin{array}{l}\text { State - current, past, } \\
\text { projection }\end{array}$ & Objectives & Cues & $\begin{array}{l}\text { Mental Models/ } \\
\text { Simulations }\end{array}$ & \begin{tabular}{|l} 
Level of \\
Situation \\
Awareness \\
\end{tabular} & Actions & Narration \\
\hline 29 & & $\begin{array}{l}\text { I have a request from Central to increase } \\
\text { the Megavar output of Locher in order to } \\
\text { raise their system voltage so they can } \\
\text { connect to West. I am checking to make } \\
\text { sure that raising the voltage in our island } \\
\text { will not negatively impact other } \\
\text { restoration efforts. }\end{array}$ & $\begin{array}{l}\text { Request, } \\
\text { System } \\
\text { Voltage, }\end{array}$ & & & & & & $\begin{array}{l}\text { Normally would } \\
\text { be a good } \\
\text { mental model of } \\
\text { future but not } \\
\text { applicable in } \\
\text { this case. }\end{array}$ & & \\
\hline 30 & RC: & $\begin{array}{l}\text { East, this is RC. After the Locher unit has } \\
\text { increased the voltage at Central's Moses } \\
\text { substation, will there be sufficient } \\
\text { Megavar reserves remaining? }\end{array}$ & $\begin{array}{l}\text { voltage, } \\
\text { substation, } \\
\text { MVAR } \\
\text { reserves } \\
\text { remaining }\end{array}$ & $\begin{array}{l}\text { increase } \\
\text { voltage, }\end{array}$ & $\begin{array}{l}\text { Will their be } \\
\text { sufficient Megavar } \\
\text { reserves remaining }\end{array}$ & & & \begin{tabular}{|l} 
D curve for \\
Locher units. \\
Needs MVAR \\
reserves to add \\
more load and \\
handle \\
contingencies
\end{tabular} & & & \\
\hline 31 & East: & $\begin{array}{l}\mathrm{RC} \text { this is East. Locher has the Megavars } \\
\text { reserves to sufficiently raise the voltage at } \\
\text { Moses. }\end{array}$ & & & & & & $\begin{array}{l}\text { Unit has MVAR } \\
\text { reserves - D } \\
\text { curve. Unit AVR } \\
\text { control Loop in } \\
\text { Auto } \\
\end{array}$ & \begin{tabular}{|l|} 
Unit has \\
MVAR reserves \\
- D curve. Unit \\
AVR control \\
Loop in Auto \\
\end{tabular} & & \\
\hline 32 & RC: & East and Central, this is RC. & & & & & & & & & \\
\hline 33 & & $\begin{array}{l}<\text { East Acknowledge }><\text { Central } \\
\text { Acknowledge }>\end{array}$ & & & & & & & & & \\
\hline 34 & & $\begin{array}{l}\text { Coordinate and raise voltage at Central's } \\
\text { Moses substation. }\end{array}$ & & $\begin{array}{l}\text { coordinate } \\
\text { and raise } \\
\text { voltage }\end{array}$ & & & & & & & \\
\hline 35 & East: & $\mathrm{RC}$ this is East: $10-4$ & & & & & & & & & \\
\hline 36 & Central: & RC this is Central: $10-4$. & & & & & & & & & \\
\hline 37 & East: & $\begin{array}{l}\text { Central this is East. Since we have } \\
\text { concurrence from the RC I suggest we } \\
\text { increase the output Locher in } 50 \text { MVAR } \\
\text { increments until your voltage differential } \\
\text { is reduced to the required level. }\end{array}$ & $\begin{array}{l}\text { concurrence } \\
\text { from RC, } 50 \\
\text { MVAR } \\
\text { increment in } \\
\text { output, } \\
\text { voltage } \\
\text { differential, } \\
\text { reqquired } \\
\text { level }\end{array}$ & $\begin{array}{l}\text { increase } \\
\text { MVAR } \\
\text { output }\end{array}$ & & & & $\begin{array}{l}\text { Increasing } \\
\text { MVARs at } \\
\text { Locher will raise } \\
\text { voltage Locher } \\
\text { and at Moses. } \\
\text { MVARs flow } \\
\text { downhill on } \\
\text { voltage. Tent and } \\
\text { pole analogy. } \\
\text { Based on Locher } \\
\text { being connected } \\
\text { to Moses being } \\
\text { connected to }\end{array}$ & $\begin{array}{l}\text { Nor } \\
\text { Normally would } \\
\text { be a good } \\
\text { mental model } \\
\text { by not } \\
\text { applicable in } \\
\text { this case. }\end{array}$ & & \\
\hline
\end{tabular}




\begin{tabular}{|c|c|c|c|c|c|c|c|c|c|c|c|}
\hline Step & Speaker & Conversation & Objects & Action & $\begin{array}{l}\text { State - current, past, } \\
\text { projection }\end{array}$ & Objectives & Cues & $\begin{array}{l}\text { Mental Models/ } \\
\text { Simulations }\end{array}$ & \begin{tabular}{|l} 
Level of \\
Situation \\
Awareness \\
\end{tabular} & Actions & Narration \\
\hline & & & & & & & & Moses & & & \\
\hline 38 & 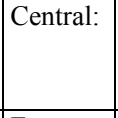 & $\begin{array}{l}\text { East this is Central: } 10-4 \text {, we'll monitor } \\
\text { voltage while you change the output at } \\
\text { Locher. }\end{array}$ & & $\begin{array}{l}\text { mointor } \\
\text { voltage }\end{array}$ & & & & & & & \\
\hline 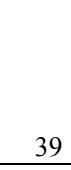 & East: & $\begin{array}{l}\text { Central, the output at Locher has been } \\
\text { increased by 50MVAR; by how much did } \\
\text { that affect the voltage at Moses? }\end{array}$ & & & & & & 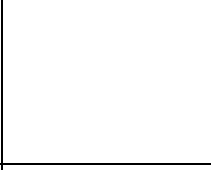 & 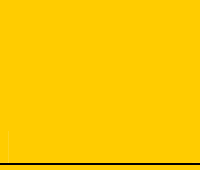 & $\begin{array}{l}\text { Locher raised } \\
\text { by } 50 \text { MVAR }\end{array}$ & \\
\hline 40 & Central: & $\begin{array}{l}\text { East this is Central. We are still seeing the } \\
\text { same voltage level at Moses, there is no } \\
\text { apparent change. Could you try raising the } \\
\text { output by another 50MVAR? }\end{array}$ & & & & & $\begin{array}{l}\text { No } \\
\text { increase } \\
\text { in } \\
\text { voltage } \\
\text { at } \\
\text { Moses. } \\
\end{array}$ & $\begin{array}{l}\text { The cues are not } \\
\text { matching with } \\
\text { the assumed } \\
\text { Mental Model }\end{array}$ & $\begin{array}{l}\text { The cues are not } \\
\text { matching with } \\
\text { the assumed } \\
\text { Mental Model }\end{array}$ & & \\
\hline 41 & East: & $\begin{array}{l}\text { 10-4 Central. Raising increasing Locher } \\
\text { reactive output an additional 50MVAR }\end{array}$ & & & & & & & & $\begin{array}{l}\text { Locher raised } \\
\text { by } 50 \text { MVAR }\end{array}$ & \\
\hline 42 & & $\begin{array}{l}\text { Central this is East. We are seeing an } \\
\text { increase on the output of Locher and } \\
\text { increased voltage at Moses. }\end{array}$ & & & & & \begin{tabular}{|l|} 
Increase \\
in \\
MVAR \\
output of \\
Locher. \\
\end{tabular} & & & & \\
\hline 43 & Central: & $\begin{array}{l}\text { East, could you try raising the output by } \\
\text { another 50MVAR }\end{array}$ & & & & & & & & & $\begin{array}{l}\text { At this point the operators are } \\
\text { not considering the possibility } \\
\text { that the interconnecting } \\
\text { transmission line might not be } \\
\text { in service. }\end{array}$ \\
\hline 44 & East: & 10-4. Give me a minute. & & & & & & & & & \\
\hline 45 & Central: & 10-4. Appreciate it. & & & & & & & & & \\
\hline
\end{tabular}




\begin{tabular}{|c|c|c|c|c|c|c|c|c|c|c|c|}
\hline Step & Speaker & Conversation & Objects & Action & $\begin{array}{l}\text { State - current, past, } \\
\text { projection }\end{array}$ & Objectives & Cues & $\begin{array}{l}\text { Mental Models/ } \\
\text { Simulations }\end{array}$ & $\begin{array}{l}\text { Level of } \\
\text { Situation } \\
\text { Awareness }\end{array}$ & Actions & Narration \\
\hline 46 & East: & $\begin{array}{l}\text { Central, Locher output has been increased } \\
\text { another } 50 \text { MVAR and the voltage at } \\
\text { Locher has increased further. Are you } \\
\text { seeing any increase in voltage at Moses? }\end{array}$ & & & & & & & & $\begin{array}{l}\text { Locher raised } \\
\text { by } 50 \text { MVAR }\end{array}$ & \\
\hline 47 & Central: & $\begin{array}{l}\text { East this is Central. The voltage is still } \\
\text { unchanged at Moses. I also noticed that } \\
\text { the line flows on the } 230 \mathrm{kV} \text { Moses to } \\
\text { Locher line has not changed, even though I } \\
\text { have indications that the breakers at both } \\
\text { ends are closed. I will check with the RC } \\
\text { to see if their indications are consistent } \\
\text { with what we are seeing. }\end{array}$ & $\begin{array}{l}\text { line flows, } \\
\text { indications } \\
\text { on breakers, } \\
\text { line ends }\end{array}$ & $\begin{array}{l}\text { check with } \\
\text { RC for } \\
\text { consistency } \\
\end{array}$ & (1) & & \begin{tabular}{|l|} 
No \\
voltage \\
increase \\
at \\
Moses. \\
No \\
increase \\
in flows \\
on \\
Moses- \\
Locher \\
line. \\
Breakers \\
closed at \\
both \\
ends \\
\end{tabular} & $\begin{array}{l}\text { Flows and } \\
\text { voltages are not } \\
\text { agreeing with } \\
\text { mental model of } \\
\text { lines between } \\
\text { Locher and } \\
\text { Moses } \\
\end{array}$ & $\begin{array}{l}\text { Flows and } \\
\text { voltages are not } \\
\text { agreeing with } \\
\text { mental model of } \\
\text { lines between } \\
\text { Locher and } \\
\text { Moses } \\
\end{array}$ & & \\
\hline 48 & East: & Central, I agree. & & & & & & & & & \\
\hline 49 & Central: & Central to RC. & & & & & & & & & \\
\hline 50 & & $<$ RC Acknowledges $>$ & & & & & & & & & \\
\hline 51 & & $\begin{array}{l}\text { East has increased the Megavar output on } \\
\text { the Locher unit and is seeing local voltage } \\
\text { increase. The voltage on the Moses, } \\
\text { however, has not changed. Additionally, } \\
\text { we are not seeing indications of increased } \\
\text { line flows on the Moses to Locher line, but } \\
\text { the breakers on both sides indicate that } \\
\text { they are closed. Can you confirm what } \\
\text { you are seeing? }\end{array}$ & $\begin{array}{l}\text { local voltage } \\
\text { increase, } \\
\text { indications } \\
\text { of increase } \\
\text { line flows, } \\
\text { both sides } \\
\end{array}$ & & $\begin{array}{l}\text { seeing local voltage } \\
\text { increase, not seeing } \\
\text { indications of } \\
\text { increased line flows, } \\
\text { breakers both sides } \\
\text { indicate closed } \\
\end{array}$ & & & & $\begin{array}{l}\text { Are suspecting } \\
\text { pattern of line } \\
\text { end open even } \\
\text { though the } \\
\text { breakers } \\
\text { indicate closed. } \\
\end{array}$ & & \\
\hline
\end{tabular}




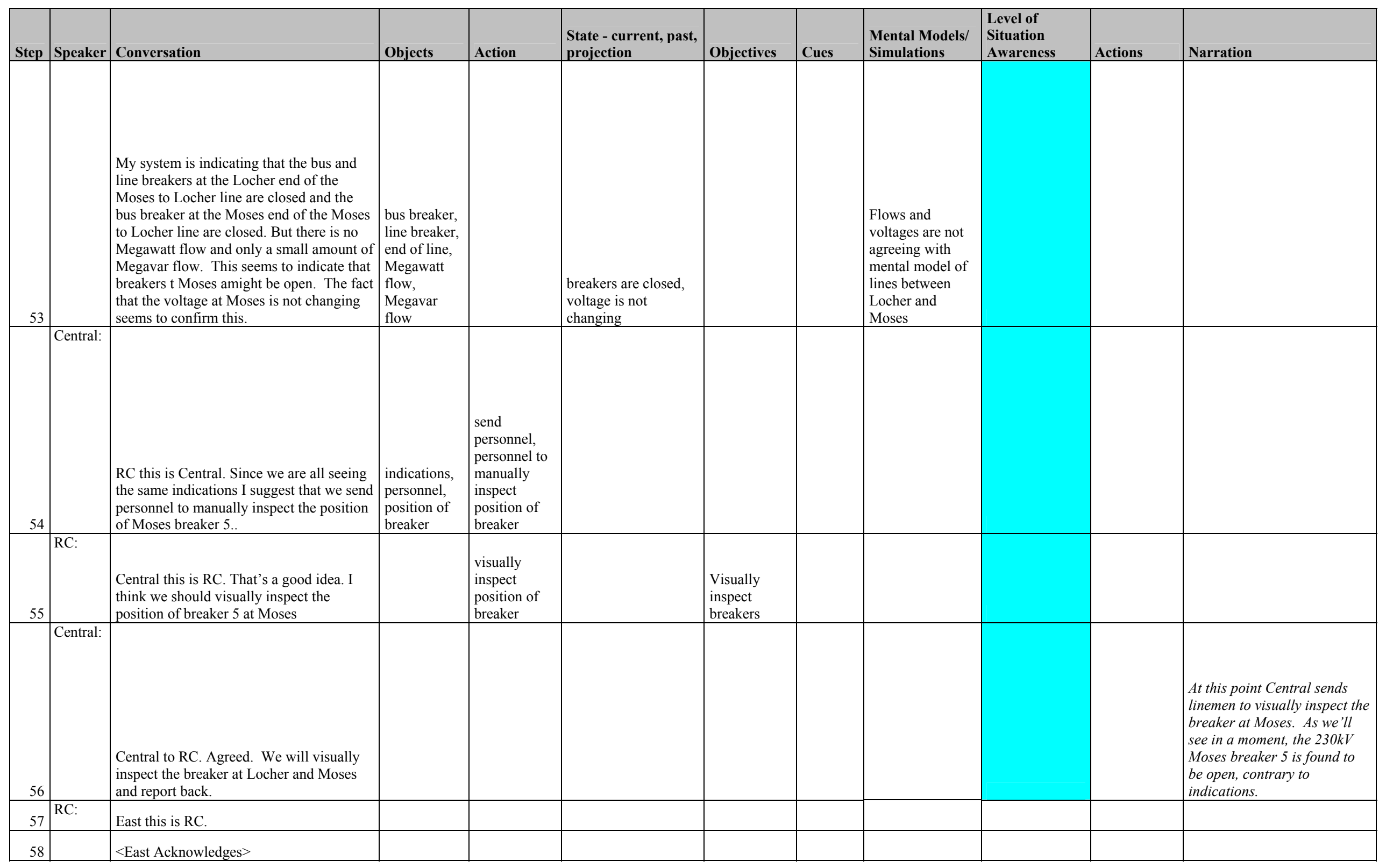




\begin{tabular}{|c|c|c|c|c|c|c|c|c|c|c|c|}
\hline Step & Speaker & Conversation & Objects & Action & $\begin{array}{l}\text { State - current, past, } \\
\text { projection }\end{array}$ & Objectives & Cues & $\begin{array}{l}\text { Mental Models/ } \\
\text { Simulations }\end{array}$ & \begin{tabular}{|l} 
Level of \\
Situation \\
Awareness \\
\end{tabular} & Actions & Narration \\
\hline 59 & & $\begin{array}{l}\text { East, we suggest you back down the } \\
\text { Megavar output of Locher in order to } \\
\text { facilitate the closing of any breaker that is } \\
\text { found to be open while indicating closed. }\end{array}$ & & \begin{tabular}{|l} 
back down \\
Megavar \\
output, \\
facilitate \\
closing of \\
breaker, open \\
while \\
indicating \\
closed \\
\end{tabular} & & $\begin{array}{l}\text { Back MVAR } \\
\text { output of } \\
\text { Locher }\end{array}$ & & & \begin{tabular}{|l} 
Correctly \\
projecting that \\
backing down
\end{tabular} & & \\
\hline 60 & East: & $\mathrm{RC}$ this is East. 10-4 & & & & & & & & & \\
\hline 61 & & $\begin{array}{l}\text { RC this is East. Locher } 1 \text { MVAR output } \\
\text { has been reduced 150MVAR. }\end{array}$ & & & $\begin{array}{l}\text { Mvar output has been } \\
\text { reduced }\end{array}$ & & & & & \begin{tabular}{|l|}
$\begin{array}{l}\text { Locher output } \\
\text { decreased by } \\
150 \text { MVAR }\end{array}$ \\
\end{tabular} & \\
\hline 62 & & $<$ RC Acknowledges $>$ & & & & & & & & & \\
\hline 63 & Central: & $\mathrm{RC}$ this is Central. & & & & & & & & & \\
\hline 64 & & $<$ RC Acknowledges $>$ & & & & & & & & & \\
\hline 65 & & $\begin{array}{l}\text { We have visually inspected the Moses to } \\
\text { Locher breaker } 5 \text { and found that it is } \\
\text { actually open even though our SCADA is } \\
\text { indicating that it's closed. So Central and } \\
\text { East are currently not connected. }\end{array}$ & SCADA & & $\begin{array}{l}\text { have visually } \\
\text { inspected, found } \\
\text { actually open, } \\
\text { SCADA indicating } \\
\text { closed } \\
\end{array}$ & & \begin{tabular}{|l|} 
Visual \\
inspectio \\
$\mathrm{n}$ \\
confirms \\
breaker \\
is open \\
and \\
telemetr \\
$\mathrm{y}$ is \\
incorrect \\
\end{tabular} & & $\begin{array}{l}\text { Confirmed that } \\
\text { breaker is } \\
\text { showing closed } \\
\text { but is really } \\
\text { opened. } \\
\end{array}$ & & \\
\hline 66 & RC: & $\begin{array}{l}\text { Central this is RC. Confirming, visual } \\
\text { inspection has shown the } 230 \mathrm{kV} \text { Moses to } \\
\text { Locher breaker } 5 \text { in the open position } \\
\text { contrary to SCADA indications. East and } \\
\text { Central are operating as independent } \\
\text { islands. }\end{array}$ & $\begin{array}{l} \\
\text { visual } \\
\text { inspection, } \\
\text { open } \\
\text { position, } \\
\text { SCADA } \\
\text { indications, } \\
\text { independent } \\
\text { islands } \\
\end{array}$ & & $\begin{array}{l}\text { operating as } \\
\text { independent islands }\end{array}$ & & & & & & \\
\hline
\end{tabular}




\begin{tabular}{|c|c|c|c|c|c|c|c|c|c|c|c|}
\hline Step & Speaker & Conversation & Objects & Action & $\begin{array}{l}\text { State - current, past, } \\
\text { projection }\end{array}$ & Objectives & Cues & $\begin{array}{l}\text { Mental Models/ } \\
\text { Simulations }\end{array}$ & \begin{tabular}{|l|} 
Level of \\
Situation \\
Awareness
\end{tabular} & Actions & Narration \\
\hline 67 & East: & $\begin{array}{l}\mathrm{RC} \text { this is East. East concurs. We are not } \\
\text { connected to Central. }\end{array}$ & & & are not connected & & & & & & \\
\hline 68 & RC: & Central this is RC. & & & & & & & & & \\
\hline 69 & & $<$ Central Acknowledges $>$ & & & & & & & & & \\
\hline 70 & & $\begin{array}{l}\text { We will update our status boards and make } \\
\text { a note in our system that the present line } \\
\text { status was incorrect. Central, what are } \\
\text { your plans to fix this fault indication? }\end{array}$ & $\begin{array}{l}\text { status } \\
\text { boards, note } \\
\text { in system, } \\
\text { line status, } \\
\text { fault } \\
\text { indication } \\
\end{array}$ & $\begin{array}{l}\text { update status } \\
\text { boards, make } \\
\text { a note in } \\
\text { system, fix } \\
\text { fault } \\
\text { indication } \\
\end{array}$ & & $\begin{array}{l}\text { Update status } \\
\text { boards and } \\
\text { note status } \\
\text { incorrect }\end{array}$ & & & & & \\
\hline 71 & Central: & $\begin{array}{l}\text { RC this is Central. Since this line is } \\
\text { already out of service we are in the } \\
\text { processes of having the faulty micro- } \\
\text { switch repaired. We hope to have the } \\
\text { faulty micro-switch replaced by the end of } \\
\text { the day. }\end{array}$ & $\begin{array}{l}\text { fault micro } \\
\text { switch }\end{array}$ & & $\begin{array}{l}\text { line is out of service, } \\
\text { in process of } \\
\text { repairing faulty } \\
\text { micro-switch, hope to } \\
\text { have replaced by end } \\
\text { of day. }\end{array}$ & & & & & & \\
\hline 72 & RC: & $\begin{array}{l}\text { 10-4 Central. Since the line will be out of } \\
\text { service for repairs to the breaker we will } \\
\text { not interconnect Central and East at this } \\
\text { time. Central, you will need to find a way } \\
\text { to adjust voltage to interconnect with West } \\
\text { without the aid of East. }\end{array}$ & & $\begin{array}{l}\text { will not } \\
\text { interconnect, } \\
\text { adjust } \\
\text { voltage, } \\
\text { interconnect } \\
\text { with west } \\
\end{array}$ & & & & & & $\begin{array}{l}\text { Decision to } \\
\text { leave line out } \\
\text { of service }\end{array}$ & $\begin{array}{l}\text { Due to other restoration } \\
\text { concerns East will not be } \\
\text { involved any further in the } \\
\text { attempts to connect West with } \\
\text { Central. }\end{array}$ \\
\hline 73 & & $\begin{array}{l}<\text { East Acknowledge }><\text { Central } \\
\text { Acknowledge }>\end{array}$ & & & & & & & & & \\
\hline 74 & Central: & West this is Central. & & & & & & & & & \\
\hline 75 & & $<$ West Acknowledges $>$ & & & & & & & & & \\
\hline
\end{tabular}




\begin{tabular}{|c|c|c|c|c|c|c|c|c|c|c|c|}
\hline Step & Speaker & Conversation & Objects & Action & $\begin{array}{l}\text { State - current, past, } \\
\text { projection }\end{array}$ & Objectives & Cues & $\begin{array}{l}\text { Mental Models/ } \\
\text { Simulations }\end{array}$ & \begin{tabular}{|l|} 
Level of \\
Situation \\
Awareness
\end{tabular} & Actions & Narration \\
\hline 76 & & $\begin{array}{l}\text { We attempted to coordinate with East to } \\
\text { raise the voltage in our island but it was } \\
\text { discovered that we are not currently } \\
\text { connected to East. We thought that we } \\
\text { were but there was a faulty breaker } \\
\text { position indicator at Moses. We will have } \\
\text { to determine how to reduce the voltage } \\
\text { difference ourselves. }\end{array}$ & $\begin{array}{l}\text { faulty } \\
\text { breaker } \\
\text { position } \\
\text { indicator } \\
\end{array}$ & $\begin{array}{l}\text { discovered } \\
\text { not } \\
\text { connected to } \\
\text { east, reduce } \\
\text { voltage } \\
\text { ourselves } \\
\end{array}$ & $\begin{array}{l}\text { We are not currently } \\
\text { connected to East. } \\
\text { We thought we were } \\
\text { connected. There was } \\
\text { a faulty breaker } \\
\text { position indicator at } \\
\text { Moses. We will have } \\
\text { to reduce voltage } \\
\text { difference ourselves. }\end{array}$ & & & & & & \\
\hline 77 & West: & $\begin{array}{l}\text { Central this is West. The restoration of the } \\
\text { distribution load centers is taking longer } \\
\text { than expected, the line crews are stretched } \\
\text { pretty thin; it will still be at Central } 6 \\
\text { hours to restore } 138 \mathrm{kV} \text { load centers. }\end{array}$ & $\begin{array}{l}\text { distribution } \\
\text { load centers, } \\
\text { line crews, } \\
138 \mathrm{kV} \text { load } \\
\text { centers } \\
\end{array}$ & \begin{tabular}{|l|} 
restoring \\
distribution \\
load centers \\
\end{tabular} & $\begin{array}{l}\text { Restoration for } \\
\text { distribution load } \\
\text { centers is taking } \\
\text { longer. Line crews } \\
\text { are stretched thin. } \\
\text { Central to take } 6 \\
\text { hours to restore } 138 \\
\text { kV load centers } \\
\end{array}$ & & & $\begin{array}{l}\text { Substation } \\
\text { operators are } \\
\text { restoring feeders } \\
\text { as MW MVAR } \\
\text { load is added } \\
\text { voltages will } \\
\text { decrease } \\
\end{array}$ & & & \\
\hline 78 & Central: & $\begin{array}{l}\text { 10-4. The voltage difference is still too } \\
\text { high and we can't wait for restoration of } \\
\text { the } 138 \mathrm{kV} \text { load centers. Do you have any } \\
\text { cap banks at Homer that can be switched } \\
\text { out of service? }\end{array}$ & cap banks & $\begin{array}{l}\text { switch cap } \\
\text { banks out of } \\
\text { service }\end{array}$ & & & $\begin{array}{l}\text { Voltage } \\
\text { differenc } \\
\text { e } \\
\text { remains } \\
\text { high } \\
\end{array}$ & & $\begin{array}{l}\text { Observes again } \\
\text { that voltage } \\
\text { difference is too } \\
\text { high to close } \\
\text { breaker. }\end{array}$ & & \\
\hline 79 & West: & $\begin{array}{l}\text { No, the only Megavar injections at Homer } \\
\text { are from the } 230 \mathrm{kV} \text { Homer-Moses line } \\
\text { which is connected at our end but open on } \\
\text { your end.. The Homer - Moses } 230 \mathrm{kV} \text { line } \\
\text { produces about } 15 \text { MVAR at no load. }\end{array}$ & $\begin{array}{l}\text { megavar } \\
\text { injections, } \\
\text { MVAR at no } \\
\text { load } \\
\end{array}$ & \begin{tabular}{|l} 
\\
line \\
connected \\
our end, line \\
open your \\
end, line \\
produces \\
MVARs at \\
no load \\
\end{tabular} & $\begin{array}{l}\text { The only Megavar } \\
\text { injections at Homer } \\
\text { are from the } 230 \mathrm{kV} \\
\text { Homer-Moses line } \\
\text { which is connected at } \\
\text { our end but open on } \\
\text { your end.. The } \\
\text { Homer - Moses } 230 \\
\text { kV line produces } \\
\text { about } 15 \text { MVAR at } \\
\text { no load. }\end{array}$ & & & $\begin{array}{l}\text { Observes that } \\
\text { Homer - Moses } \\
\text { line is really a } \\
\text { capacitor }\end{array}$ & $\begin{array}{l}\text { Observes that } \\
\begin{array}{l}\text { Homer - Moses } \\
\text { line is really a } \\
\text { capacitor }\end{array} \\
\end{array}$ & & \\
\hline
\end{tabular}




\begin{tabular}{|c|c|c|c|c|c|c|c|c|c|c|c|}
\hline Step & Speaker & Conversation & Objects & Action & $\begin{array}{l}\text { State - current, past, } \\
\text { projection }\end{array}$ & Objectives & Cues & $\begin{array}{l}\text { Mental Models/ } \\
\text { Simulations }\end{array}$ & \begin{tabular}{|l|} 
Level of \\
Situation \\
Awareness \\
\end{tabular} & Actions & Narration \\
\hline 80 & Central: & $\begin{array}{l}\text { If you opened the } 230 \mathrm{kV} \text { Homer breaker } \\
\text { and isolated the } 230 \mathrm{kV} \text { Homer-Moses line, } \\
\text { would that significantly impact the voltage } \\
\text { level at any of the other substations in your } \\
\text { island? }\end{array}$ & & $\begin{array}{l}\text { Open } \\
\text { breaker, } \\
\text { isolate line } \\
\text { and impact } \\
\text { voltage level } \\
\text { at substations } \\
\end{array}$ & & & & $\begin{array}{l}\text { Opening the line } \\
\text { and removing its } \\
\text { charging will } \\
\text { reduce the } \\
\text { voltage }\end{array}$ & $\begin{array}{l}\text { Realizes that } \\
\text { opening the line } \\
\text { and removing } \\
\text { its charging will } \\
\text { reduce the } \\
\text { voltage }\end{array}$ & & \\
\hline 81 & West & $\begin{array}{l}\text { It would lower the voltage at Homer but } \\
\text { the voltage level at the other sub-stations } \\
\text { shouldn't cause any problems. }\end{array}$ & & $\begin{array}{l}\text { lower } \\
\text { voltage }\end{array}$ & $\begin{array}{l}\text { Opening the Homer } \\
\text { breaker to isolate the } \\
\text { Homer - Moses line } \\
\text { would lower the } \\
\text { voltage at Homer }\end{array}$ & & & $\begin{array}{l}\text { Voltage at } \\
\text { Homer will be } \\
\text { lowered }\end{array}$ & $\begin{array}{l}\text { Voltage at } \\
\text { Homer will be } \\
\text { lowered }\end{array}$ & & \\
\hline 82 & Central: & $\begin{array}{l}\text { Ok West. I suggest that you open the } 230 \\
\mathrm{kV} \text { Homer breaker } 1 \text {, isolate the } 230 \mathrm{kV} \\
\text { line and we close the } 230 \mathrm{kv} \text { breaker on } \\
\text { our side. This will transfer the line } \\
\text { capacitance from your system to ours and } \\
\text { should lower the voltage at Homer and } \\
\text { raise the voltage at Moses. }\end{array}$ & (1) & $\begin{array}{l}\text { Open breaker } \\
\text { your end, } \\
\text { islolate line, } \\
\text { close breaker } \\
\text { our side. } \\
\text { Transfer the } \\
\text { line } \\
\text { capacitance } \\
\text { form your } \\
\text { system to our } \\
\text { system. } \\
\text { Lower } \\
\text { voltage at } \\
\text { Homer, raise } \\
\text { voltage at } \\
\text { Moses } \\
\end{array}$ & $\begin{array}{l}\text { Ok West. I suggest } \\
\text { that you open the } 230 \\
\mathrm{kV} \text { Homer breaker } 1, \\
\text { isolate the } 230 \mathrm{kV} \\
\text { line and we close the } \\
230 \mathrm{kv} \text { breaker on our } \\
\text { side. This will } \\
\text { transfer the line } \\
\text { capacitance from } \\
\text { your system to ours } \\
\text { and should lower the } \\
\text { voltage at Homer and } \\
\text { raise the voltage at } \\
\text { Moses. } \\
\end{array}$ & & & \begin{tabular}{|l} 
\\
\\
Engergizing line \\
from Moses will \\
raise voltage at \\
Moses \\
\end{tabular} & \begin{tabular}{|l} 
\\
\\
Engergizing \\
line from Moses \\
will raise \\
voltage at \\
Moses \\
\end{tabular} & & \\
\hline 83 & West: & $\begin{array}{l}\text { West-(to Central): I agree. Let's confirm } \\
\text { with the RC before we proceed. }\end{array}$ & & & & & & & & & \\
\hline 85 & & $<$ RC Acknowledges $>$ & & & & & & & & & \\
\hline
\end{tabular}




\begin{tabular}{|c|c|c|c|c|c|c|c|c|c|c|c|}
\hline Step & Speaker & Conversation & Objects & Action & $\begin{array}{l}\text { State - current, past, } \\
\text { projection }\end{array}$ & Objectives & Cues & $\begin{array}{l}\text { Mental Models/ } \\
\text { Simulations }\end{array}$ & \begin{tabular}{|l|} 
Level of \\
Situation \\
Awareness
\end{tabular} & Actions & Narration \\
\hline 86 & & $\begin{array}{l}\text { We have a plan that should reduce the } \\
\text { voltage mismatch across the } 230 \mathrm{kV} \text { Moses } \\
\text { to Homer line and allow us to interconnect } \\
\text { West and Central service areas. We } \\
\text { propose to transfer the line capacitance of } \\
\text { the } 230 \mathrm{kV} \text { Homer - Moses line from West } \\
\text { to Central. }\end{array}$ & $\begin{array}{l}\text { west area, } \\
\text { central area }\end{array}$ & $\begin{array}{l}\text { interconnect } \\
\text { west and } \\
\text { central areas, } \\
\text { transfer the } \\
\text { line } \\
\text { capacitance } \\
\end{array}$ & $\begin{array}{l}\text { We have a plan that } \\
\text { should reduce the } \\
\text { voltage mismatch } \\
\text { across the } 230 \mathrm{kV} \\
\text { Moses to Homer line } \\
\text { and allow us to } \\
\text { interconnect West } \\
\text { and Central service } \\
\text { areas. We propose to } \\
\text { transfer the line } \\
\text { capacitance of the } \\
\text { 230kV Homer - } \\
\text { Moses line from } \\
\text { West to Central. }\end{array}$ & & & & $\begin{array}{l}\text { RC is } \\
\text { confirming the } \\
\text { mental model of } \\
\text { line acting as } \\
\text { capacitor and } \\
\text { plan to transfer } \\
\text { capacitance } \\
\text { from West to } \\
\text { Central. }\end{array}$ & & \\
\hline 87 & & $\begin{array}{l}\text { West will open the } 230 \mathrm{kV} \text { Homer breaker } \\
\text { 1. Central will close the } 230 \mathrm{kV} \text { Moses } \\
\text { breaker } 8 \text {. This should lower the voltage } \\
\text { at Homer and raise the voltage at Moses. } \\
\text { If all goes according to plan, we can then } \\
\text { interconnect on the } 230 \mathrm{kV} \text { system, using } \\
\text { the Homer breaker } 1 \text {. }\end{array}$ & & & $\begin{array}{l}\text { West will open the } \\
230 \mathrm{kV} \text { Homer } \\
\text { breaker } 1 \text {. Central } \\
\text { will close the } 230 \mathrm{kV} \\
\text { Moses breaker } 8 \text {. } \\
\text { This should lower the } \\
\text { voltage at Homer and } \\
\text { raise the voltage at } \\
\text { Moses. If all goes } \\
\text { according to plan, we } \\
\text { can then interconnect } \\
\text { on the } 230 \mathrm{kV} \\
\text { system, using the } \\
\text { Homer breaker } 1 .\end{array}$ & & & & & & \\
\hline 88 & RC: & Central 10-4. West are you listening in? & & & & & & & & & \\
\hline 89 & & $<$ West Acknowledges $>$ & & & & & & & & & \\
\hline
\end{tabular}




\begin{tabular}{|c|c|c|c|c|c|c|c|c|c|c|c|}
\hline Step & Speaker & Conversation & Objects & Action & $\begin{array}{l}\text { State - current, past, } \\
\text { projection }\end{array}$ & Objectives & Cues & $\begin{array}{l}\text { Mental Models/ } \\
\text { Simulations }\end{array}$ & \begin{tabular}{|l|} 
Level of \\
Situation \\
Awareness
\end{tabular} & Actions & Narration \\
\hline 91 & Central: & $\mathrm{RC}$, Central. That is correct. & & & & & & & & & \\
\hline 92 & RC: & RC to West, do you concur with this plan? & & & & & & & & & \\
\hline 93 & West: & $\mathrm{RC}$ this is West. We concur. & & & & & & & & & \\
\hline 94 & RC: & $\begin{array}{l}\text { Central and West, this is RC. Proceed } \\
\text { with that plan. Please keep me informed. }\end{array}$ & & & & & & & & & \\
\hline 95 & & $\begin{array}{l}<\text { Acknowledge West }><\text { Acknowledge } \\
\text { Central }>\end{array}$ & & & & & & & & & \\
\hline 96 & West: & West to Central. & & & & & & & & & \\
\hline 97 & & $<$ Central Acknowledges $>$ & & & & & & & & & \\
\hline 98 & & $\begin{array}{l}\text { Central, we will now open the Homer } \\
\text { breaker } 1 \text {. Standby }\end{array}$ & & & $\begin{array}{l}\text { The Homer breaker, } \\
1 \text {, indicates open. }\end{array}$ & & & & & $\begin{array}{l}\text { CB } 999 \\
\text { Opened }\end{array}$ & \\
\hline
\end{tabular}




\begin{tabular}{|c|c|c|c|c|c|c|c|c|c|c|c|}
\hline Step & Speaker & Conversation & Objects & Action & $\begin{array}{l}\text { State - current, past, } \\
\text { projection }\end{array}$ & Objectives & Cues & $\begin{array}{l}\text { Mental Models/ } \\
\text { Simulations }\end{array}$ & \begin{tabular}{|l} 
Level of \\
Situation \\
Awareness
\end{tabular} & Actions & Narration \\
\hline 100 & & $\begin{array}{l}\text { The Homer breaker } 1 \text { now indicates open } \\
\text { on our system. The voltage at Homer is } \\
\mathrm{kV} \text {. }\end{array}$ & & & $\begin{array}{l}\text { The Homer breaker } 1 \\
\text { now indicates open } \\
\text { on our system. The } \\
\text { voltage at Homer is } \\
\text { kV. }\end{array}$ & & \begin{tabular}{|l|} 
Breaker \\
679 \\
shows \\
open. \\
Voltage \\
at Homer \\
is \\
lowered \\
\end{tabular} & & $\begin{array}{l}\text { Operator } \\
\text { monitors } \\
\text { voltage at } \\
\text { Homer }\end{array}$ & & \\
\hline 102 & & $\begin{array}{l}\text { The } 230 \mathrm{kV} \text { Moses breaker } 8 \text {, indicates } \\
\text { closed. The voltage at Moses is reading } \\
\mathrm{kV} \text {. }\end{array}$ & & & $\begin{array}{l}\text { The } 230 \mathrm{kV} \text { Moses } \\
\text { breaker } 8 \text {, indicates } \\
\text { closed. The voltage } \\
\text { at Moses is reading } \\
\mathrm{kV} \text {. }\end{array}$ & & \begin{tabular}{|l|} 
Breaker \\
94 shows \\
closed
\end{tabular} & & $\begin{array}{l}\text { Operator } \\
\text { monitors } \\
\text { voltage at } \\
\text { Moses } \\
\end{array}$ & & \\
\hline 103 & West: & $\begin{array}{l}\text { Roger that, Central. Our EMS confirms } \\
\text { breaker } 8 \text { at Moses closed with a voltage } \\
\text { of } \quad \mathrm{kV} \text {. }\end{array}$ & & & & & $\begin{array}{l}\text { Voltage } \\
\text { at Moses } \\
\text { is raised }\end{array}$ & & & & $\begin{array}{l}\text { At this point, the } \\
\text { Interconnection Checklist } \\
\text { between West, Central, and } \\
\text { RC has been successfully } \\
\text { completed. }\end{array}$ \\
\hline 104 & RC: & West and Central this is RC & & & & & & & & & \\
\hline 105 & & $\begin{array}{l}<\text { Central Acknowledges }><\text { West } \\
\text { Acknowledges }>\end{array}$ & & & & & & & & & \\
\hline 106 & & $\begin{array}{l}\text { Since all requirements of the } \\
\text { Interconnection Checklist have been met, } \\
\text { West and Central, you are clear to } \\
\text { interconnect your islands. Inform me } \\
\text { when it is complete so we can continue } \\
\text { with the restoration plan. }\end{array}$ & $\begin{array}{l}\text { Requirement } \\
\text { s of } \\
\text { Interconnecti } \\
\text { on checklist }\end{array}$ & & $\begin{array}{l}\text { Since all } \\
\text { requirements of the } \\
\text { Interconnection } \\
\text { Checklist have been } \\
\text { met, West and } \\
\text { Central, you are clear } \\
\text { to interconnect your } \\
\text { islands.. }\end{array}$ & $\begin{array}{l}\text { Connect the } \\
\text { two islands }\end{array}$ & & & & & \\
\hline
\end{tabular}




\begin{tabular}{|c|c|c|c|c|c|c|c|c|c|c|c|}
\hline Step & Speaker & Conversation & Objects & Action & $\begin{array}{l}\text { State - current, past, } \\
\text { projection }\end{array}$ & Objectives & Cues & $\begin{array}{l}\text { Mental Models/ } \\
\text { Simulations }\end{array}$ & \begin{tabular}{|l} 
Level of \\
Situation \\
Awareness
\end{tabular} & Actions & Narration \\
\hline 107 & Central: & $\begin{array}{l}\text { RC this is Central: } 10-4 \text {. The } \\
\text { Interconnection Checklist is complete and } \\
\text { Central and West will attempt to connect } \\
\text { our two islands. }\end{array}$ & & & $\begin{array}{l}\text { The interconnection } \\
\text { checklist is complete }\end{array}$ & & & & $\begin{array}{l}\text { Projection that } \\
\text { islands can be } \\
\text { successfully } \\
\text { connected. } \\
\end{array}$ & & \\
\hline 108 & & Central to West. & & & & & & & & & \\
\hline 110 & & $\begin{array}{l}\mathrm{RC} \text { has given approval to connect our two } \\
\text { islands. The last step is for you to close } \\
\text { the } 230 \text { V Homer breaker, breaker } 1 \text {. Do } \\
\text { you agree? }\end{array}$ & & & & & & & & & \\
\hline 111 & West: & $\begin{array}{l}\text { Central this is West. West agrees that the } \\
\text { voltage, frequency and phase are within } \\
\text { spec according to the Interconnection } \\
\text { Checklist for closing the } 230 \mathrm{kV} \text { breaker, } \\
1 .\end{array}$ & $\begin{array}{l}\text { Voltage, } \\
\text { frequency, } \\
\text { phase, spec }\end{array}$ & & $\begin{array}{l}\text { Voltage, frequency, } \\
\text { phase are within spec }\end{array}$ & & & $\begin{array}{l}\text { Sychroscope with } \\
\text { voltage, } \\
\text { frequency and } \\
\text { phase in } \\
\text { tolerance }\end{array}$ & $\begin{array}{l}\text { Sychroscope } \\
\text { with voltage, } \\
\text { frequency and } \\
\text { phase in } \\
\text { tolerance }\end{array}$ & & \\
\hline 112 & & Closing. Homer 1. Standby & & & & & & & & & \\
\hline 113 & & $\begin{array}{l}\text { The } 230 \mathrm{kV} \text { Homer breaker, } 1 \text {, is now } \\
\text { indicating closed on our end and we are } \\
\text { seeing Megawatts and Megavar transfers } \\
\text { across the line. }\end{array}$ & $\begin{array}{l}\text { megawatt } \\
\text { and megavar } \\
\text { transfers }\end{array}$ & \begin{tabular}{|l} 
seeing \\
megawatt \\
and megavar \\
transfers \\
\end{tabular} & $\begin{array}{l}\text { The } 230 \mathrm{kV} \text { Homer } \\
\text { breaker, } 1 \text {, is now } \\
\text { indicating closed on } \\
\text { our end and we are } \\
\text { seeing Megawatts } \\
\text { and Megavar } \\
\text { transfers across the } \\
\text { line. }\end{array}$ & & $\begin{array}{l}\text { Homer } \\
\text { breaker } \\
999 \\
\text { closed } \\
\end{array}$ & & & & \\
\hline 114 & & $<$ Central Acknowledge $>$ & & & & & & & & & \\
\hline 115 & Central: & $\begin{array}{l}10-4 \text {, West. Our SCADA is also } \\
\text { indicating breaker } 1 \text { is closed and that } \\
\text { there are Megawatt and Megavar flows on } \\
\text { the line. }\end{array}$ & $\begin{array}{l}\text { megawatt } \\
\text { and megavar } \\
\text { flows }\end{array}$ & \begin{tabular}{|l} 
seeing \\
megawatt \\
and megavar \\
flows \\
\end{tabular} & & & \begin{tabular}{|l|} 
MW and \\
MVAR \\
flows on \\
Homer - \\
Moses \\
Line \\
\end{tabular} & & & & \\
\hline 116 & West: & West to RC: & & & & & & & & & \\
\hline
\end{tabular}




\begin{tabular}{|c|c|c|c|c|c|c|c|c|c|c|c|}
\hline Step & Speaker & Conversation & Objects & Action & $\begin{array}{l}\text { State - current, past, } \\
\text { projection }\end{array}$ & Objectives & Cues & $\begin{array}{l}\text { Mental Models/ } \\
\text { Simulations }\end{array}$ & \begin{tabular}{|l|} 
Level of \\
Situation \\
Awareness
\end{tabular} & Actions & Narration \\
\hline 118 & & $\begin{array}{l}\text { We have closed the } 230 \mathrm{kV} \text { Homer } \\
\text { breaker } 1 \text { and the } 230 \mathrm{kV} \text { Homer-Moses } \\
\text { line is now in service. West and Central } \\
\text { are now interconnected. }\end{array}$ & & & $\begin{array}{l}\text { We have closed the } \\
230 \mathrm{kV} \text { Homer } \\
\text { breaker 1 and the } \\
230 \mathrm{kV} \text { Homer-Moses } \\
\text { line is now in service. } \\
\text { West and Central are } \\
\text { now interconnected. }\end{array}$ & & & $\begin{array}{l}\text { Two islands are } \\
\text { connected with } \\
\text { increase inertia } \\
\text { and capacity }\end{array}$ & $\begin{array}{l}\text { Two islands are } \\
\text { connected with } \\
\text { increase inertia } \\
\text { and capacity } \\
\end{array}$ & & \\
\hline 119 & RC: & $\begin{array}{l}\text { RC-(to West): } 10-4 \text { West and Central. We } \\
\text { also show the } 230 \mathrm{kV} \text { Homer to Moses } \\
\text { line closed and power transfers on that } \\
\text { line. The West and Central areas are } \\
\text { connected. }\end{array}$ & & $\begin{array}{l}\text { show line } \\
\text { closed and } \\
\text { show power } \\
\text { transfers }\end{array}$ & $\begin{array}{l}\text { west and central are } \\
\text { interconnected }\end{array}$ & & & & & & $\begin{array}{l}\text { That concludes this } \\
\text { demonstration. Please stand } \\
\text { by while we enable your } \\
\text { telephones to ask questions. }\end{array}$ \\
\hline
\end{tabular}




\section{Illustration of Operator Performance Assessment Based on Scenario Script}

\section{SA Level 1: Perceiving critical cues}

Prior to Step 79, the SA of the West, Central, and RC operators is at Level 1. They perceive the critical factors: The voltage at Homer is high and the voltage at Moses is low, but they do not seem to understand why this is happening and how it can be corrected.

\section{SA Level 2: Understanding what the critical cues mean}

In Step 79, the West operator's SA increases to Level 2. He is focusing on the MVAR injections from the closed end of the Homer-Moses line into the Homer bus and he states, "...the only Megavar injections at Homer are from the $230 \mathrm{kV}$ Homer-Moses line which is connected at our end but open on your end. The Homer-Moses $230 \mathrm{kV}$ line produces about 15 MVAR at no load."

\section{SA Level 3: Understanding what will happen in the near future}

In Step 82, the Central operator's SA increases to Level 3. He states: “Ok West. I suggest that you open the $230 \mathrm{kV}$ Homer breaker 1, isolate the $230 \mathrm{kV}$ line and we close the $230 \mathrm{kV}$ breaker on our side. This will transfer the line capacitance from your system to ours and should lower the voltage at Homer and raise the voltage at Moses." The Central operator understands why the voltage at Homer is high and is proposing an action to lower the voltage at Homer and increase the voltage at Moses by transferring the line capacitance from Homer to Moses.

\section{Shared understanding}

The level of coordination and sharing of information between the system operators is high.

In Steps 78 to 83, the Central and West operators interact and jointly increase their SA from Level 1 to Level 3. In Step 86 and 87, the SA of the RC is also brought up to Level 3 and the RC reiterates his Level 3 understanding in Step 90.

\section{Finding the right mental model}

The simple mental model of transferring line capacitance is the crux of the whole scenario.

The operators increased their SA from Level 1 to Level 3 only after they retrieved the mental model that an open line acts as a capacitor from their long-term memory.

\section{Finding the correct action}

This scenario reinforces the point (Endsley 1997) that when an operator has a high level of situational awareness, then the correct action can be very obvious.

\section{Conclusion}

The fact that the SA Level can be tracked for each operator in this scenario with such high precision and the fact that we can correlate this improvement in SA so directly to the retrieval of such a basic mental model suggest that the Human Factors Framework will be very useful for many applications.

\section{More detailed monitoring of cues}

The cues that were monitored during a scenario could be enumerated at a more detailed level if the simulation software were able to recreate the displays that were opened along with the state 
of the system as part of the playback feature. The operator and instructor could then play back the scenario and highlight the variables that were key indicators. However, this level of detailed review does not seem to be needed when there are good communications between multiple role players.

\section{Short-Term Working Memory versus Long-Term Memory}

The authors have categorized the elements in the RPD Model as follows:

- The situation and the cues are real-world elements. The situation is either the real world or some mathematical model in the simulator. The cues are also part of the real world. They are variables that are observable by the system operator through his monitoring systems (SCADA, map boards, weather, television, relays, etc.) and conversations with other system operators and his environment.

- The mental models are stored in long-term memory.

- The mental simulations, story, and action scripts are built up in real time in short-term memory.

The mental model of a line acting as a capacitor was in long-term memory for the West, Central, and RC operators. However, it was not until Step 78 that we see it being retrieved and used in short-term memory. A summary of the analysis is as follows:

- In Step 17, Central asks West, "Is there anything you can do to lower the voltage at Homer?"

- In Step 18, West responds, "We do not have any voltage control devices at Homer or any adjacent station."

This shows that they had not considered the mental model at that time.

- In Step 78, Central asks West, "Do you have any cap banks that can be switched out of service?"

- In Step 79, West responds, "No, the only Megavar injections at Homer are from the 230 kV Homer-Moses line."

Once the connection had been made, the West, Central, and RC operators all agree immediately on a common solution with virtually no discussion. And they all accept the common mental model of transferring the line capacitance from Homer to Moses.

\section{Underlying Premise of RPDM}

The operators in this scenario reinforced the underlying premise of the RPDM. Once they identified a viable plan, they tended to quickly validate it and then attempt to put it into action. 
They did not spend any time in the scenario weighing the pros and cons of different options. This was true even though the first solution that they chose was not the simplest and most effective one:

- After they found that the first solution of using the generator to raise voltage would not work because of the open breaker, they were forced to develop an alternative.

- At this point, they again quickly identified the solution to transfer the line charging capacitance for Homer to Moses.

- At no point did any operator suggest the option of changing taps at Homer.

This willingness to go with the first feasible solution is remarkable, especially given the number of participants and potential for more diversity of opinions.

\section{Conclusion}

This section has used the processes and principles of Recognition Primed Decision Making and Cognitive Task Analysis to analyze the script for the Island Synchronization Scenario. The results are very promising:

- The enhanced RPD model seems to explain the thought processes of the system operators at all the steps in the scenario.

- The system operators' SA can be rated using Endsley's three Levels at each step of the scenario.

- The mental model that is key to solving the voltage problem is very clearly identified.

- The mental simulation that the operators run using this mental model is very clearly identified.

Later in the scenario, the West Operator (Steps 79 and 81) and Central Operator (Steps 80 and 82) correctly observe that voltage at Homer can be lowered and voltage at Moses can be raised by disconnecting the Homer-Moses line from Homer and then re-energizing it from Moses. An excerpt from the scenario analysis is shown in the following figure. 


\begin{tabular}{|r|l|l|l|l|}
\hline West: & & $\begin{array}{l}\text { No, the only Megavar injections at Homer are } \\
\text { from the 230kV Homer-Moses line which is } \\
\text { connected at our end but open on your end. The } \\
\text { Homer - Moses } 230 \mathrm{kV} \text { line produces about } 15 \\
\text { MVAR at no load. }\end{array}$ & Observes that Homer - Moses \\
\hline 79 & line is really a capacitor \\
\hline 80 & Central: & $\begin{array}{l}\text { If you opened the 230kV Homer breaker and } \\
\text { isolated the 230kV Homer-Moses line, would that } \\
\text { significantly impact the voltage level at any of the } \\
\text { other substations in your island? }\end{array}$ & $\begin{array}{l}\text { It would lower the voltage at Homer but the } \\
\text { voltage level at the other sub-stations shouldn't } \\
\text { cause any problems. }\end{array}$ & $\begin{array}{l}\text { Opening the line and removing } \\
\text { its charging will reduce the } \\
\text { voltage }\end{array}$ \\
\hline 82
\end{tabular}




\section{Possible Areas for Improvement}

Central and West operators could have observed earlier in the scenario that voltage at Homer can be lowered and voltage at Moses can be raised by disconnecting the Homer-Moses line from Homer and the re-energizing it from Moses. The RC directs (Step 11) the West and Central operators to coordinate to equalize the voltage. He could have advised them at this point that the voltage at Homer could be lowered and voltage at Moses could be raised by disconnecting Homer-Moses line from Homer and then re-energizing it from Moses. The Central operator states (Step 17) that he does not have any way of controlling voltage at the Moses station. He overlooks that the Homer-Moses line can be used to raise voltage at Moses. He does not take the time to consider if there are taps on adjacent transformers that can be used to control the weak bus at Moses.

\begin{tabular}{|c|c|c|c|c|}
\hline & $\mathrm{A}$ & $\mathrm{B}$ & $\mathrm{C}$ & $\mathrm{E}$ \\
\hline 1 & Speaker & Conversation & Objectives & Mental Models/Simulations \\
\hline 15 & SPP RC: & $\begin{array}{l}\text { Coordinate to equalize voltage across the } 230 \mathrm{kV} \\
\text { East Manhattan to Concordia breaker, breaker } \\
230-94 \text {. Once you've agreed on a plan, contact } \\
\text { me prior to synchronizing the two islands. }\end{array}$ & $\begin{array}{l}\text { Coordinate and equalize } \\
\text { voltage }\end{array}$ & $\begin{array}{l}\text { Misses mental model that the } \\
\text { unloaded Concordia - E. } \\
\text { Manhattan line is a capacitor }\end{array}$ \\
\hline 16 & Sunflower: & This is Sunflower: $10-4$ & & \\
\hline 17 & & & & \\
\hline 18 & Westar: & This is Westar: $10-4$ & & \\
\hline 19 & & & & \\
\hline 20 & Sunflower: & Sunflower to Westar: & & \\
\hline 21 & & <Westar acknowledge $>$ & & \\
\hline 22 & & $\begin{array}{l}\text { Is there anything you can do at the E. Manhattan } \\
\text { substation to raise the voltage? }\end{array}$ & & \\
\hline 23 & & & & \\
\hline 24 & Westar: & $\begin{array}{l}\text { No, is there anything you can do to lower the } \\
\text { voltage at Concordia? }\end{array}$ & & $\begin{array}{l}\text { Misses mental model that the } \\
\text { unloaded Concordia - } \mathrm{E} \text {. } \\
\text { Manhattan line is a capacitor }\end{array}$ \\
\hline 25 & & & & \\
\hline 26 & Sunflower: & $\begin{array}{l}\text { We don't have any voltage control devices at } \\
\text { Concordia, or any adjacent substation. }\end{array}$ & & $\begin{array}{l}\text { Concordia } 230 \mathrm{k} V \text { is a weak } \\
\text { bus, because it is being fed } \\
\text { from the } 115 \mathrm{kV} \text { system. } \\
\text { Misses mental model that the } \\
\text { unloaded Concordia - } E \text {. } \\
\text { Manhattan line is a capacitor. } \\
\text { Misses the standard operating } \\
\text { procedure on Open Weak end } \\
\text { First or Close the Strong End } \\
\text { First. Misses fact that voltage } \\
\text { of } 230 \mathrm{kV} \text { bus is fed from the } \\
115 \mathrm{k} V \text { side and could be } \\
\text { controlled by the } 230-115 \mathrm{kV} \\
\text { transformer taps }\end{array}$ \\
\hline
\end{tabular}


The West operator states (Step 18) that he does not have voltage control devices at the Homer station.

- The Homer-Moses transmission line is in fact a voltage control device.

- The taps on the $230 / 115 \mathrm{kV}$ transformer might also be used to control the $230 \mathrm{kV}$ bus when the $230 \mathrm{kV}$ bus is weak.

\section{Possible Areas for Enhancing the Scenario}

Include the enabling learning objectives: monitor and control transformer taps and auto regulation modes.

- The base case would be set up with the transformer taps in auto regulation mode.

- Operators would need to monitor tap settings and ensure regulation modes are set to manual.

- The instructor could fail to put a tap into regulation mode to reflect a bad control point.

- The operator would have to detect the tap moving over time.

- The enabling learning objectives could be extended to include identifying possible points of synchronization that have synch-scopes.

\section{Lessons Learned for Voltage Control Under System Restoration}

Lessons learned that could be pointed out during debriefings:

- Under islanded light load conditions, everything responds differently compared to normal integrated operating conditions.

- The system operates like nothing you have seen before: unless you have seen a real restoration or run a simulator.

- $230 \mathrm{kV}$ buses that are normally strong may be very weak.

- Ferranti rise into a weak bus is greatly increased compared to Ferranti rise into a strong bus.

- Lines are operating close to zero MW load. They are like large capacitors.

- Cables can be even bigger capacitors.

- Watch out for runaway transformer taps.

- Put all regulators in MAN mode before energizing transformers.

- Monitor the ability to absorb reactive power in each island before energizing HV lines. 


\section{Appendix 2: Relevant Mental Models}

This section enumerates the mental models that are relevant to managing power system voltages under system restoration conditions. The diagrams have been taken from the following Modules in the Emergency Operations with PowerSimulator (EOPS) Curricula:

- Course 5: Preventing Voltage Collapse: Module 5.2: Voltage and MVAR Characteristics of Generators

- Course 5: Preventing Voltage Collapse: Module 5.6: Transformers

- Course 7: System Restoration: Module 7.4: Voltage and MVAR Control.

These mental models are therefore also relevant to operating the illustrative restoration scenario described in Appendix 1.

\section{MVAR and Voltage Balance}

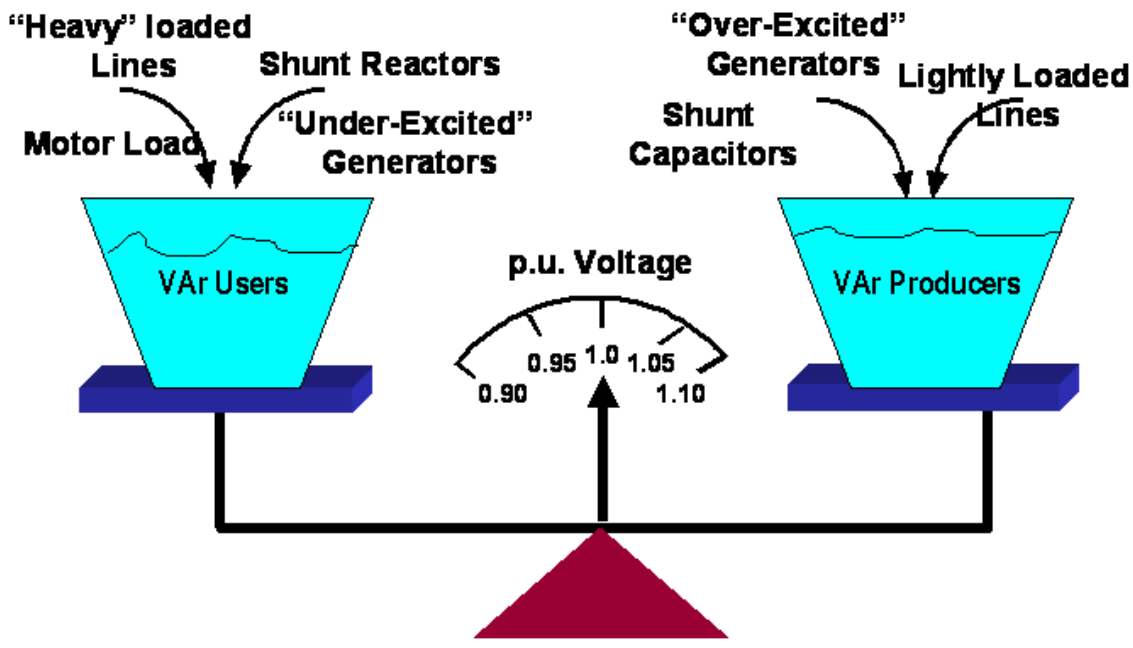

\section{Equivalent Circuit for Overhead Transmission Line}

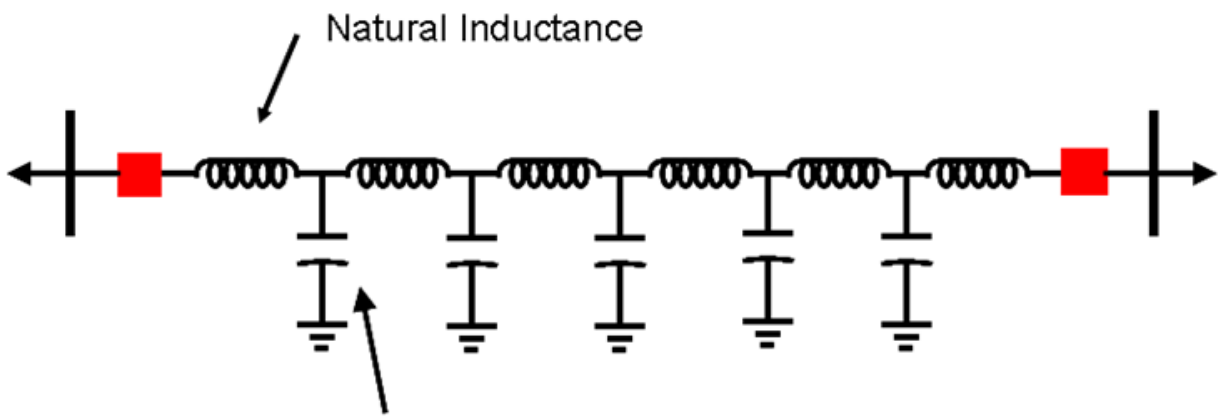

Natural Capacitance 
MVAR Charging for Different Voltage Lines and Cables

Transmission Line Charging

\begin{tabular}{|l|r|}
\hline Nominal Voltage & MVAR/Mile \\
\hline $69 \mathrm{~K} V$ Line & 0.025 \\
\hline 115/138 KV Line & 0.1 \\
\hline 230 KV Line & 0.3 \\
\hline 345 KV Line & 0.8 \\
\hline 500 KV Line & 1.7 \\
\hline 115/138 KV Cable & $2.0-7.0$ \\
\hline 230 KV Cable & $5.0-15.0$ \\
\hline 345 KV Cable & $15.0-30.0$ \\
\hline
\end{tabular}

MVARs Flowing out of Open-Ended Line

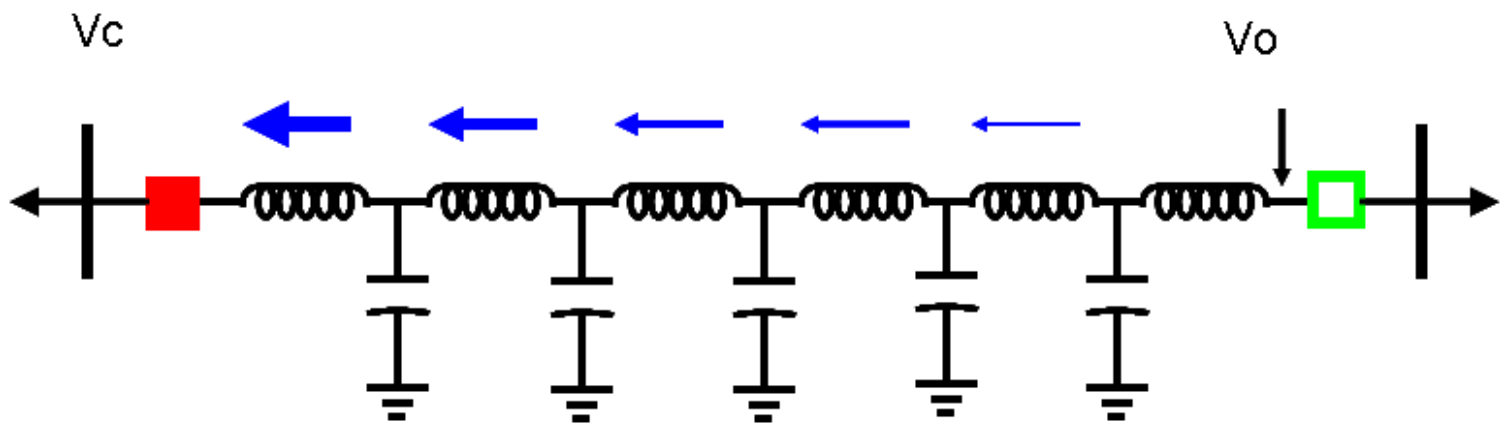

Width is proportional to MVAR flow 


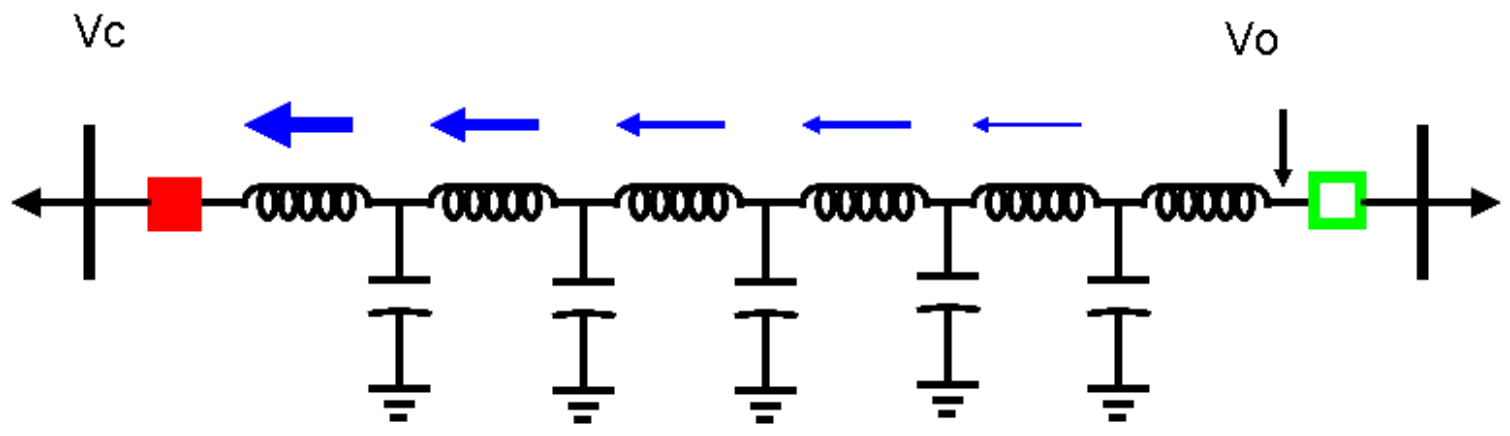

Ferranti Rise for Different Line Lengths

Ferranti Rise Across an Open Ended Line $\mathrm{Vo} / \mathrm{Vc}$

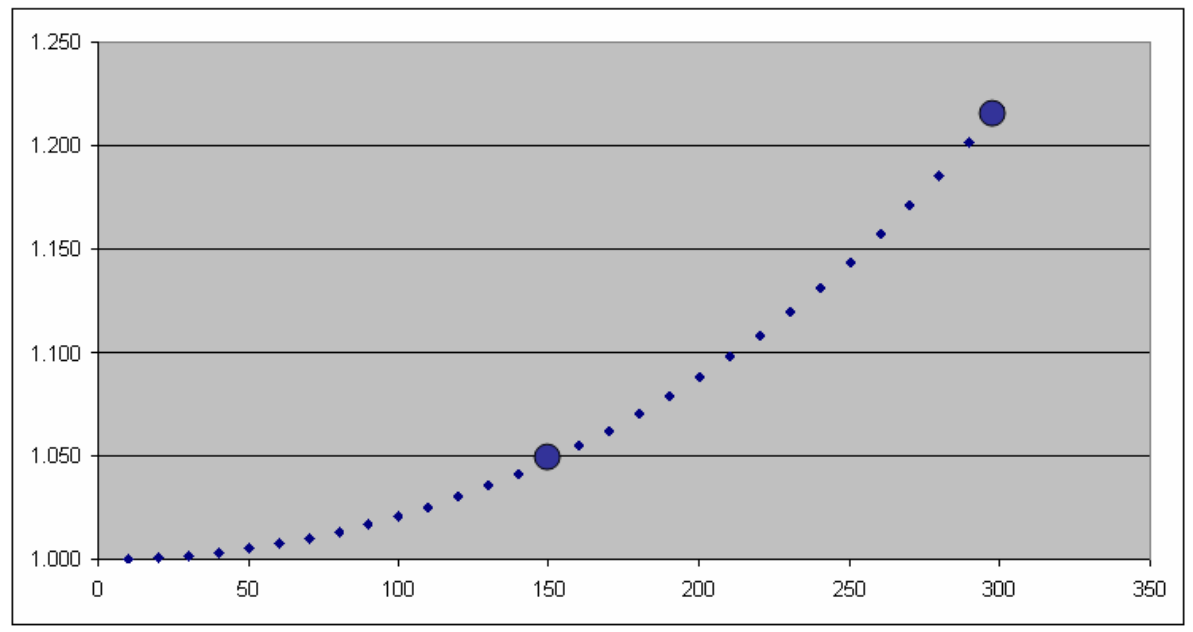

Line Length - Miles 
Rule of Thumb Using Quadratic Approximation

\section{Quadratic Approximation to Ferranti Rise Curve}

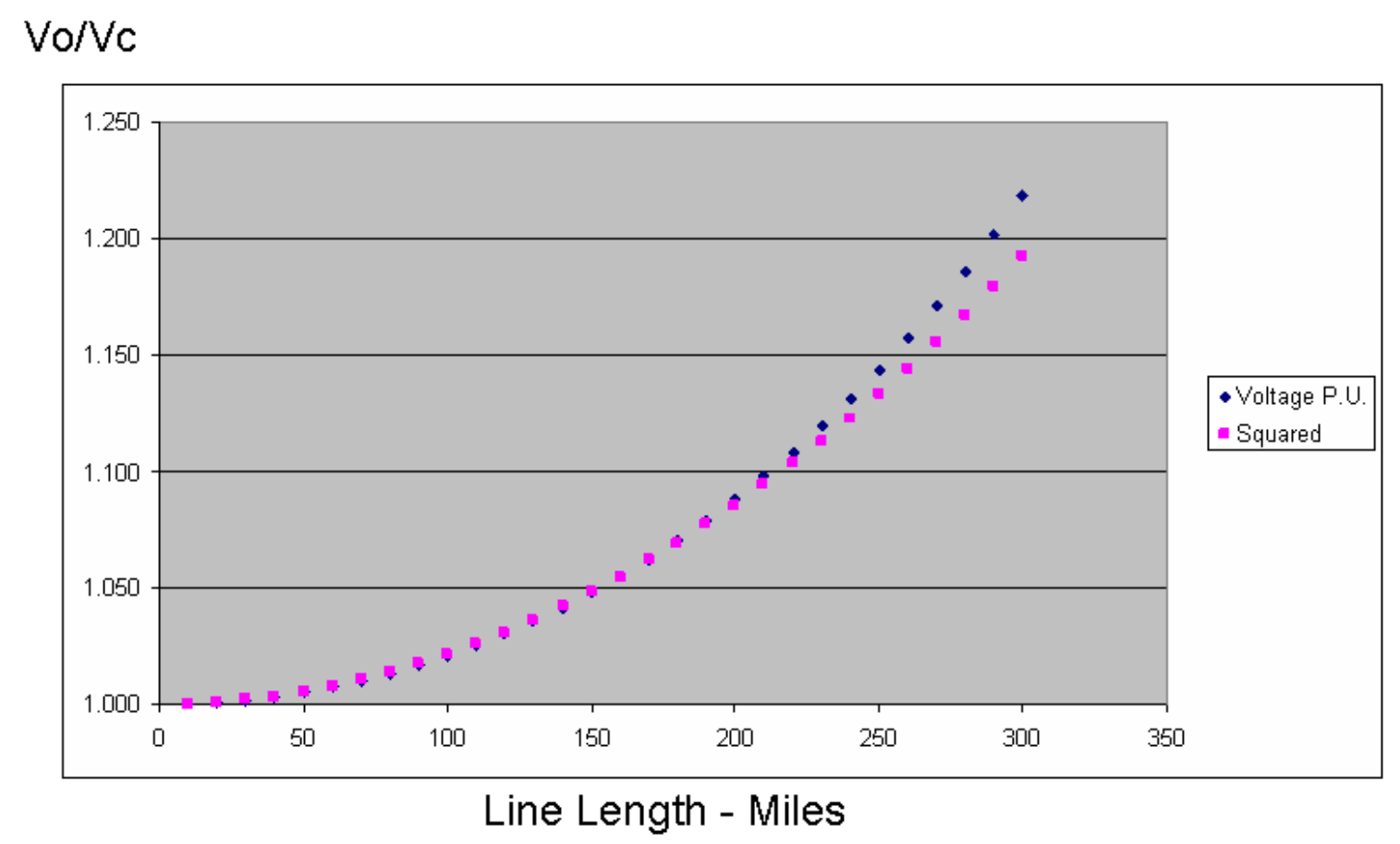

\section{Rule of Thumb}

A 150-mile line of ANY voltage level produces Ferranti rise at open end of 5\%. From this you can calculate Ferranti rise for other lengths. 


\section{Strong Bus and Weak Bus}

Strength of bus is measured by the per unit reactance in series to the closest regulating generator bus.

\begin{tabular}{|r|l|l|l|l|}
\hline & $\begin{array}{l}\text { Equivalent } \\
\text { Impedance } \\
\text { Between Bus at } \\
\text { Closed End of } \\
\text { Sine and } \\
\text { Strength } \\
\text { Generator Bus - } \\
\text { Per Unit }\end{array}$ & Description & Transmission Line Example & $\begin{array}{l}\text { Charging } \\
\text { MVARs that will } \\
\text { produce 1\% } \\
\text { Voltage } \\
\text { Increase }\end{array}$ \\
\hline & & & & \\
\hline 1 & 10 & Weak & $\begin{array}{l}\text { Bus is attached to generator } \\
\text { via 200 miles of 115 kV line }\end{array}$ & 100 \\
\hline 100 & 0.1 & Strong & $\begin{array}{l}\text { Bus is attached to generator } \\
\text { via 80 miles of 230 kV line }\end{array}$ & 1000 \\
\hline 1000 & 0.01 & Very Strong & $\begin{array}{l}\text { Bus is attached to generator } \\
\text { via 10 miles of 230 kV line }\end{array}$ & 100 \\
\hline
\end{tabular}

\section{Effect of Ferranti Rise with Weak and Strong Source Bus}

\section{Effect of Ferranti Rise with Strong Source Bus}

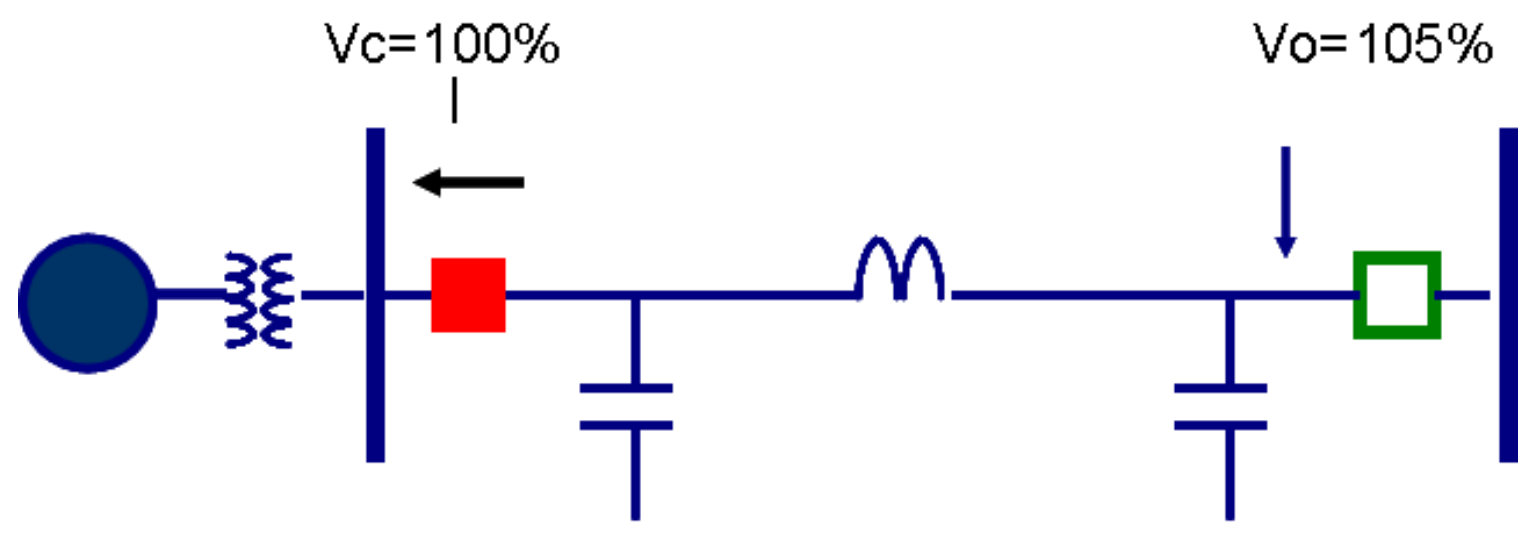


Effect of Ferranti Rise with Weak Source Bus

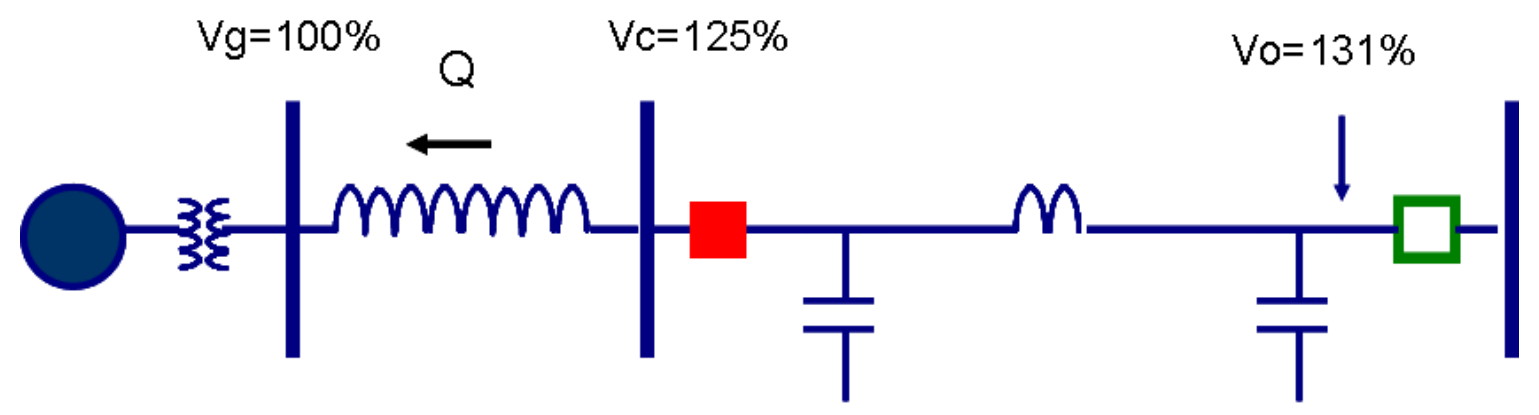

The voltage rise on bus at the closed end has to be added to the voltage rise along the line.

\section{Generator MVAR Capability Curve}

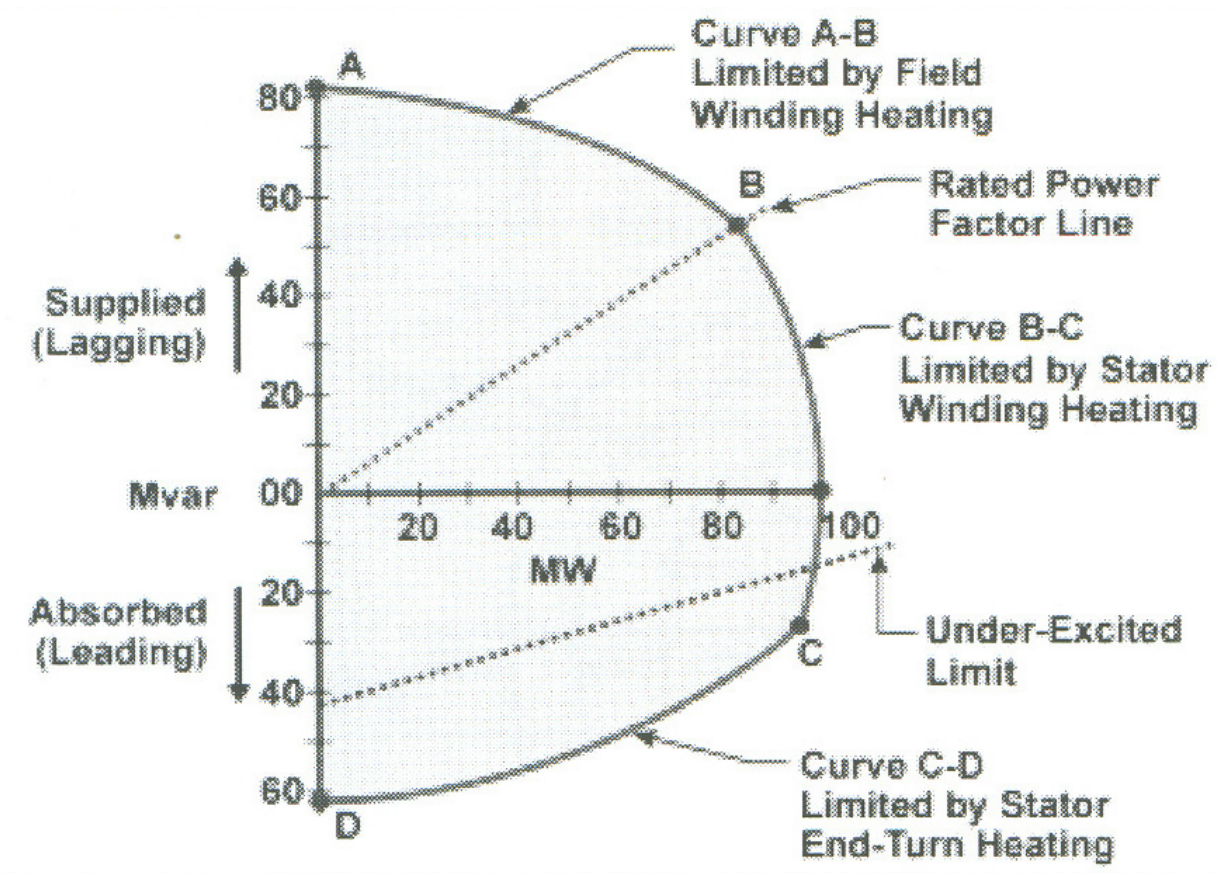

Figure 5-40

Reactive Capability Curve 
MVARs Flow Down Hill on Voltage Magnitude Difference

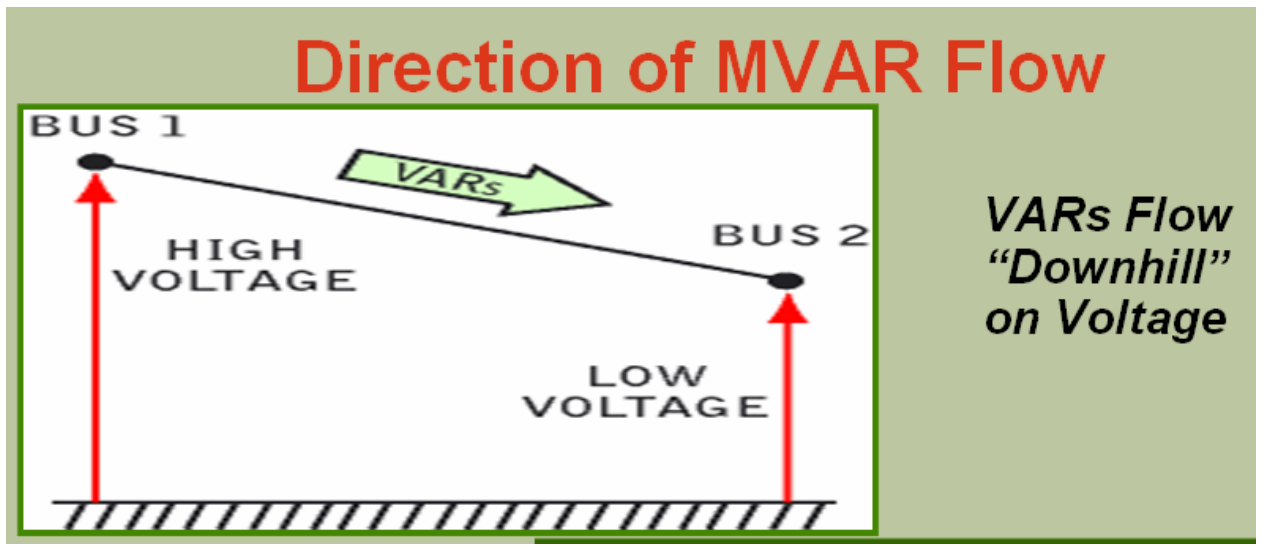


Tent, Pole, and Blimp Analogy for Voltage Rise

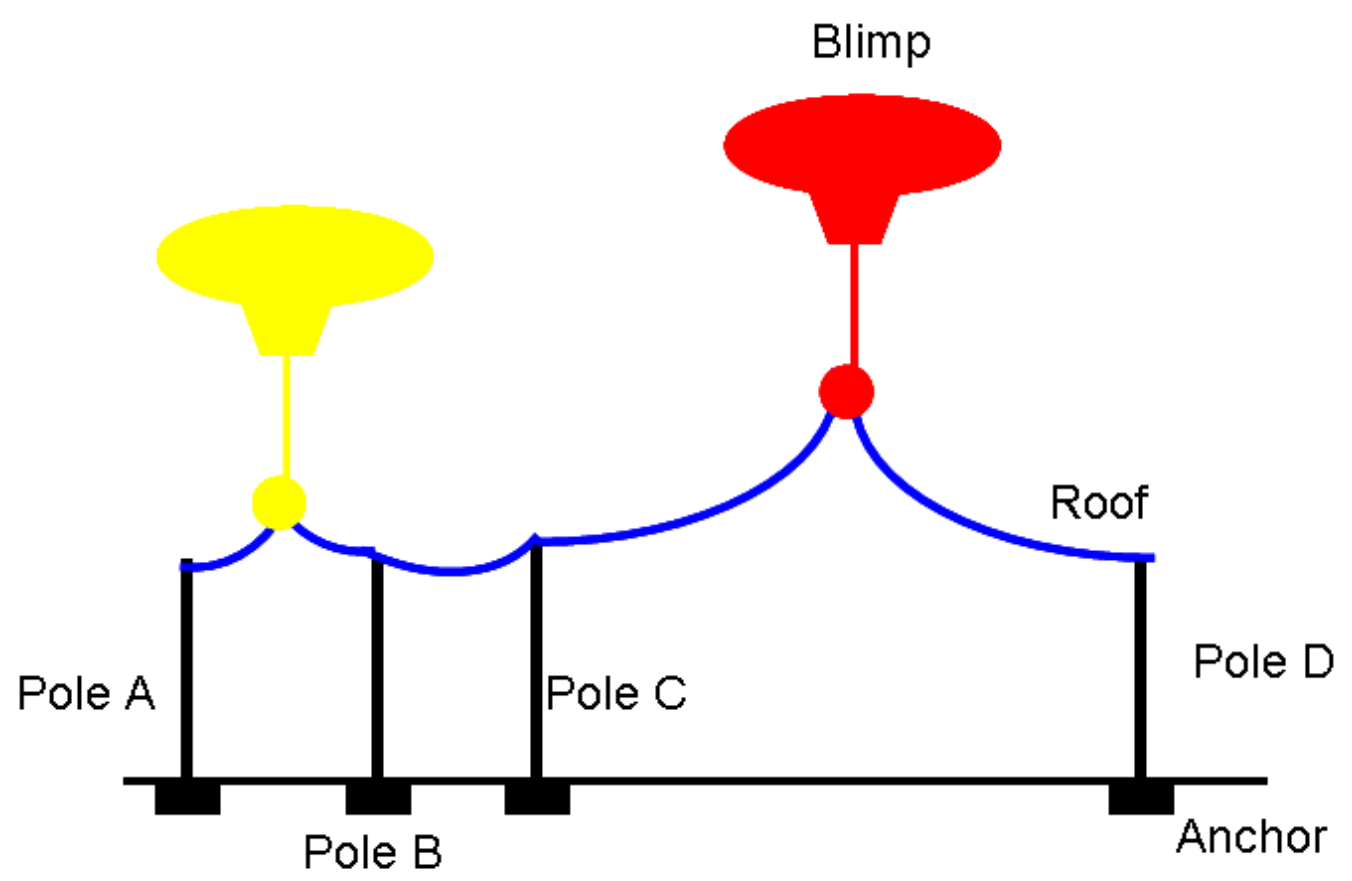

The blimp that is attached to the point in tent roof without adjacent poles raises the roof the most

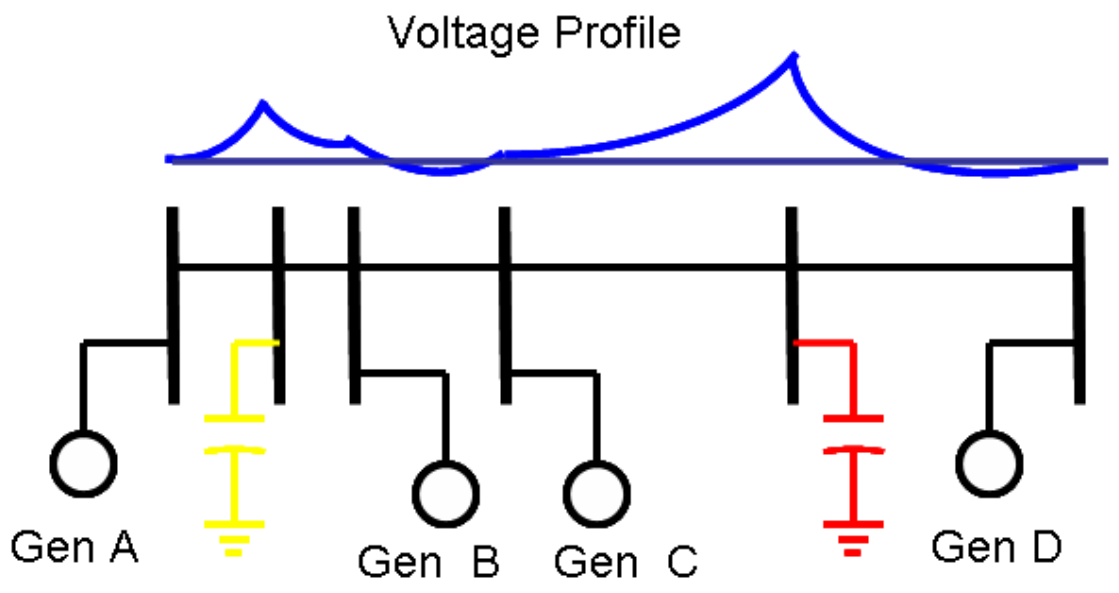

The capacitor that is attached to the point in the network without adjacent generators raises the voltage profile the most 
Tent, Pole, and Weight Analogy for Voltage Sag
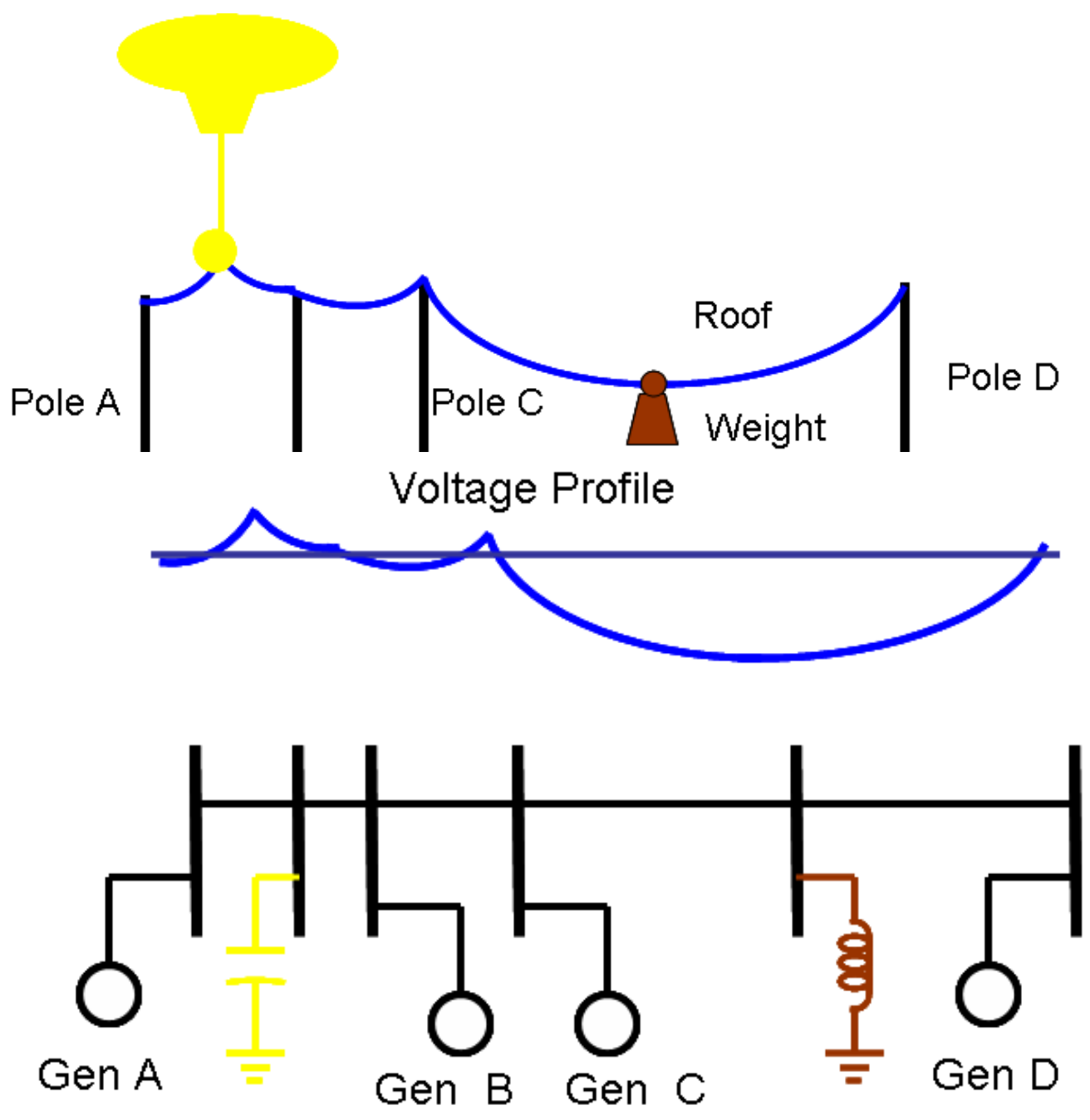

The voltage will sag way down when an inductive load is applied at the weak bus 


\section{Diagram of Physical Arrangement of Transformer Core, Windings, and Taps}

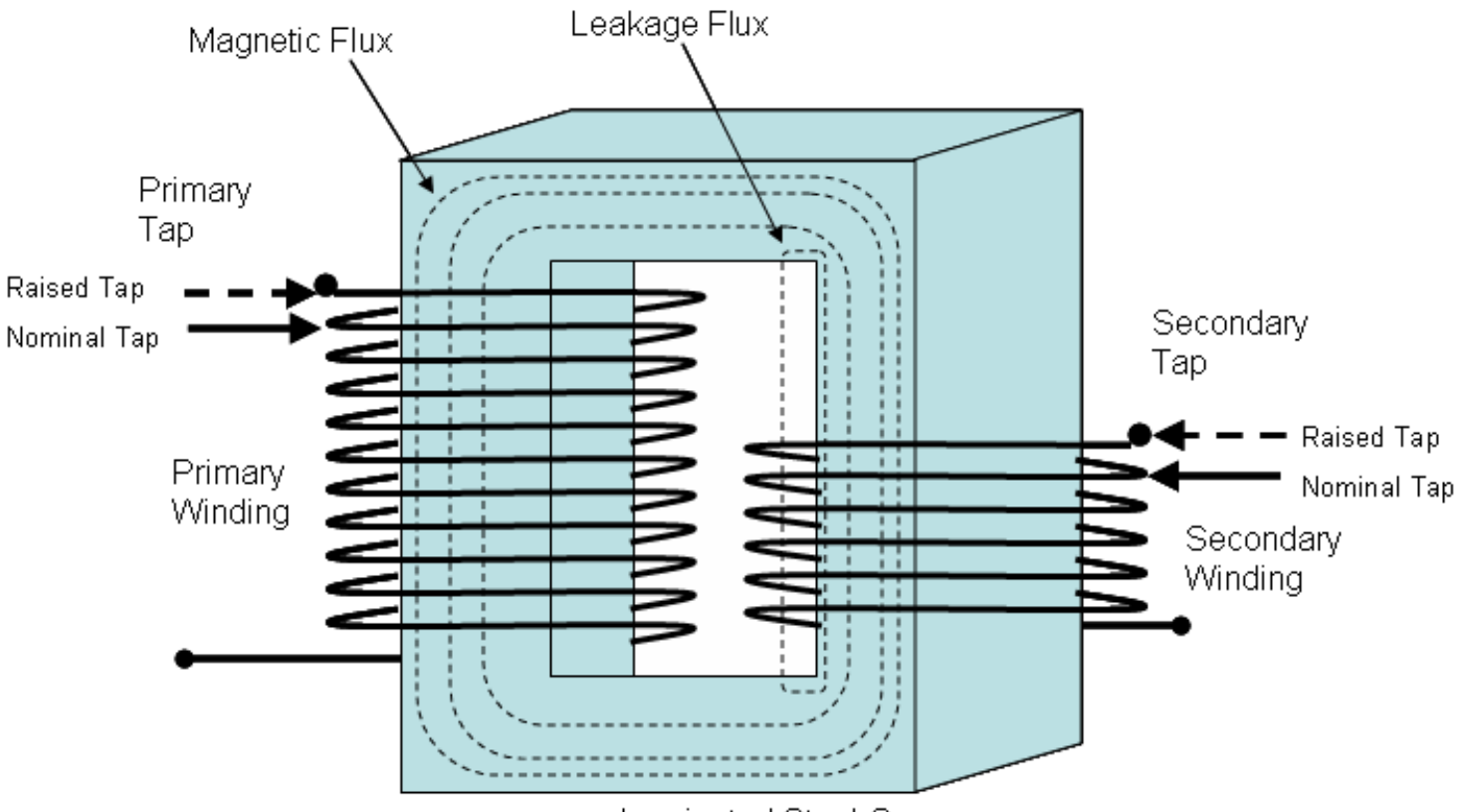

Laminated Steel Core

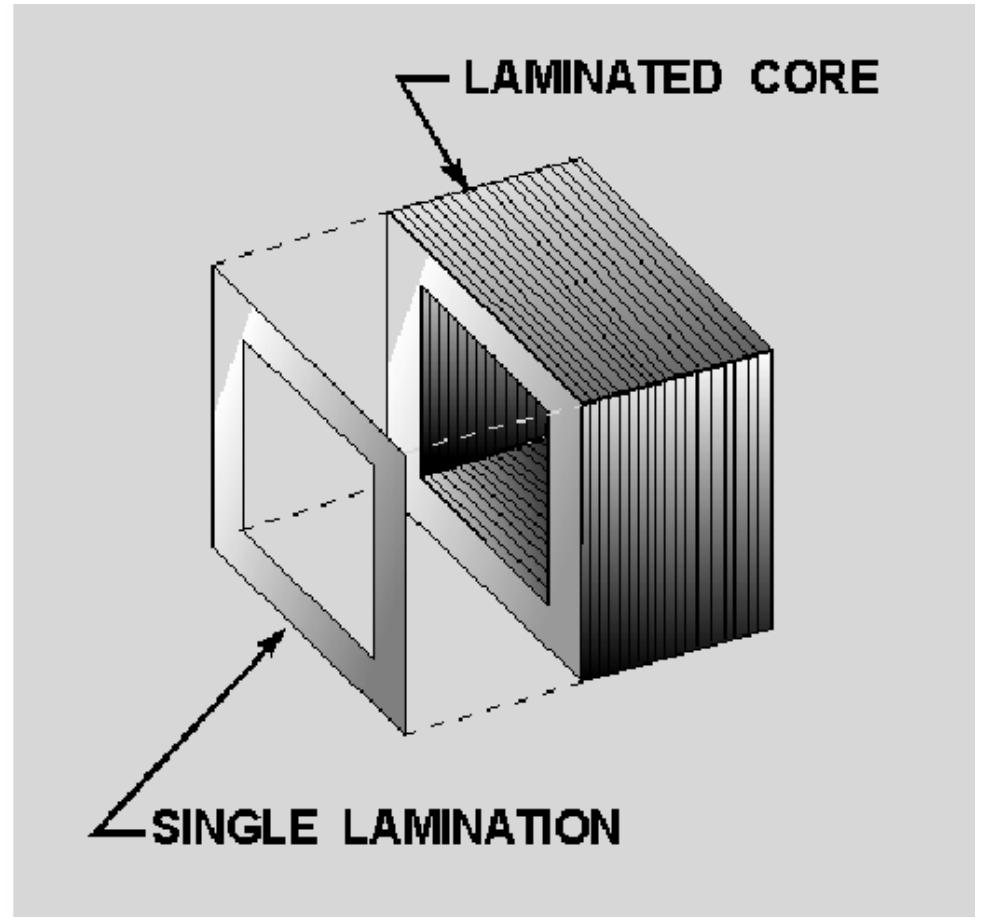




\section{Transformer Damage with Exposure to High Voltages}

The flux in the transformer core is directly proportional to the voltage and inversely proportional to the frequency. The measured Volts per Hertz ratio is therefore an excitation indication. For almost all transformers, damage occurs at an over-excitation or Volts-per-Hertz level of 1.25 pu. When the allowable Volts per Hertz ratio is exceeded, the magnetic core saturates. During saturation, excessive core flux increases the inter-lamination voltages causing iron damage (burning, pitting). Also, at this high level, the normal magnetic path cannot accommodate the increased flux, which then flows in leakage paths neither laminated nor designed to carry it, causing heat damage.

Transformer magnetizing currents increase dramatically when the transformer becomes saturated at high voltage levels. These large currents can destroy the transformer. The damage builds up over time. Transformers must not be subjected to prolonged over-voltage.

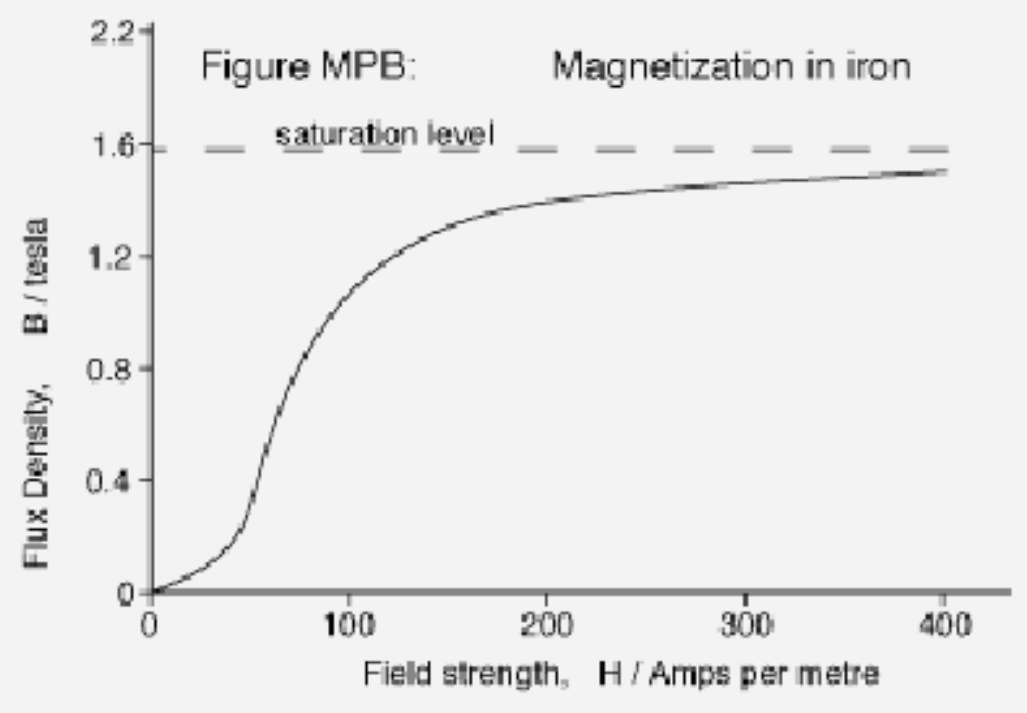




\section{Runaway Transformer Taps}

There is a danger of runaway transformer taps under the conditions shown at both the Homer and Moses stations. The Homer $230 \mathrm{kV}$ and $115 \mathrm{kV}$ buses are both higher than their normal operating limits. The Moses $230 / 115 \mathrm{kV}$ transformer would normally have its automatic tap changer set to regulate the low side voltage within a specified range. If the low side voltage is high, then the regulator will adjust the tap changer to lower the low side tap based on the assumption that the $230 \mathrm{kV}$ bus is a strong bus. However, in the restoration scenario, the $115 \mathrm{kV}$ bus is the stronger bus. So lowering the low side tap will raise the high side voltage. This is going to aggravate the situation and could cause even more damage to the transformer.

\section{Runaway Tap with Regulation of Low Side Bus Low side Bus is Strong - High side Bus is Weak}

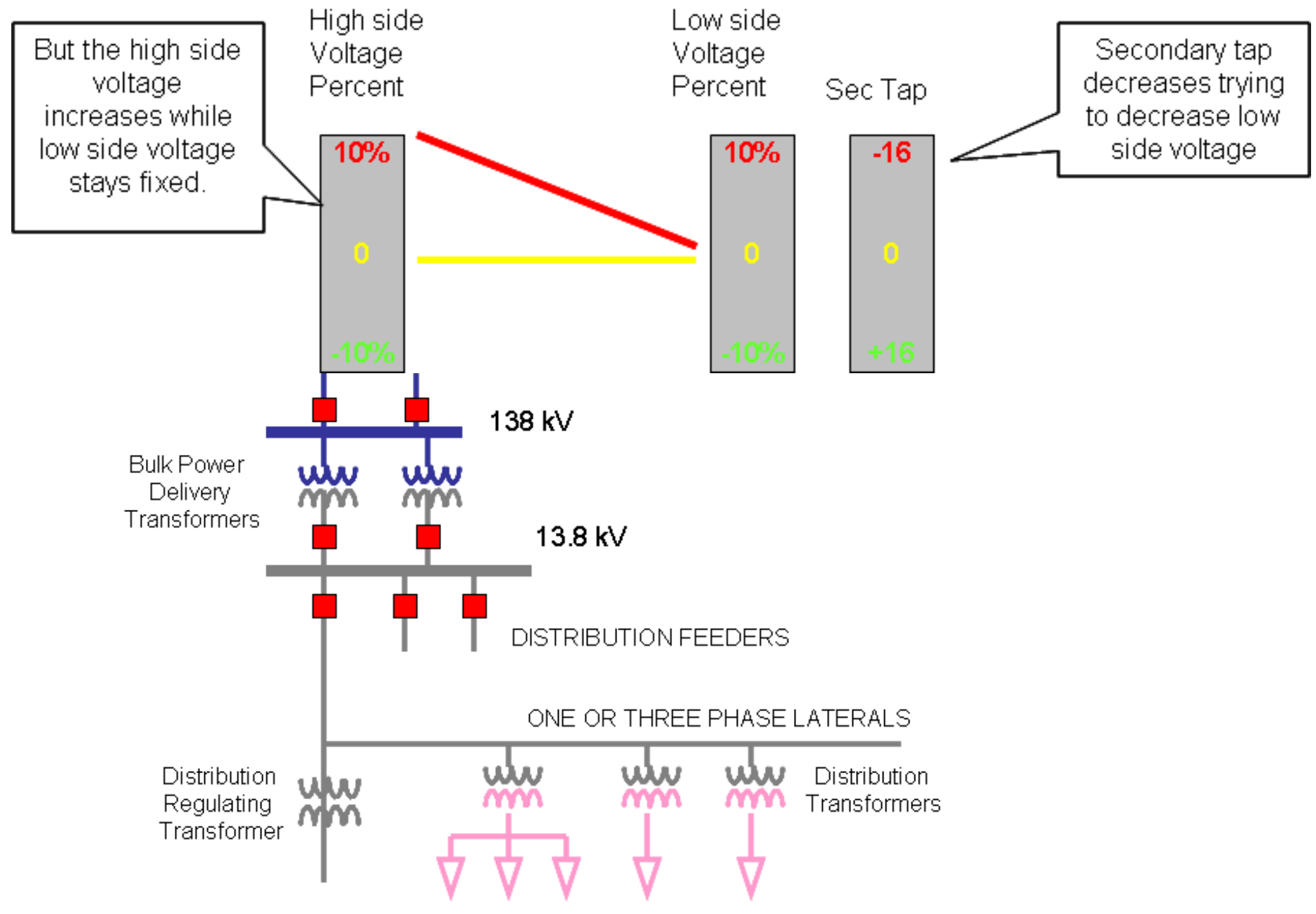

